\title{
A PARAMETRIC STUDY ON THE USE OF STRAIN SOFTENING/HARDENING FRC FOR RC ELEMENTS FAILING IN BENDING
}

\author{
Mahsa Taheri ${ }^{1}$, Joaquim A. O. Barros ${ }^{2}$, Hamidreza Salehian ${ }^{3}$ \\ ${ }^{1}$ Researcher, Dep. Civil Eng., Minho University, Guimarães, Portugal, taheri@ civil.uminho.pt \\ ${ }^{2}$ Associate Prof., ISISE, Dep. Civil Eng., Minho University, Guimarães, Portugal, barros@civil.uminho.pt, \\ corresponding Author \\ ${ }^{3} \mathrm{PhD}$ Student, ISISE, Dep. Civil Eng., Minho University, Guimarães, Portugal, salehian@ @ivil.uminho.pt
}

\begin{abstract}
Using a design oriented model, which was recently developed for the prediction of the moment-curvature relationship of a cross section of beams made by strain softening or strain hardening fiber reinforced concrete (FRC) and that can also include a certain percentage of longitudinal steel bars, a parametric study is carried out to evidence the effect of relevant characteristics of the post-cracking behavior of these materials in the moment-curvature and force-deflection responses of this type of structural elements. The study also analyzes the influence of the reinforcement ratio of longitudinal steel bars, $\rho$, in order to show that for a certain content of fibers the benefits of fiber reinforcement, mainly at serviceability limit state conditions, decrease with the increase of $\rho$. Adopting the formulation of Model Code 2010, the moment-crack width relationship of FRC beams reinforced with steel bars are obtained and the predictive performance of this approach is assessed by comparing analytical and experimental results.
\end{abstract}

Keyword: Fiber reinforced concrete; Strain softening; Strain hardening; Longitudinal steel bars; Moment-curvature response; Force-deflection response; Flexural failure; Crack width 


\section{INTRODUCTION}

The reinforcement of discrete fibers can decrease the crack opening and crack spacing in concrete elements, contributing to increase the durability and integrity of concrete structures (ACI 544 2010). In consequence of the crack arrestment provided by the pullout resisting mechanisms offered by fibers bridging the crack surfaces, the load carrying capacity, the energy dissipation and the ductility at serviceability and at ultimate limit design states are increased (Barros 2008, Cunha et al. 2010). However, the potentialities of fibers as a reinforcement system are not yet well explored, mainly for structural applications, since few models in a format adjusted for design practice, like closed-form solutions are available (Olesen (2001), Stang and Olesen (1998), Barragan (2002)).

Soranakom (2008) has recently developed a closed-form solution capable of determining the moment-curvature relationship of a cross section of a beam reinforced longitudinally with steel bars and made by strain softening fiber reinforced concrete (FRC). Strain-softening (SS) FRC has the characteristic of presenting a post-cracking tensile stress that is lower than its tensile strength. In the last years, with the advent of new generation of fibers, admixtures and superplasticizers, as well as a better knowledge of particle distribution process, behavior of the aggregate-paste and fiber-paste interface zones, and FRC mixing procedures in the context of FRC technology, tensile strainhardening $(\mathrm{SH})$ fiber reinforced cement-based materials are being developed, with the special characteristics of having a post-cracking tensile stress that is higher than their stress at crack initiation (Li 2003, Fantili et al. 2009, Kang et al. 2010, Pereira et al. 2010). The typical feature of SH-FRC is the development of a diffuse crack pattern before the localization of the failure macro-crack (Pereira et al. 2010). The model of Soranakom (2008) is, however, not prepared to simulate reinforced beams made by SH-FRC. In fact, the tensile post-cracking behavior of a FRC is simulated by an abrupt stress decay branch (vertical branch) at crack initiation, followed by a constant residual tensile strength and a stress cut-off at a certain ultimate tensile strain. This post-cracking tensile stress-strain diagram does not allow the simulation of SH-FRC, since the available experimental research on the tensile behavior of these materials shows a gradual increase of stress after the crack initiation of the matrix, up to the failure crack localization.

In the present work the model proposed by Soranakom (2008) is extended in order to be obtained a closed-form solution able of determining the moment-curvature relationship of SS- or SH-FRC elements failing in bending that can also include tensile steel bars. In the present mode a parameter $(\alpha)$ is introduced to simulate distinct softening/stiffening modulus just after crack initiation, turning the model developed by Soranakom (2008) applicable 
for both SS- and SH-FRC. This apparently minor alteration is quite relevant in the structural analysis of FRC elements failing in bending. In fact, in the parametric study to be presented later, the introduction of a gradual stress variation after crack initiation, which depends on the values attributed to $\alpha$ parameter, has a significant impact on the moment-curvature relationship, and, consequently, on the corresponding force-deflection response, for both SS- and SH-FRC, mainly in the phase between crack initiation and yielding of the steel bars. This aspect is quite important since this is the phase when fibers can contribute for the verifications of the serviceability limit states imposed by design codes. Furthermore, available FEM-based numerical research also evidence that the structural response of a FRC structure is quite dependent on the value attributed to the softening/stiffening modulus corresponding to the branch just after crack initiation of the constitutive model that defines the post-cracking behavior of the FRC (Ventura-Gouveia et al. 2011). As larger is $\alpha$ as higher is the load carrying capacity of a FRC-structure after crack initiation.

Soranakom and Mobasher (2008) have proposed a stress-strain diagram for SS- and SH-FRC, but their model was not prepared to simulate the reinforcement provided by longitudinal steel bars. The model that will be presented hereafter is, therefore, a generalization of these two models, capable of analyzing the mutual influence of the parameters that define the softening/stiffening character of a FRC and the percentage of longitudinal reinforcement, on the behavior of RC beams failing in bending.

Using this model, in the present work a parametric study is performed to show the influence of the main characteristics of SS- and SH-FRC materials in the moment-curvature relationship and in the force-deflection response of beams failing in bending. Finally, another parametric study is carried out in order to show the influence of the residual tensile strength versus steel reinforcement ratio on the flexural resistance corresponding to a certain crack width. The model is briefly described and the parametric studies are presented and discussed.

\section{NUMERICAL STRATEGY FOR THE EVALUATION OF THE MOMENT-CURVATURE AND FORCE- DEFLECTION OF FRC BEAMS FAILING IN BENDING}

\subsection{Constitutive laws for the intervening materials}

Tensile stress-strain relationship of FRC can be regarded as having three phases (Figure 1a): the initial linear elastic behavior characterized by the elastic tensile modulus $(E)$ and concrete crack strain $\left(\varepsilon_{c r}\right)$. For current practical 
application of FRC, fiber reinforcement mechanisms have a negligible influence in this phase, therefore the $E$ and $\varepsilon_{c r}$ can be assumed equal to the corresponding values of the homologous plain concrete. Experimental evidence (Barragan 2002, Cunha et al. 2009, Oliveira 2010) shows that after crack initiation in SS-FRC, in general, an abrupt decay of the residual tensile strength occurred for a relatively low increase of tensile deformability, since this phase is mainly controlled by the concrete fracture characteristics. This second phase is, in a simplified way, assumed as a linear branch characterized by the post-cracking strain-softening modulus $E_{c r}=\eta E$ (negative value for SS-FRC) and the transition strain $\varepsilon_{t r n}=\alpha \varepsilon_{c r}$. These two variables are also used to simulate the second phase of SH-FRC, but in this type of relatively high tensile and ductile FRC the $\varepsilon_{t r n}$ can be several times higher the $\varepsilon_{c r}$ due to the formation of a diffuse crack pattern (Markovic 2006, Stähli 2008, Fantilli et al. 2009, Kang et al. 2009). In the present approach, after the tensile transition phase, the tensile residual strength is assumed constant up to the ultimate tensile strain $\left(\varepsilon_{t u}=\beta_{t u} \varepsilon_{c r}\right)$, above which it is assumed that FRC lost its tensile capacity. Experimental research with SSFRC shows that, in general, after a minimum post-crack residual strength, a pseudo-hardening phase occurred due to the fiber pullout mechanisms (Cunha et al. 2009, Oliveira 2010), followed by a smooth softening branch up to complete loss of tensile load carrying capacity of the specimen. Therefore, the amplitude of this third phase (between $\varepsilon_{t r n}$ and $\varepsilon_{t u}$ ) is, in general, of relatively high strain amplitude. In case of SH-FRC this third phase can be regarded the transition phase between the stabilization of the diffuse crack pattern and the formation of the crack failure (localization), which corresponds to a strain amplitude that, in general, is smaller than the one corresponding to the second phase (between $\varepsilon_{c r}$ and $\varepsilon_{t r n}$ ). The third phase is, therefore, characterized by the residual tensile strength $\sigma_{c s t}=\mu \sigma_{c r}$

According to this approach the FRC post-cracking stress-strain constitutive law can be characterized by $\alpha, \mu$ and $\beta_{t u}$ parameters, since the $\eta$ softening/hardening modulus parameter is dependent on the $\alpha$ and $\mu$ parameters:

$$
\eta=-\frac{(1-\mu)}{(\alpha-1)}
$$

Experimental research shows that for both SS and SH-FRC the compressive strength is marginally affected by the presence of fibers, unless quite high content of fibers is used (Barros 1999). In fact, the benefits of fiber reinforcement for the compression behavior are most reflected in the compression softening phase, with an increase 
of the energy dissipated that can be quite significant, depending on the characteristics of the fibers and surrounding matrix (Cunha et al. 2008). Therefore, the simplified constitutive law represented in Figure $1 \mathrm{~b}$ was adopted to simulate the FRC in compression, which is the same proposed by Soranakom and Mobasher (2008). This law is composed by an initial linear branch characterized by the elasticity modulus $E_{c}=\gamma E$ up to the compressive "yield" strain $\left(\varepsilon_{c y}=\omega \varepsilon_{c r}\right)$, and is continued with a constant value of compressive "yield" stress $\left(\sigma_{c y}=E_{c} \varepsilon_{c y}\right)$ up to the ultimate compressive strain $\left(\varepsilon_{c u}=\lambda_{c u} \varepsilon_{c r}\right)$, after which it is assumed that FRC lost the capacity of supporting compressive loads.

In Figure 1c is represented the idealized stress-strain relationship to simulate the tensile behavior of the steel bars, which is composed by an initial linear elastic branch, characterized by the elasticity modulus $E_{s}=\gamma_{S} E$, up to the yield strain $\left(\varepsilon_{s y}=\zeta \varepsilon_{c r}\right)$, and continues with a plastic response of a constant yield stress $\left(\sigma_{s y}=E_{s} \varepsilon_{s y}\right)$ up to attain the ultimate tensile strain $\left(\varepsilon_{s u}=\psi_{s u} \varepsilon_{c r}\right.$ ), after which it is assumed that the steel lost its tensile capacity.

\subsection{The closed-form solution to estimate the moment-curvature relationship}

The closed-form solution was derived for a rectangular cross section of width $b$ and height $d$, as shown in Figure 2 . The reinforcement ratio of steel bars $(\rho)$ is the quotient between the total area of steel bars $\left(A_{s}\right)$ and the cross section area $(b d)$ of the element. The central distance of steel bars from tensile face of section is represented by $d^{\prime}$.

The tensile and compressive stress relationships of the cross section components can be normalized by the FRC stress at crack initiation, $\sigma_{c r}\left(=E \varepsilon_{c r}\right)$, in according to the following equations:

$$
\frac{\sigma_{t}(\beta)}{E \varepsilon_{c r}}= \begin{cases}\beta & 0<\beta \leq 1 \\ 1+\eta(\beta-1) & 1<\beta \leq \alpha \\ \mu & \alpha<\beta \leq \beta_{t u} \\ 0 & \beta>\beta_{t u}\end{cases}
$$




$$
\begin{aligned}
& \frac{\sigma_{c}(\lambda)}{E \varepsilon_{c r}}= \begin{cases}\gamma \lambda & 0<\lambda \leq \omega \\
\gamma \omega & \omega<\lambda \leq \lambda_{c u} \\
0 & \lambda>\lambda_{c u}\end{cases} \\
& \frac{\sigma_{s}(\psi)}{E \varepsilon_{c r}}= \begin{cases}\gamma_{s} \psi & 0<\psi \leq \zeta \\
\gamma_{s} \zeta & \zeta<\psi \leq \psi_{s u} \\
0 & \psi>\psi_{s u}\end{cases}
\end{aligned}
$$

where, $\sigma_{t}$ and $\sigma_{c}$ are the tensile and the compressive stress in the FRC, respectively, and $\sigma_{s}$ is the tensile stress in the steel bars. The other dimensionless parameters are obtained from the following equations (Figure 1):

$$
\begin{gathered}
\alpha=\frac{\varepsilon_{t r n}}{\varepsilon_{c r}} ; \beta_{t u}=\frac{\varepsilon_{t u}}{\varepsilon_{c r}} ; \eta=\frac{E_{c r}}{E} ; \mu=\frac{\sigma_{c s t}}{E \varepsilon_{c r}} \\
\gamma=\frac{E_{c}}{E} ; \omega=\frac{\varepsilon_{c y}}{\varepsilon_{c r}} ; \lambda_{c u}=\frac{\varepsilon_{c u}}{\varepsilon_{c r}} \\
\gamma_{s}=\frac{E_{s}}{E} ; \zeta=\frac{\varepsilon_{s y}}{\varepsilon_{c r}} ; \quad \psi_{s u}=\frac{\varepsilon_{s u}}{\varepsilon_{c r}}
\end{gathered}
$$

The normalized tensile strain at the concrete bottom fiber $(\beta)$, the normalized compressive strain at the concrete top fiber $(\lambda)$, and the normalized tensile strain of the steel $(\psi)$ are defined as (Figure 2):

$$
\beta=\frac{\varepsilon_{t b o t}}{\varepsilon_{c r}} ; \lambda=\frac{\varepsilon_{c t o p}}{\varepsilon_{c r}} ; \psi=\frac{\varepsilon_{s}}{\varepsilon_{c r}}
$$

A linear variation of strain can be assumed on the depth of the section and, hence, parameters $\beta, \lambda$, and $\psi$ are linearly related together:

$$
\begin{gathered}
\lambda=\frac{k}{1-k} \beta \\
\psi=\frac{1-k-\Delta}{1-k} \beta
\end{gathered}
$$


where $k$ and $\Delta$ are the neutral axis depth ratio and the normalized central distance of steel bars from tensile face of section, respectively (Figure 2).

The nine strain configurations indicated in Table 1 need to be considered (Taheri et al. 2010). There are three possible main configurations for tensile strain at bottom fiber (Table 1): $0 \leq \beta \leq 1,1<\beta \leq \alpha$, and $\alpha<\beta \leq \beta_{t u}$. Each configuration 2 and 3 (see Table 1) has four possible conditions due to the value of compressive concrete strain at top fiber in either elastic $(0<\lambda \leq \omega)$ or plastic $\left(\omega<\lambda \leq \lambda_{c u}\right)$ behavior in compression, and also due to the value of tensile steel strain in either elastic $(0<\psi \leq \zeta)$ or plastic $\left(\zeta<\psi \leq \psi_{s u}\right)$ behavior.

For each strain configuration the value of $k$ parameter can be obtained by the equations presented in Table 2 (Taheri et al. 2010). After having been obtained the correct value of $k$ in each strain configuration, internal moment is obtained by operating on the force components and their distance from neutral axis. The corresponding curvature is also determined as the ratio between the concrete compressive strain at top fiber and the depth of the neutral axis. The moment and curvature at stage $i$ of the loading process $\left(M_{i}, \phi_{i}\right)$ is obtained from the following equations:

$$
\begin{gathered}
M_{i}=M_{i}^{\prime} \quad M_{c r} \\
\phi_{i}=\phi_{i}^{\prime} \quad \phi_{c r}
\end{gathered}
$$

where, $M_{i}^{\prime}$ and $\phi_{i}^{\prime}$ are the normalized moment and curvature at stage $i$ obtained from Table 3. $M_{c r}$ and $\phi_{c r}$ are the cracking moment and the corresponding curvature calculated for a rectangular section from the following equations:

$$
\begin{aligned}
M_{c r} & =\frac{1}{6} b d^{2}\left(E \varepsilon_{c r}\right) \\
\phi_{c r} & =\frac{2 \varepsilon_{c r}}{d}
\end{aligned}
$$

\subsection{Model to estimate the force-deflection relationship}

Using the moment-curvature relationship, the force-deflection response of a statically determinate element failing in bending can be determined using the algorithm described in Figure 3. According to this algorithm, a statically determinate beam or slab is discretized in Euler-Bernoulli beam elements of 2 nodes. The load increment $\Delta p^{q}$ is imposed to the total applied load in each stage of loading $(q)$ (step 2) and the corresponding moment is calculated in 
the centre of each element (step 3). The tangential or the secant flexural stiffness (the developed model has both approaches implemented) of each element, $(E I)_{T e}$, is determined from its moment-curvature relationship (step 4) that is calculated by the model and is stored in a data file (each element has its own M- $\phi$ file). The $(E I)_{T e}$ is used to evaluate the tangential stiffness matrix of each element, $\underline{K}_{T e}$ (step 5). The tangential stiffness matrix of the structure, $\underline{K}_{T E}$, is obtained by assembling the tangential stiffness matrix of each element (step 6). The increment vector of displacements in the $q$ stage of loading is calculated by solving the system of linear equation represented in step 7, and is used to obtain the total displacement vector of the structure (step 8). Therefore, the present approach can simulate the deformability of a beam/slab composed of zones of distinct moment-curvature, giving to the model the possibility of predicting with enough accuracy the force-deflection response of quite heterogeneous structures in terms of material constitutive laws and arrangements of the materials, as long as these constitutive laws are known (Barros et al. 2006). The predictive performance of the developed model was assessed in another work (Taheri et al. 2010) by simulating the deflection response of FRC shallow beams reinforced with distinct $\rho$ values.

\section{PARAMETRIC STUDIES}

\subsection{Introduction}

Figure 4 illustrates the variables of the tensile stress-strain diagram of FRC materials that are considered in the parametric study: $\alpha$ parameter for SS-FRC (the $\mu$ parameter is maintained constant and equal to 0.333, Figure 4a); $\mu$ parameter for SS-FRC (the $\alpha$ parameter is maintained constant and equal to 10.00 , Figure $4 \mathrm{~b}$ ); $\alpha$ parameter for SH-FRC (the $\mu$ parameter is maintained constant and equal to 3, Figure 4c); $\mu$ parameter for SH-FRC (the $\alpha$ parameter is maintained constant and equal to 3.00, Figure 4d). For each one of these parameters the influence of the steel reinforcement ratio, $\rho$, is also analyzed, assuming values of $\rho$ varying from 0.0 (pure FRC) to $0.8 \%$, which cover most of the cases in which hybrid reinforcement (fibers and steel bars) is technically and economically justifiable. The influence of each variable is evaluated in terms of normalized moment-curvature diagram $\left(M^{\prime}-\phi^{\prime}\right)$, as well as in terms of a beam's normalized force-deflection response $\left(p^{\prime}-u^{\prime}\right)$, where $p^{\prime}=p / p_{c r}$ and $u^{\prime}=u / u_{c r}$, being $p_{c r}$ and $u_{c r}$ the beam distributed load at FRC crack initiation and the corresponding deflection, respectively. $p_{c r}$ is the $p$ load when in the center of the beam the bending moment coincides with $M_{c r}$. For the parametric study, 
a simply supported beam of $5 \mathrm{~m}$ span length subject to a constant distributed load $(p)$ is considered. The geometry characteristics of the cross section of this beam and the values that define the diagrams representing the constitutive laws of the intervening materials are indicated in Table 4.

The results of the parametric study are represented in Figures 5 to 12. As expected, for statically determinate elements the variation of $p^{\prime}-u^{\prime}$ follows closely the variation of $M^{\prime}-\phi^{\prime}$.

\subsection{Influence of $\alpha$ parameter for SS-FRC}

Figures 5a-d shows that the maximum normalized moment $M_{\max }^{\prime}\left(=M_{\max } / M_{c r}\right)$ increase with the $\alpha$ parameter for SS-FRC for all the $\rho$ considered values. In consequence of the higher flexural stiffness $(E I)$ provided by the increase of $\alpha$ parameter, the beam's load carrying capacity increases (Figures 5e-h). In Figure 6a is represented the effectiveness of the $\alpha$ parameter in terms of the cross section resisting bending moment, $\Delta M / M_{\text {min }}$, where $\Delta M=M_{\max }-M_{\min }$ is the difference between the maximum resisting bending moment $\left(M_{\max }\right)$, which occurs for $\alpha=15 \quad\left(M_{\max }=M_{\alpha=15}\right)$ and the minimum resisting bending moment $\left(M_{\min }\right)$, which occurs for $\alpha=1.01\left(M_{\min }=M_{\alpha=1.01}\right)$. Figure 6b represents the effectiveness of $\alpha$ parameter in terms of beam's load carrying capacity ( $\Delta p / p_{\min }$, where $\Delta p=p_{\max }-p_{\min }$ with $p_{\max }=p_{\alpha=15}$ and $p_{\min }=p_{\alpha=1.01}$ ). From Figure 6 it is clearly visible that the effectiveness in terms of $\Delta M / M_{\min }$ and $\Delta p / p_{\min }$ provided by the increase of $\alpha$ decreases with the increase of $\rho$ (if the remaining FRC parameters are maintained constant). It is also visible that, for statically determinate elements the effectiveness of increasing the $\alpha$ parameter is higher in terms of cross section resisting bending moment than in terms of beam's load carrying capacity. The maximum effectiveness in terms of cross section resisting bending moment occurred for the interval of $\phi^{\prime}$ varying between $2.4(\rho=0.8)$ and $4.2(\rho=0.0)$, while in terms of beams load carrying capacity occurred in the range of $u^{\prime} \in[2.6(\rho=0.8)-5.1(\rho=0.0)]$. According to the Eurocode 2 (prEN 1992-1-1 2002), the maximum deflection for serviceability limit states $\left(u_{S L S, \max }\right)$ should be restricted to the interval $L / 250-L / 500$ (depending on the type and utility of a structure), where $L$ is the beam's span length. For the present beam $u_{S L S, \max } \in[10-20] \mathrm{mm}$, which is approximately 10 to 20 times higher than the $u_{c r}$ 
$\left(u_{S L S, \max } / u_{c r} \in[10-20]\right)$. Taking into account the results of Figures $5 \mathrm{e}-\mathrm{h}$ it can be concluded that the increase of $\alpha$ is quite effective in terms of serviceability limit states.

According to the fiber pullout mechanisms and their influence on the FRC tensile behavior, to increase $\alpha$ it should be selected fibers that provide the maximum effectiveness in terms of fiber pullout resistance for the minimum slip between fiber and surrounding paste. Therefore, for the same content of fibers it is preferable the use of fibers of high aspect ratio and with a geometry configuration capable of increasing, as much as possible (but without the occurrence of fiber rupture), the fiber pullout force at the incipient formation of micro-cracks.

\subsection{Influence of $\mu$ parameter for SS-FRC}

Figures $7 \mathrm{a}-\mathrm{d}$ and Figures $7 \mathrm{e}-\mathrm{h}$ represent the influence of the post-cracking residual strength parameter, $\mu$, of SSFRC in terms of $M^{\prime}-\phi^{\prime}$ and $p^{\prime}-u^{\prime}$ responses, respectively. When compared to the influence of $\alpha$ parameter (Figure 5) it can be concluded that, as expected, $\mu$ parameter provides higher increment in terms of both $M_{\max }^{\prime}$ and $p_{\max }^{\prime}$. However, experimental research on uniaxial tensile tests with FRC indicates that the increment of $\mu$ requires higher increase of fiber concrete than the increment of $\alpha$ (Barragán 2002, Li, 2003, Markovic 2006, Fantilli et al. 2009, Cunha et al. 2009, Kang et al. 2010), so cost considerations should be taken into account in the selection of the most appropriate hybrid reinforcement for a certain target of FRC post-cracking performance. Still comparing Figures 5 and 7 it is verified that the increase of $\mu$ provides a continuous increase of $\Delta M$ and $\Delta p$ between crack initiation and the yield initiation of the conventional reinforcement, while in the case of an increase of $\alpha$ the $\Delta M$ and $\Delta p$ decrease with the increase of $\phi^{\prime}$ and $u^{\prime}$, respectively. This has a significant impact on the effectiveness of fiber reinforcement for the serviceability limit states (SLS) due to crack opening and deflection of structural elements, since for SLS the structures are working between concrete crack initiation and the yield initiation of conventional reinforcement.

In terms of the load carrying capacity of statically determinate elements failing in bending, Figure 8b evidences that the effectiveness of increasing the $\mu$ of SS-FRC is smaller when $\rho=0$, than when the beams have the minimum reinforcement ratio that assures a stabilized crack propagation, $\rho_{\text {stab }}$ (about $\rho_{\text {stab }} \cong 0.2 \%$ ). For SS-FRC beams without conventional reinforcement, apart the case of $\mu=0.99$, the $M^{\prime}-\phi^{\prime}$ curve of the remaining cases has a softening branch, leading to a marginal increase in terms beam's load carrying capacity (Figures 7a and 7e). For 
beams with $\rho=\rho_{\text {stab }}$, the increase of $\mu$ has the most favorable impact in terms of $\Delta M$ and $\Delta p$ (Figure 7). However, for beams with $\rho>\rho_{\text {stab }}$, the effectiveness of increasing the $\mu$ parameter in terms of $\Delta M / M_{\text {min }}$ and $\Delta p / p_{\text {min }}$ decreases with the increase of $\rho$ (Figure 8).

Finally it should be mentioned that to increase $\mu$ in SS-FRC it is required the existence of higher number of fibers with an orientation that forms an angle between 0 and 30 degrees with the orthogonal to the crack surfaces. Available research shows that above 30 degrees there is a high probability of fiber rupture (Cunha et al. 2010, Oliveira 2010).

\subsection{Influence of $\alpha$ parameter for SH-FRC}

Figure 9 represents the influence of increasing $\alpha$ parameter of SH-FRC (Figure 4c), in terms of $M^{\prime}-\phi^{\prime}$ and $p^{\prime}-u^{\prime}$. Since the tensile stiffness after crack initiation decreases with the increase of $\alpha(\eta$ decreases, see Figure 1a), the flexural capacity of the cross section and the beam's load carrying capacity decrease with the increase of $\alpha$ (Figure 9). When compared to Figures 5 and 7, Figure 9 evidences that a much higher increase of $M^{\prime}$ and $p^{\prime}$ is obtained in SH- than in SS-FRC, regardless the $\rho$ values. For all the $\alpha$ and $\rho$ values considered, a pronounced hardening behavior is registered after crack initiation. However, the decrease of $\alpha$ in SH-FRC, which means retaining as much as possible the initial elastic tensile stiffness $(\eta \cong 1$, see Figure 1a), requires the use of high content fiber reinforcement systems that can delay the degeneration of micro-cracks into meso- and macro-cracks (Stähli and Van Mier 2004).

Figure 10 shows that the $M_{\max }^{\prime}-M_{\min }^{\prime}\left(=M_{\alpha=5}-M_{\alpha=20}\right)$ and $p_{\max }^{\prime}-p_{\min }^{\prime}\left(=p_{\alpha=5}-p_{\alpha=20}\right)$ decreases with the increase of $\rho$ (maintaining the remaining FRC properties).

\subsection{Influence of $\mu$ parameter for SH-FRC}

Figure 11 represents the effect of the increase of $\mu$ of SH-FRC (Figure 4d) in terms of $M^{\prime}-\phi^{\prime}$ and $p^{\prime}-u^{\prime}$ responses. Figures 11a and 11e show that, even for $\rho=0$ a quite significant increase of $M^{\prime}$ and $p^{\prime}$ is obtained with the increase of $\mu$ for SH-FRC. Regardless the $\rho$ values, a hardening response in terms of $M^{\prime}-\phi^{\prime}$ and $p^{\prime}-u^{\prime}$ is obtained for all values considered for $\mu$. In between the crack initiation and the yield initiation of steel bars, an increase of $M^{\prime}$ and $p^{\prime}$ is registered with the increase of $\mu$. Furthermore the $\phi^{\prime}$ and $u^{\prime}$ corresponding to the yield 
initiation of steel bars increase with $\mu$. However, after yield initiation of steel bars the variation of $M^{\prime}-\phi^{\prime}$ and $p^{\prime}-u^{\prime}$ is almost constant for the distinct values of $\mu$, regardless $\rho$ values. It is also observed that for SH-FRC elements the variation of $\mu$ induces similar tendency on the variation of the maximum normalized bending moment $M_{\max }^{\prime}$ and on the variation of the maximum normalized load carrying capacity $p_{\max }^{\prime}$.

Figure 12 shows that the effectiveness of $\mu$ of SH-FRC, in terms of $\Delta M / M_{\min }$ and $\Delta p / p_{\min }$, decreases with the increase of $\rho$. However, the relatively high costs of a fiber reinforcement system that assures SH characteristics to a FRC in order to provide the same $M^{\prime}$ and $p^{\prime}$ of a conventional reinforcement systems is still only justifiable in very specific structural systems, such is the case of elements of geometric complexity, elements that corrosion of steel bars cannot occur, and in cases where time consuming to prepare and apply conventional reinforcement systems has significant impact on the final costs of the structure. Therefore, the use of SH-FRC is still limited to composite structural systems that can effectively mobilize the benefits derived from the relatively high post-cracking residual strength and ultimate tensile deformability of these materials (Wuest 2007).

\section{Evaluation of the moment-crack width relationship for fibrous concrete reinforced with steel bars}

Model Code (2010a) recommends equation (15) to calculate the crack width of flexural members reinforced simultaneously with fibers and steel bars:

$$
w_{d}=\frac{1}{2} \cdot \frac{d_{s, e q}}{\rho_{s, e f}} \cdot \frac{\left(f_{c t m}-f_{F t s m}\right)}{\tau_{b m}} \cdot \frac{1}{E_{s}} \cdot\left(\sigma_{s}-k_{1} \sigma_{s r}+\eta_{r} \varepsilon_{r} E_{s}\right)
$$

where $d_{s, e q}$ is the equivalent diameter of tensile bars in the section, and $f_{c t m}$ is the average value of the axial tensile strength of fibrous concrete (that can be assumed as equal to the $f_{c t m}$ of the plain concrete of same strength class). $f_{F t s m}$ is the average value of $f_{F t s}$, which is the residual strength of fibrous concrete, calculated from equation 16, where $f_{R 1}$ is the residual flexural tensile strength at a crack mouth opening displacement (CMOD) of $0.5 \mathrm{~mm}$, evaluated from the force-CMOD relationship determined from three point notched beam bending tests carried out according to the recommendations of Model Code 2010 (2010b).

$$
f_{\text {Fts }}=0.45 f_{R 1}
$$


In equation (15), $\tau_{b m}$ is the average bond strength between reinforcing bars and concrete, $k_{1}$ is an empirical coefficient to assess the mean strain over the length where slip between steel and concrete occurs, $\eta_{r}$ is the coefficient taking into account the shrinkage contribution, $\varepsilon_{r}$ is the strain at the onset of cracking. In the short term and instantaneous loading $k_{1}$ and $\eta_{r}$ can be considered equal to 0.6 and zero, respectively, while $\tau_{b m}$ is obtained from the following equation (Model Code 2010a):

$$
\tau_{b m}=1.8 f_{c t m}
$$

$\sigma_{s r}$ in equation (15) is the maximum steel stress in a crack at the crack formation stage, and is determined from:

$$
\sigma_{s r}=\frac{\left(f_{c t m}-f_{F t s m}\right)}{\rho_{s, e f}} \cdot\left(1+\gamma_{s} \rho\right)
$$

where $\rho_{s, e f}$ is the effective reinforcement ratio obtained by diving the total area of steel bars $\left(A_{s}=\rho b d\right)$ by the effective area of concrete in tension $\left(A_{c, e f}\right)$. For case of FRC sections, the effective area of concrete in tension can be considered equal to the total area of concrete in tension $(=b d(1-k))$, which is dependent of the actual position of the neutral axis. Therefore, the effective reinforcement ratio of a steel reinforced FRC section can be obtained from the following equation:

$$
\rho_{s, e f}=\frac{\rho}{(1-k)}
$$

When using the model proposed to determine the moment-curvature relationship for a cross section of fibrous concrete reinforced with steel bars, described in the previous sections, at each equilibrium configuration of the curvature evolution process the normalized depth of the neutral axis $(k)$ is known, as well as the average stress in the steel bars $\left(\sigma_{s}=\varepsilon_{s} E_{s}\right)$. Introducing this information into equations (19), (18) and (15), the relationship between the crack width and bending moment can be obtained.

To evaluate the predictive performance of proposed formulation, the obtained results are compared with those measured in previous experimental programs (Vandewalle 2000, Tan et al. 1995) composed of two series of steel reinforced FRC beams subjected to four point loading (Figure 13). The geometrical and mechanical properties of the considered beams are summarized in Table 5. The values of parameters utilized in the proposed formulation are indicated in Table 6. Since in these experimental programs it is not available data for a full characterization of the 
FRC tensile behavior according to the post-cracking diagram that is proposed in the present model, some values of the parameters indicated in Tables 5 and 6 were estimated taking into account the recommendations of the CEB-FIP Model Code 2010, and considering the data available in the corresponding papers.

The moment-maximum crack width relationships determined with the developed model and registered experimentally, for both considered beams, are compared in Figure 14, where it can be concluded that this approach can predict with enough accuracy the variation of the maximum crack during the loading process of a section of a fibrous concrete element reinforced with steel bars.

To evidence the usefulness of the present model for design purpose, mainly in terms of serviceability states due to crack width limit, a parametric study was executed by evaluating the $M_{w d} / M_{c r}$ ratio for distinct values of $\rho$ and $\mu$, where $M_{w d}$ is the resisting bending moment for a certain crack with, $w_{d}$ (determined from Eq. (15)). In this parametric study range of values of [0.2-1.0]\% and [0-0.8] were considered for $\rho$ and $\mu$, respectively, since they covered the major part of FRC for structural applications. Due to the lack of a comprehensible experimental research on the correlation between FRC residual tensile strength $\left(\mu \sigma_{c r}\right)$ and $f_{F t s m}$, it is assumed that $\mu \sigma_{c r}=f_{F t s m}$, however, specific research should be done in this topic in order to obtain a reliable relationship between $\mu$ and $f_{\text {Ftsm }}$.

In figure 15 the variation of $M_{w d} / M_{c r}$ ratio for the distinct par of values considered for $\rho$ and $\mu$, is represented in two distinct formats where $M_{w d}$ is the resisting bending moment for a design crack width of $0.1 \mathrm{~mm}$, which is the minimum value recommended by Euro Code (prEN 1992-1-1, 2002) in terms of crack width serviceability limit state. The values of the model parameters adopted in this parametric study are indicated in Table 7. The obtained results show clearly the benefits of the post-cracking residual strength of a FRC for any steel reinforcement ratio considered. If the total costs of adopting an FRC of a certain residual strength are known for the replacement of a certain percentage of conventional reinforcement, this approach can be extended to obtain the most cost effective reinforcement solution for structural applications.

\section{CONCLUSIONS}

In this work a design oriented closed-form formulation was proposed for the flexural design of elements failing in bending, built by strain-softening (SS) or strain-hardening (SH) fiber reinforced concrete (FRC) that can also include tensile steel bars, which is designated as hybrid reinforcing system. The minimum number of parameters was used to characterize the FRC behavior in tension and compression, as well as the tensile behavior of steel bars. The closed- 
form solution was developed in order to determine the moment-curvature relationship of rectangular cross sections. Using the moment-curvature relationship and implementing an algorithm based on the stiffness-method, a numerical strategy was developed for the prediction of the force-deflection response of hybrid reinforced elements failing in bending. This methodology was used to execute a parametric study in order to evidence the influence of the main parameters of SS- and SH-FRC on the cross section flexural resistance and on the load carrying capacity of hybrid reinforced elements. The relevance of both the strain softening/hardening modulus and the residual strength of SS and SH-FRC, as well as the influence of the reinforcement ratio of steel bars, $\rho$, of this hybrid concept were analyzed in terms of moment-curvature relationship and beam's load carrying capacity. Based on the influence of parameters that characterize the post-cracking constitutive law of FRC, and taking into account the fiber reinforcement mechanisms determined from fiber pullout tests, some recommendations were proposed concerning to costs considerations of this hybrid reinforcement system. In fact, a quite significant increase of beam's load carrying capacity can be obtained when using SH-FRC, but the relatively high costs of this composite material recommends its use in very special applications. Even for statically determinate elements, a SH-FRC can increase significantly the load carrying capacity of beams for the deflection limits corresponding to serviceability limit states (between concrete crack initiation and yield of conventional reinforcement), mainly for beams with the minimum $\rho$ that assures a stabilized crack propagation. In fact, the increase of beam's load carrying capacity provided by certain FRC is as smaller as higher is $\rho$. The developed closed-form solution and the equations proposed by fib bulletins 55 and 56 of the Model Code 2010 were adopted to determine the maximum crack width versus bending moment relationship of a cross section of fibrous concrete beams reinforced with steel bars. The good predictive performance of this strategy was assessed using available experimental data. A design methodology was also proposed capable of determining the most competitive hybrid reinforcement solution (fibers and steel bars) for crack width control.

\section{ACKNOWLEDGEMENTS}

This work is part of the research project QREN number 3456, PONTALUMIS- Development of a prototype of a pedestrian bridge in GFRP-ECC concept, involving the Company ALTO - Perfis Pultrudidos, Lda., the ISISE/University of Minho and the ICIST/Technical University of Lisbon. The third author wishes to acknowledge the support provided by this project, while the first author wishes to acknowledge the financial support obtained from the project PTDC/ECM/73099/2006. 


\section{REFERENCES}

ACI 544.5R-10, "Report on the Physical properties and durability of fiber-reinforced concrete", Reported by ACI Committee 433, ACI, 31 pp., March 2010.

Barragán, B.E., "Failure and toughness of steel fiber reinforced concrete under tension and shear", PhD Thesis, Universitat Politécnica de Catalunya, Barcelona, Spain, 2002.

Barros, J.A.O., "Steel fiber reinforced self-compacting concrete - from the material characterization to the structural analysis”, HAC2008, 1st Spanish Congress on Self-Compacting Concrete, Valencia, Spain, 31-58, 18-19 February, 2008. (Invited Keynote Lecturer)

Barros, J.A.O.; Figueiras, J.A., "Flexural behavior of steel fiber reinforced concrete: testing and modelling", Journal of Materials in Civil Engineering, ASCE, 11(4), 331-339, 1999.

Barros, J.A.O.; Oliveira, J.T.; Lourenço, P.J.B.; Bonaldo, E., "Flexural behavior of reinforced masonry panels”, ACI Structural Journal, 13(3), May-June, 418-426, 2006.

Cunha, V.M.C.F.; Barros, J.A.O.; Sena-Cruz, J.M., "Pullout behaviour of steel fibres in self-compacting concrete", ASCE Journal of Materials in Civil Engineering, 22(1), January 2010.

Cunha, V.M.C.F.; Barros, J.A.O.; Sena-Cruz, J.M., "Tensile behavior of steel fiber reinforced self-compacting concrete", Session "Fiber-Reinforced Self-Consolidating Concrete", Salons G\&H, Hotel Marriott, New Orleans USA, 11 November de 2009.

Cunha, V.M.C.F.; Barros, J.A.O.; Sena-Cruz, J.M., "Modelling the influence of age of steel fibre reinforced self compacting concrete on its compressive behaviour", RILEM Materials and Structures Journal, 41(3), 465-478, 2008. EFNARC, "Specification and Guidelines for Self-Compacting Concrete.” ISBN 09539733 4 4, 32 pp, 2002.

EN197-1:2000, “Cement. Composition, specifications and conformity criteria for low heat common cements.” ISBN: 058036456 9, 52pp, 2000.

prEN 1992-1-1, "Eurocode 2: Design of concrete structures - Part 1: General rules and rules for buildings", April 2002. 
Fantilli, A. P, Mihashi, H., Vallini P., "Multiple cracking and strain hardening in fibre-reinforced concrete under uniaxial tension”, Cement and Concrete Research 39, 1217-1229, 2009.

Kang, S.T., Lee, Y., Park, Y.D., and Kim, J.K., “Tensile fracture properties of an Ultra High Performance Fibre Reinforced Concrete (UHPFRC) with steel fibre”, Composite Structures, 92, 61-71, 2010.

Li, V.C., "On Engineered Cementitious Composites (ECC) - A Review of the Material and Its Applications", J. Adv. Conc. Tech., 1 (3): 215-230, 2003.

Markovic, I., "High-performance hybrid-fibre concrete - development and utilisation”, PhD Thesis, Delft University of Technology, 2006.

Model Code 2010a, First Complete draft, Volume 2, fib, April 2010

Model Code 2010b, First Complete draft, Volume 1, fib, March 2010

Naaman, A. E. \& Reinhard, H. W., "Proposed classification of HPFRC composites based on their tensile response", Proceedings 3rd international Conference on Construction materials: Performance, Innovations and Structural Implications (ConMat'05) and Mindess Symposium, p. 458, Eds: N. Banthia, A. B., T. Uomoto \& Shah, S., University of British Columbia, Vancouver, Canada, 2005.

Oliveira, F.L., "Design-oriented constitutive model for steel fiber reinforced concrete", PhD Thesis, Universitat Politécnica de Catalunya, Barcelona, Spain, 2010.

Olesen, J.F., "Ficticious crack propagation in fibre-reinforced beams", Journal of Engineering Mechanic, 127(3), 272-280, 2001.

Pereira, E.B., Fischer, G., Barros, J.A.O., Lepech, M., "Crack formation and tensile stress-crack opeing behavior of fiber reinforced cementitious composites (SHCC)", Proceedings of FraMCoS-7, Eds: B. H. Oh, O. C. Choi \& L. Chung, Jeju, Korea, May 23-28, 2010.

Soranakom C., "Multi scale modeling of fibre and fabric reinforced cement based composites", PhD thesis, Arizona State University, 2008.

Soranakom, C., Mobasher, B., "Correlation of tensile and flexural response of strain softening and strain hardening cement composites", Cement \& Concrete Composites, 30, 465-477, 2008. 
Stang, H., Olesen J.F., "On the interpretation of bending tests of FRC-materials", Proceedings FRAMCOS-3, Vol. 1 (Fracture mechanics of concrete structures), 511-520, 1998.

Stähli, P. and Van Mier, J.G.M., “Three-fibre-type hybrid fibre concrete”, In proceedings FRAMCOS-5, Editors V.C. Li et al., Vail, USA, 1105-1112, 2004

Stähli, P., "Ultra-fluid, oriented hybrid-fibre-concrete”, PhD Thesis, ETH, Zürich, Switzerland, 2008

Taheri, M.; Barros, J.A.O.; Salehian, H.R., "A design model for strain-softening and strain-hardening fiber reinforced elements reinforced by longitudinal steel bars failing in bending - implementation and parametric studies”, Technical report 06-DEC/E-10, Dep. Civil Eng., School Eng. University of Minho, March 2010.

Tan, K-H., Paramasivam, P., Tan, K-C., "Cracking characteristics of reinforced steel fibre concrete beams under short- and long-term loading”, Advanced Cement Based Materials, 2, 127-137, 1995.

Vandewalle, L., "Cracking behaviour of concrete beams reinforced with a combination of ordinary reinforcement and steel fibres", Materials and Structures, 33, 164-170, 2000.

Ventura-Gouveia, A., Barros, J.A.O., Azevedo, A.F.M., "Crack constitutive model for the prediction of punching failure modes of fiber reinforced concrete laminar structures", Computers and Concrete Journal, in press, 2011.

Wuest, J., "Comportement structural des bétons de fibres ultra performants en traction dans des elements composes", PhD thesis, Thesis n. 3987, EPFL, 2007. (in French) 


\section{Notation}

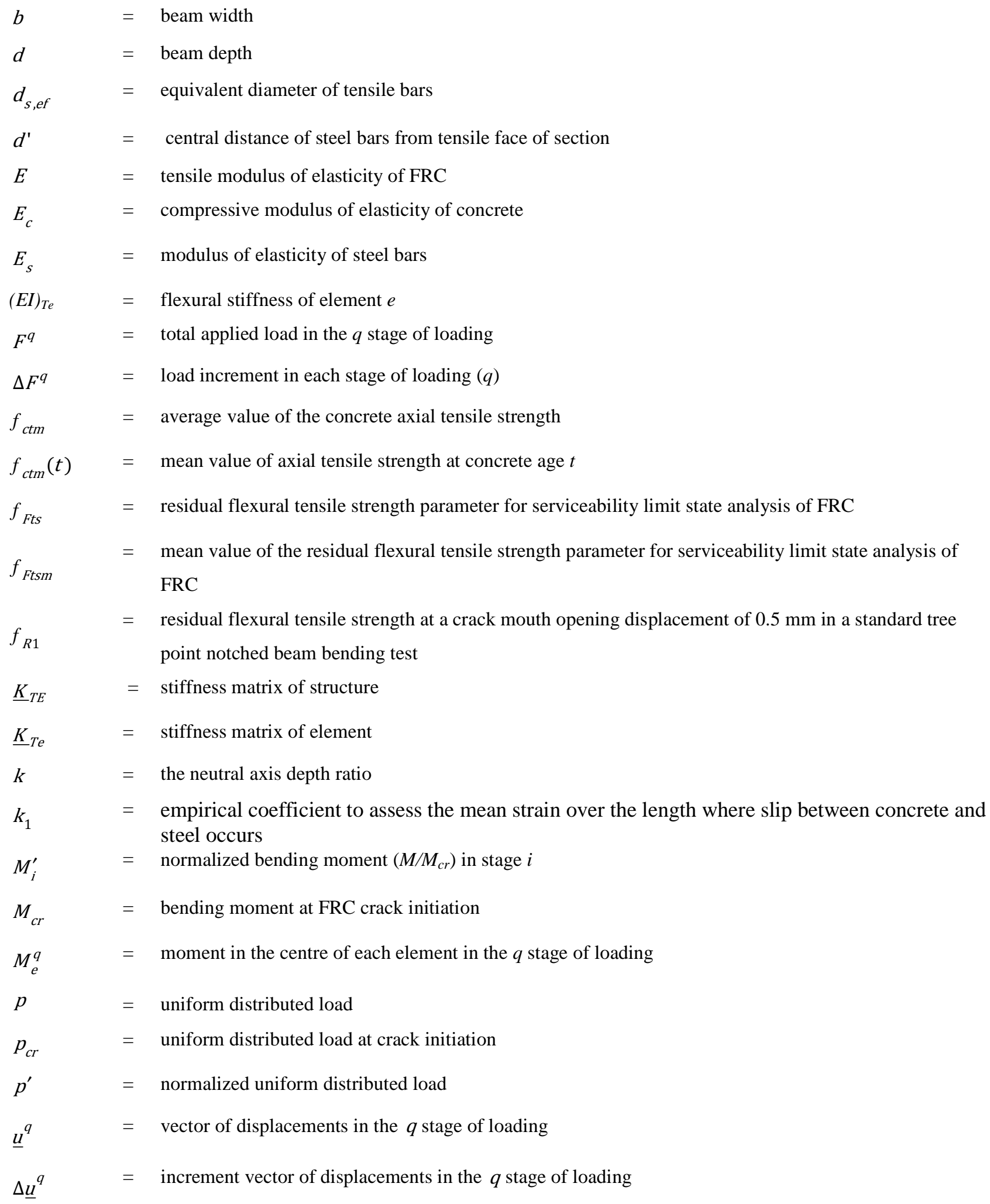




\begin{tabular}{|c|c|c|}
\hline$u$ & $=$ & deflection at beam's mid-span \\
\hline$u_{c r}$ & $=$ & deflection at beam's mid-span at crack initiation \\
\hline$u^{\prime}$ & $=$ & normalized deflection at beam's mid-span \\
\hline$W$ & $=$ & crack width \\
\hline$\alpha$ & $=$ & normalized transition strain \\
\hline$\beta$ & $=$ & normalized tensile strain at bottom fiber \\
\hline$\beta_{t u}$ & $=$ & normalized ultimate tensile strain \\
\hline$\gamma$ & $=$ & normalized compressive modulus of elasticity of FRC \\
\hline$\gamma_{s}$ & $=$ & normalized modulus of elasticity of steel bars \\
\hline$\varepsilon_{c y}$ & $=$ & compressive yield strain of FRC \\
\hline$\varepsilon_{c u}$ & $=$ & ultimate compressive strain of FRC \\
\hline$\varepsilon_{r}$ & $=$ & strain at the onset of cracking \\
\hline$\varepsilon_{s y}$ & $=$ & tensile yield strain of steel bars \\
\hline$\varepsilon_{s u}$ & $=$ & ultimate tensile strain of steel bars \\
\hline$\varepsilon_{c r}$ & $=$ & tensile strain at crack initiation of FRC \\
\hline$\varepsilon_{t r n}$ & $=$ & tensile strain at transition point of FRC \\
\hline$\varepsilon_{t u}$ & $=$ & ultimate tensile strain of FRC \\
\hline$\zeta$ & $=$ & normalized transition tensile strain of steel bars \\
\hline$\eta$ & $=$ & normalized post-crack modulus of FRC \\
\hline$\eta_{r}$ & $=$ & coefficient taking into account the shrinkage contribution \\
\hline$\lambda$ & $=$ & normalized compressive strain at the FRC top fiber \\
\hline$\lambda_{c u}$ & $=$ & normalized ultimate compressive strain of FRC \\
\hline$\mu$ & $=$ & Normalized post-crack residual strength of FRC \\
\hline$\rho$ & $=$ & reinforcement ratio of longitudinal steel bars \\
\hline$\rho_{s, e f}$ & $=$ & effective steel reinforcement ratio \\
\hline$\sigma_{c}$ & $=$ & compressive stress of FRC \\
\hline$\sigma_{t}$ & $=$ & tensile stress of FRC \\
\hline$\sigma_{s}$ & $=$ & tensile stress of the steel bars \\
\hline$\sigma_{s r}$ & $=$ & the maximum steel stress in a crack in the crack formation stage \\
\hline$\sigma_{c r}$ & $=$ & tensile strength of FRC \\
\hline
\end{tabular}




$\begin{array}{lll}\sigma_{c s t} & =\text { residual tensile stress of FRC } \\ \tau_{b m} & =\text { mean bond strength between reinforcing bars and concrete } \\ \phi_{c r} & =\text { curvature at crack initiation of FRC } \\ \phi_{i}^{\prime} & =\text { normalized curvature } \phi / \phi_{c r} \\ \psi & =\text { normalized tensile strain of steel bars } \\ \psi_{s u} & =\text { normalized ultimate steel tensile strain of steel bars } \\ \omega & =\text { normalized compressive yield strain of FRC } \\ \Delta & =\text { normalized central distance of steel bars from tensile face of section }\end{array}$




\section{LIST OF TABLE CAPTIONS}

Table 1 - Variation of the material parameters in the possible strain configurations (Taheri et al. 2010).

Table 2 - Equation for the neutral axis depth ratio for each strain configuration (Taheri et al. 2010).

Table 3 - Equation for the normalized moment and curvature for each strain configuration (Taheri et al. 2010).

Table 4 - Geometric data and values for the constitutive models for the parametric study (see Figures 1 and 2).

Table 5 - Geometrical and mechanical properties of the beams.

Table 6 - Values computed for the constitutive models for series of beams.

Table 7 - Geometric data and values for the parameters of the constitutive model for the parametric study on the influence of $\rho$ and $\mu$ on the $M_{w d} M_{c r}$ (see Fig. 15). 


\section{TABLE CAPTIONS}

Table 1 - Variation of the material parameters in the possible strain configurations (Taheri et al. 2010).

\begin{tabular}{cccc}
\hline $\begin{array}{c}\text { Strain } \\
\text { configuration }\end{array}$ & Tension & FRC & Steel bars \\
\cline { 2 - 4 } 2 & $0 \leq \beta \leq 1$ & Compression & $0 \leq \psi \leq \zeta$ \\
2.1 .1 & $1<\beta \leq \alpha$ & $0 \leq \lambda \leq \omega$ & $0 \leq \psi \leq \zeta$ \\
2.1 .2 & $1<\beta \leq \alpha$ & $0 \leq \lambda \leq \omega$ & $\zeta<\psi \leq \psi_{\text {su }}$ \\
2.2 .1 & $1<\beta \leq \alpha$ & $\omega<\lambda \leq \lambda_{c u}$ & $0 \leq \psi \leq \zeta$ \\
2.2 .2 & $1<\beta \leq \alpha$ & $\omega<\lambda \leq \lambda_{c u}$ & $\zeta<\psi \leq \psi_{s u}$ \\
3.1 .1 & $\beta>\alpha$ & $0 \leq \lambda \leq \omega$ & $0 \leq \psi \leq \zeta$ \\
3.1 .2 & $\beta>\alpha$ & $0 \leq \lambda \leq \omega$ & $\zeta<\psi \leq \psi_{s u}$ \\
3.2 .1 & $\beta>\alpha$ & $\omega<\lambda \leq \lambda_{c u}$ & $0 \leq \psi \leq \zeta$ \\
3.2 .2 & $\beta>\alpha$ & $\omega<\lambda \leq \lambda_{c u}$ & $\zeta<\psi \leq \psi_{s u}$ \\
& & & \\
\hline
\end{tabular}


Table 2 - Equation for the neutral axis depth ratio for each strain configuration (Taheri et al. 2010).

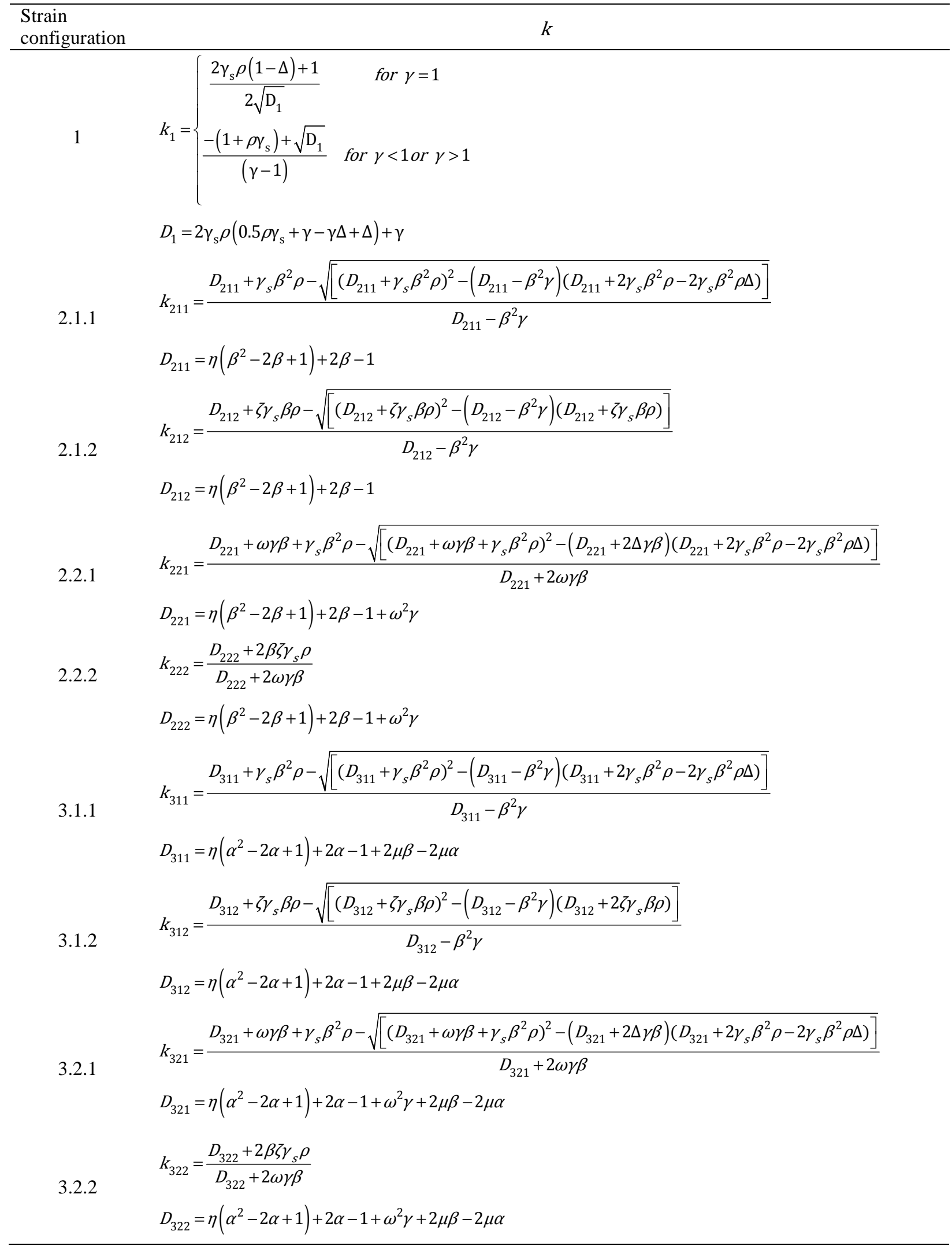


Table 3 - Equation for the normalized moment and curvature for each strain configuration (Taheri et al. 2010).

\begin{tabular}{|c|c|c|}
\hline $\begin{array}{l}\text { Strain } \\
\text { configuration }\end{array}$ & $M^{\prime}$ & $\phi^{\prime}$ \\
\hline 1 & $M_{1}^{\prime}=\frac{2 \beta\left[(\gamma-1) k_{1}^{3}+\left(3 \gamma_{s} \rho+3\right) k_{1}^{2}+\left(6 \gamma_{s} \rho(\Delta-1)-3\right) k_{1}+3 \gamma_{s} \rho(\Delta-1)^{2}+1\right]}{\left(1-k_{1}\right)}$ & $\phi_{1}^{\prime}=\frac{\beta}{2\left(1-k_{1}\right)}$ \\
\hline 2.1 .1 & $\begin{array}{l}M_{211}^{\prime}=\frac{\left(2 \beta \gamma+C_{211}\right) k_{211}^{3}+\left(6 \gamma_{s} \beta \rho-3 C_{211}\right) k_{211}^{2}+\left(3 C_{211}+12 \gamma_{s} \beta \rho(\Delta-1)\right) k_{211}+6 \gamma_{s} \beta \rho(\Delta-1)^{2}-C_{211}}{\left(1-k_{211}\right)} \\
C_{211}=\frac{-2 \eta \beta^{3}+3 \eta \beta^{2}-3 \beta^{2}-\eta+1}{\beta^{2}}\end{array}$ & $\phi_{211}^{\prime}=\frac{\beta}{2\left(1-k_{211}\right)}$ \\
\hline 2.1 .2 & $\begin{array}{l}M_{212}^{\prime}=\frac{\left(2 \beta \gamma+C_{212}\right) k_{212}^{3}+3\left(2 \gamma_{s} \zeta \rho-C_{212}\right) k_{212}^{2}+3\left(C_{212}+2 \gamma_{s} \zeta \rho(\Delta-2)\right) k_{212}+6 \gamma_{s} \zeta \rho(1-\Delta)-C_{212}}{\left(1-k_{212}\right)} \\
C_{212}=\frac{-2 \eta \beta^{3}+3 \eta \beta^{2}-3 \beta^{2}-\eta+1}{\beta^{2}}\end{array}$ & $\phi_{212}^{\prime}=\frac{\beta}{2\left(1-k_{212}\right)}$ \\
\hline 2.2 .1 & $\begin{array}{l}M_{221}^{\prime}=\frac{-\left(3 \omega \gamma+C_{221}\right) k_{221}^{3}+3\left(\omega \gamma+C_{221}+2 \gamma_{s} \beta \rho\right) k_{221}^{2}+3\left(4 \gamma_{s} \beta \rho(\Delta-1)-C_{221}\right) k_{221}+6 \gamma_{s} \beta \rho(\Delta-1)^{2}+C_{221}}{\left(1-k_{221}\right)} \\
C_{221}=\frac{2 \eta \beta^{3}-3 \eta \beta^{2}+3 \beta^{2}-\omega^{3} \gamma+\eta-1}{\beta^{2}}\end{array}$ & $\phi_{221}^{\prime}=\frac{\beta}{2\left(1-k_{221}\right)}$ \\
\hline 2.2.2 & $\begin{array}{l}M_{222}^{\prime}=\left(3 \omega \gamma+C_{222}\right) k_{222}^{2}-2\left(3 \zeta \gamma_{s} \rho+C_{222}\right) k_{222}+6\left(\zeta \gamma_{s} \rho-\zeta \gamma_{s} \rho \Delta\right)+C_{222} \\
C_{221}=\frac{2 \eta \beta^{3}-3 \eta \beta^{2}+3 \beta^{2}-\omega^{3} \gamma+\eta-1}{\beta^{2}}\end{array}$ & $\phi_{222}^{\prime}=\frac{\beta}{2\left(1-k_{222}\right)}$ \\
\hline 3.1 .1 & $\begin{array}{l}M_{311}^{\prime}=\frac{\left(C_{311}-2 \beta \gamma\right) k_{311}^{3}-3\left(2 \gamma_{s} \beta \rho+C_{311}\right) k_{311}^{2}+3\left(C_{311}-4 \gamma_{s} \beta \rho(\Delta-1)\right) k_{311}-6 \gamma_{s} \beta \rho(\Delta-1)^{2}-C_{311}}{\left(k_{311}-1\right)} \\
C_{311}=\frac{3\left(\mu \beta^{2}-\mu \alpha^{2}-\eta \alpha^{2}+\alpha^{2}\right)+2 \eta \alpha^{3}+\eta-1}{\beta^{2}}\end{array}$ & $\phi_{311}^{\prime}=\frac{\beta}{2\left(1-k_{311}\right)}$ \\
\hline 3.1 .2 & $\begin{array}{l}M_{312}^{\prime}=\frac{\left(C_{312}-2 \beta \gamma\right) k_{312}^{3}-3\left(2 \gamma_{s} \zeta \rho+C_{312}\right) k_{311}^{2}+3\left(C_{312}+2 \gamma_{s} \zeta \rho(2-\Delta)\right) k_{312}+6 \gamma_{s} \zeta \rho(\Delta-1)-C_{312}}{\left(k_{312}-1\right)} \\
C_{311}=\frac{3\left(\mu \beta^{2}-\mu \alpha^{2}-\eta \alpha^{2}+\alpha^{2}\right)+2 \eta \alpha^{3}+\eta-1}{\beta^{2}}\end{array}$ & $\phi_{312}^{\prime}=\frac{\beta}{2\left(1-k_{312}\right)}$ \\
\hline 3.2 .1 & $\begin{array}{l}M_{321}^{\prime}=\frac{-\left(3 \omega \gamma+C_{321}\right) k_{321}^{3}+3\left(\omega \gamma+C_{321}+2 \gamma_{s} \beta \rho\right) k_{321}^{2}+3\left(4 \gamma_{s} \beta \rho(\Delta-1)-C_{321}\right) k_{321}+6 \gamma_{s} \beta \rho(\Delta-1)^{2}+C_{321}}{\left(1-k_{321}\right)} \\
C_{321}=\frac{3\left(\mu \beta^{2}-\mu \alpha^{2}-\eta \alpha^{2}+\alpha^{2}\right)+2 \eta \alpha^{3}-\omega^{3} \gamma+\eta-1}{\beta^{2}}\end{array}$ & $\phi_{321}^{\prime}=\frac{\beta}{2\left(1-k_{321}\right)}$ \\
\hline 3.2 .2 & $\begin{array}{l}M_{322}^{\prime}=\left(3 \omega \gamma+C_{322}\right) k_{222}^{2}-2\left(3 \zeta \gamma_{s} \rho+C_{322}\right) k_{322}+6\left(\zeta \gamma_{s} \rho-\zeta \gamma_{s} \rho \Delta\right)+C_{322} \\
C_{322}=\frac{3\left(\mu \beta^{2}-\mu \alpha^{2}-\eta \alpha^{2}+\alpha^{2}\right)+2 \eta \alpha^{3}-\omega^{3} \gamma+\eta-1}{\beta^{2}}\end{array}$ & $\phi_{322}^{\prime}=\frac{\beta}{2\left(1-k_{322}\right)}$ \\
\hline
\end{tabular}


Table 4 - Geometric data and values for the constitutive models for the parametric study (see Figures 1 and 2).

\begin{tabular}{ccccccccccccccc}
\hline $\begin{array}{c}b \\
(\mathrm{~mm})\end{array}$ & $\begin{array}{c}d \\
(\mathrm{~mm})\end{array}$ & $\begin{array}{c}d^{\prime} \\
(\mathrm{mm})\end{array}$ & $\begin{array}{c}\varepsilon_{c r} \\
(\%)\end{array}$ & $\begin{array}{c}E \\
(\mathrm{GPa})\end{array}$ & $\beta_{t u}$ & $\alpha$ & $\mu$ & $\gamma$ & $\omega$ & $\lambda_{c u}$ & $\gamma_{s}$ & $\zeta$ & $\psi_{s u}$ & $\begin{array}{c}\rho \\
(\%)\end{array}$ \\
\hline 250 & 500 & 50 & 0.01 & 30 & 150 & $\begin{array}{c}{[1.01-15]^{* *}} \\
{[5.0-20.0]^{* *}}\end{array}$ & {$[1.02-2.98]^{* *}$} & 1 & 10 & 40 & 10 & 12 & 120 & {$[0.0-0.8]$} \\
\hline
\end{tabular}

* For strain softening $\quad$ ** For strain hardening 
Table 5 - Geometrical and mechanical properties of the beams

\begin{tabular}{cccccccccccc}
\hline $\begin{array}{c}\text { Beam } \\
\text { series }\end{array}$ & Reference & $\begin{array}{c}b \\
(\mathrm{~mm})\end{array}$ & $\begin{array}{c}d \\
(\mathrm{~mm})\end{array}$ & $\begin{array}{c}d^{\prime} \\
(\mathrm{mm})\end{array}$ & $\begin{array}{c}L 1 \\
(\mathrm{~mm})\end{array}$ & $\begin{array}{c}L 2 \\
(\mathrm{~mm})\end{array}$ & $A_{s}$ & $\begin{array}{c}f_{c k} \\
(\mathrm{MPa})\end{array}$ & $\begin{array}{c}f_{R 1} \\
(\mathrm{MPa})\end{array}$ & $\begin{array}{c}f_{y} \\
(\mathrm{MPa})\end{array}$ & $\begin{array}{c}E_{s} \\
(\mathrm{GPa})\end{array}$ \\
\hline B1 & $\begin{array}{c}\text { Vandewalle } \\
(2000)\end{array}$ & 200 & 350 & 35 & 750 & 1750 & $2 \Phi 20$ & 37.5 & $4.30^{\mathrm{a}}$ & 500 & 200 \\
$\mathrm{~B} 2$ & $\begin{array}{c}\text { Tan et al. } \\
(1995)\end{array}$ & 100 & 125 & 25 & 665 & 665 & $2 \Phi 10$ & 34.5 & $0.95^{\mathrm{a}}$ & 500 & 200 \\
\hline
\end{tabular}

${ }^{\mathrm{a}}$ Estimated 
Table 6 - Values computed for the constitutive models for series of beams

\begin{tabular}{ccccccccccccc}
\hline $\begin{array}{c}\text { Beam } \\
\text { series }\end{array}$ & $\begin{array}{c}\mathrm{E} \\
(\mathrm{GPa})\end{array}$ & $\begin{array}{c}\varepsilon_{c r} \\
(\%)\end{array}$ & $\alpha$ & $\mu$ & $\beta_{t u}$ & $\gamma$ & $\omega$ & $\lambda_{c u}$ & $\rho(\%)$ & $\gamma_{s}$ & $\zeta$ & $\psi_{s u}$ \\
\hline B1 & 34.66 & 0.01 & $1.5^{\mathrm{a}}$ & $0.35^{\mathrm{a}}$ & $190^{\mathrm{a}}$ & 1.0 & 17.5 & 35 & 0.898 & 5.77 & 25 & 450 \\
$\mathrm{~B} 2$ & 33.96 & 0.01 & $1.01^{\mathrm{a}}$ & $0.10^{\mathrm{a}}$ & $180^{\mathrm{a}}$ & 1.0 & 17.5 & 35 & 1.257 & 5.89 & 25 & 450 \\
\hline
\end{tabular}

${ }^{\mathrm{a}}$ Estimated 
Table 7 - Geometric data and values for the parameters of the constitutive model for the parametric study on the influence of $\rho$ and $\mu$ on the $M_{w d} / M_{c r}$ (see Fig. 15).

\begin{tabular}{ccccccccccccccc}
\hline $\begin{array}{c}b \\
(\mathrm{~mm})\end{array}$ & $\begin{array}{c}d \\
(\mathrm{~mm})\end{array}$ & $\begin{array}{c}d^{\prime} \\
(\mathrm{mm})\end{array}$ & $\begin{array}{c}\varepsilon_{c r} \\
(\%)\end{array}$ & $\begin{array}{c}E \\
(\mathrm{GPa})\end{array}$ & $\beta_{t u}$ & $\alpha$ & $\mu$ & $\gamma$ & $\omega$ & $\lambda_{c u}$ & $\gamma_{s}$ & $\zeta$ & $\psi_{s u}$ & $\begin{array}{c}\rho \\
(\%)\end{array}$ \\
\hline 250 & 500 & 50 & 0.01 & 30 & 150 & 3 & {$[0.0-0.8]$} & 1 & 10 & 40 & 6.67 & 12 & 120 & {$[0.2-1.0]$} \\
\hline
\end{tabular}




\section{LIST OF FIGURE CAPTIONS}

Figure 1 - Idealized stress-strain response of FRC: (a) tensile behaviour, (b) compressive behaviour (based on Soranakom and Mobasher 2008); and (c) idealized stress-strain diagram for steel bars.

Figure 2 - Main variables that describe the geometry and the strain profile in a FRC reinforced rectangular cross section.

Figure 3 - Numerical approach to simulate the deformational behavior of structural elements failing in bending.

Figure 4 - Stress-strain response of FRC materials; (a) the effect of variation of parameter $\alpha$ in strain-softening FRC,

(b) the effect of variation of parameter $\mu$ in strain-softening FRC, (c) the effect of variation of parameter $\alpha$ in strainhardening FRC (d) the effect of variation of parameter $\mu$ in strain-hardening FRC.

Figure 5 - The effect of $\alpha$ parameter of SS-FRC in terms of: (a-d) normalized moment-curvature, and (e-h) normalized distributed load-deflection at mid-span for steel reinforcement ratio of $0.0,0.2,0.4,0.8 \%$.

Figure 6 - The effect of $\alpha$ parameter of SS-FRC in terms of normalized increase of: (a) flexural, and (b) load carrying capacity $\left(\Delta M=M_{\alpha=15}-M_{\text {min }}, M_{\text {min }}=M_{\alpha=1.01}, \Delta p=p_{\alpha=15}-p_{\text {min }}, p_{\text {min }}=p_{\alpha=1.01}\right)$.

Figure 7 - The effect of $\mu$ parameter of SS-FRC in terms of: (a-d) normalized moment-curvature, and (e-h) normalized distributed load-deflection at mid-span for steel reinforcement ratio of $0.0,0.2,0.4,0.8 \%$.

Figure 8 - The effect of $\mu$ parameter of SS-FRC in terms of normalized increase of: (a) flexural, and (b) load carrying capacity $\left(\Delta M=M_{\mu=0.99}-M_{\min }, M_{\text {min }}=M_{\mu=1.01}, \Delta p=p_{\mu=0.99}-p_{\min }, p_{\min }=p_{\mu=0.01}\right.$.

Figure 9 - The effect of $\alpha$ parameter of SH-FRC in terms of: (a-d) normalized moment-curvature, and (e-h) normalized distributed load-deflection at mid-span for steel reinforcement ratio of 0.0, 0.2, 0.4, $0.8 \%$.

Figure 10 - The effect of $\alpha$ parameter of SH-FRC in terms of normalized increase of: (a) flexural, and (b) load carrying capacity $\left(\Delta M=M_{\alpha=5}-M_{\min }, M_{\min }=M_{\alpha=20}, \Delta p=p_{\alpha=5}-p_{\min }, p_{\min }=p_{\alpha=20}\right.$ ).

Figure 11 - The effect of $\mu$ parameter of SH-FRC in terms of: (a-d) normalized moment-curvature, and (e-h) normalized distributed load-deflection at mid-span for steel reinforcement ratio of 0.0, 0.2, 0.4, $0.8 \%$. 
Figure 12 - The effect of $\mu$ parameter of SH-FRC in terms of normalized increase of: (a) flexural, and (b) load carrying capacity $\left(\Delta M=M_{\mu=2.98}-M_{\min }, M_{\min }=M_{\mu=1.02}, \Delta p=p_{\mu=2.98}-p_{\min }, p_{\min }=p_{\mu=1.02}\right)$.

Figure 13 - Geometrical properties of beams experimentally tested for the evaluation of the crack width in fibrous concrete reinforced with steel bars.

Figure 14 - Moment versus maximum crack width determined from the developed model and from experimental tests; (a) B1, (b) B2.

Figure 15 - Influence of $\rho$ and $\mu$ on the $M_{w d} / M_{c r}$, where $M_{w d}$ is the resisting bending moment for a crack width of 0.1 $\left.\mathrm{mm}\left(w_{d}=0.1 \mathrm{~mm}\right): \mathrm{a}\right)$ discrete, and $\left.\mathrm{b}\right)$ continuous representation. 
FIGURE CAPTIONS

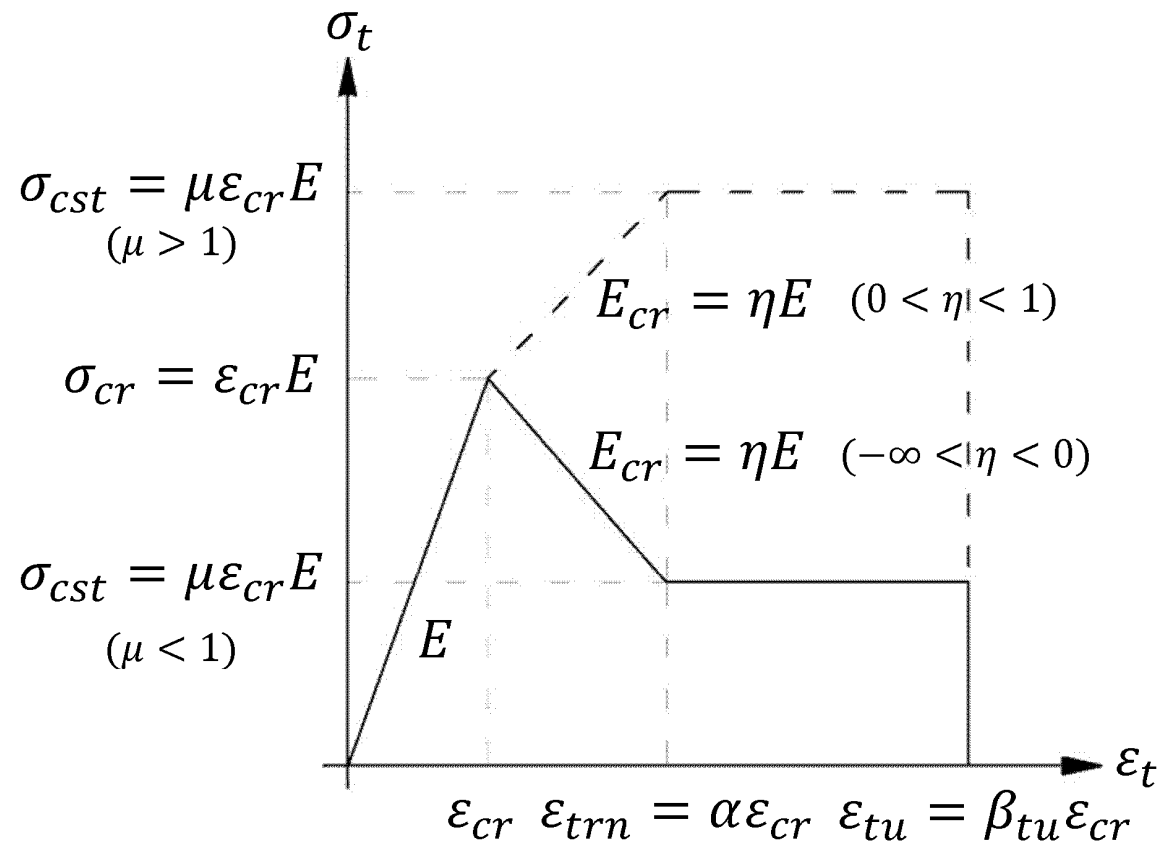

Figure1a 


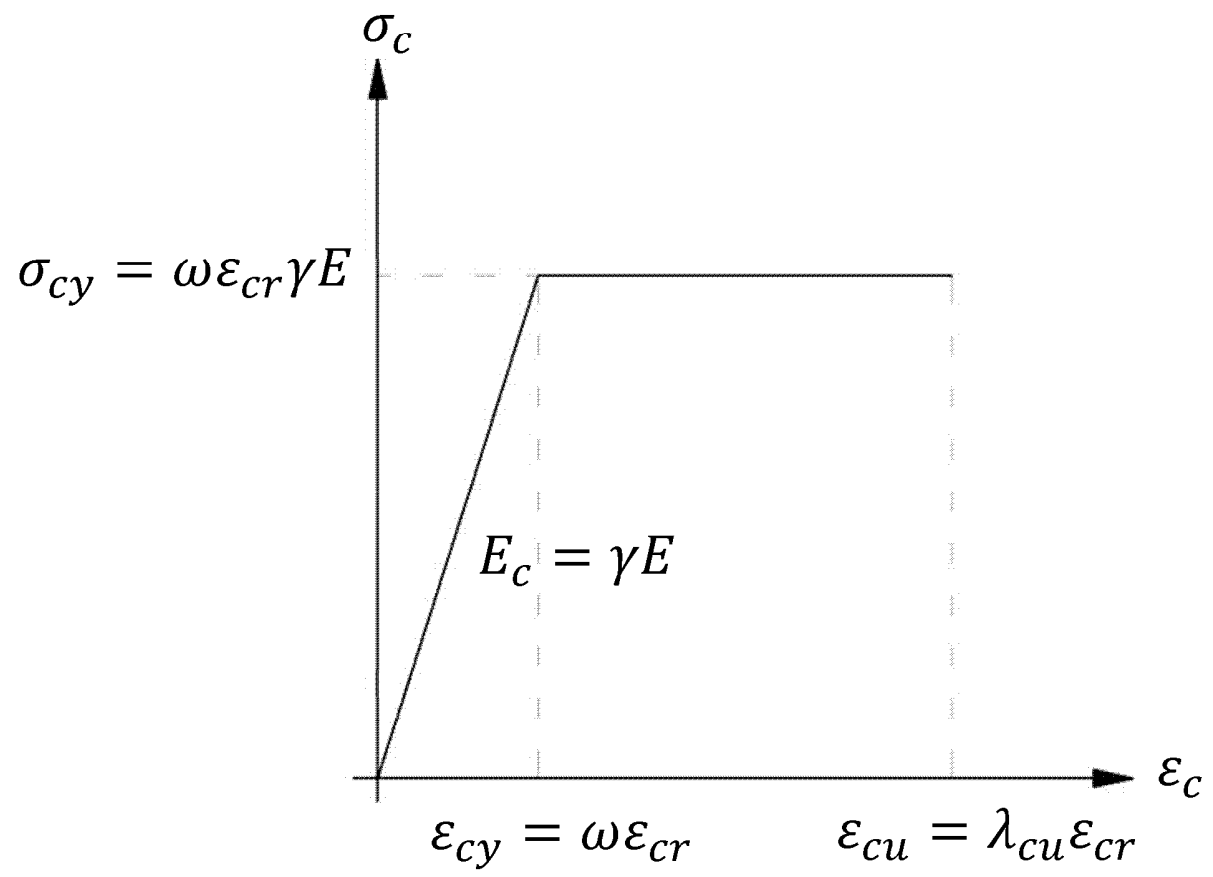

Figure1b 


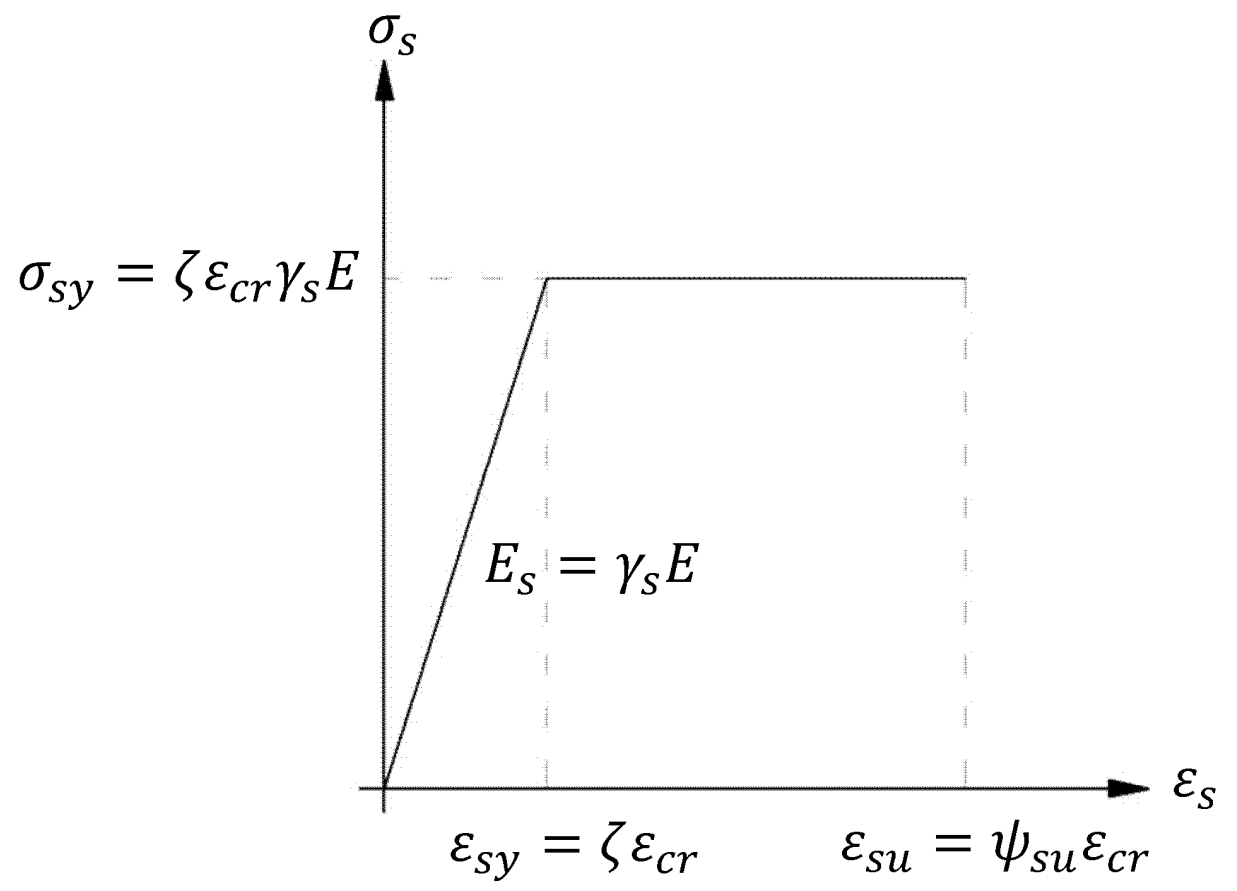

Figure1c 


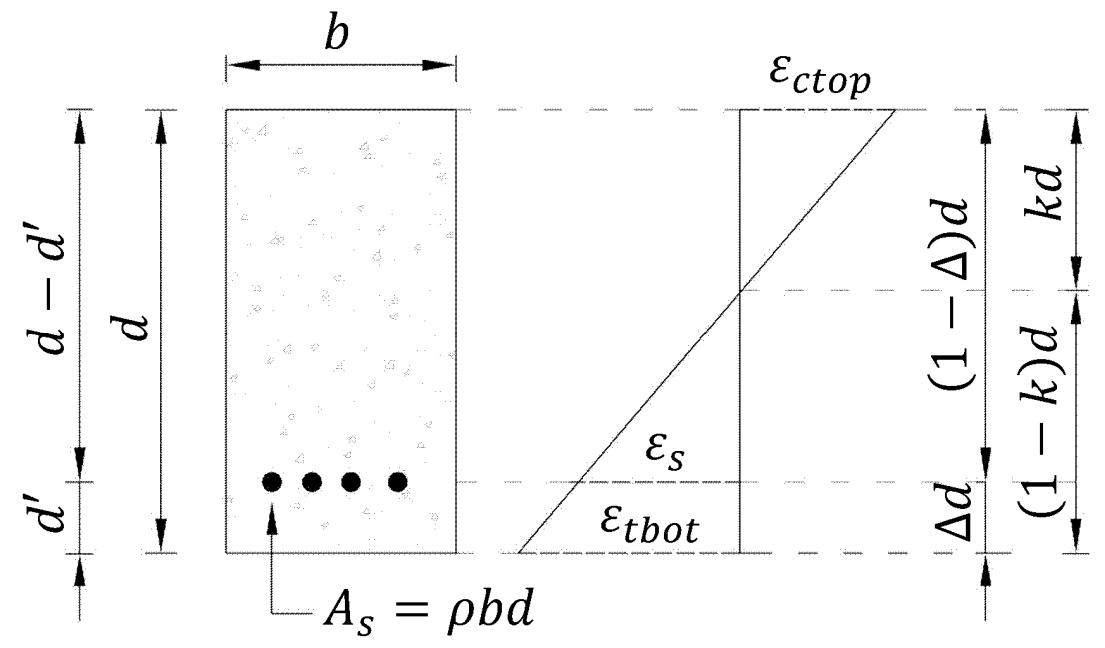

Figure2 


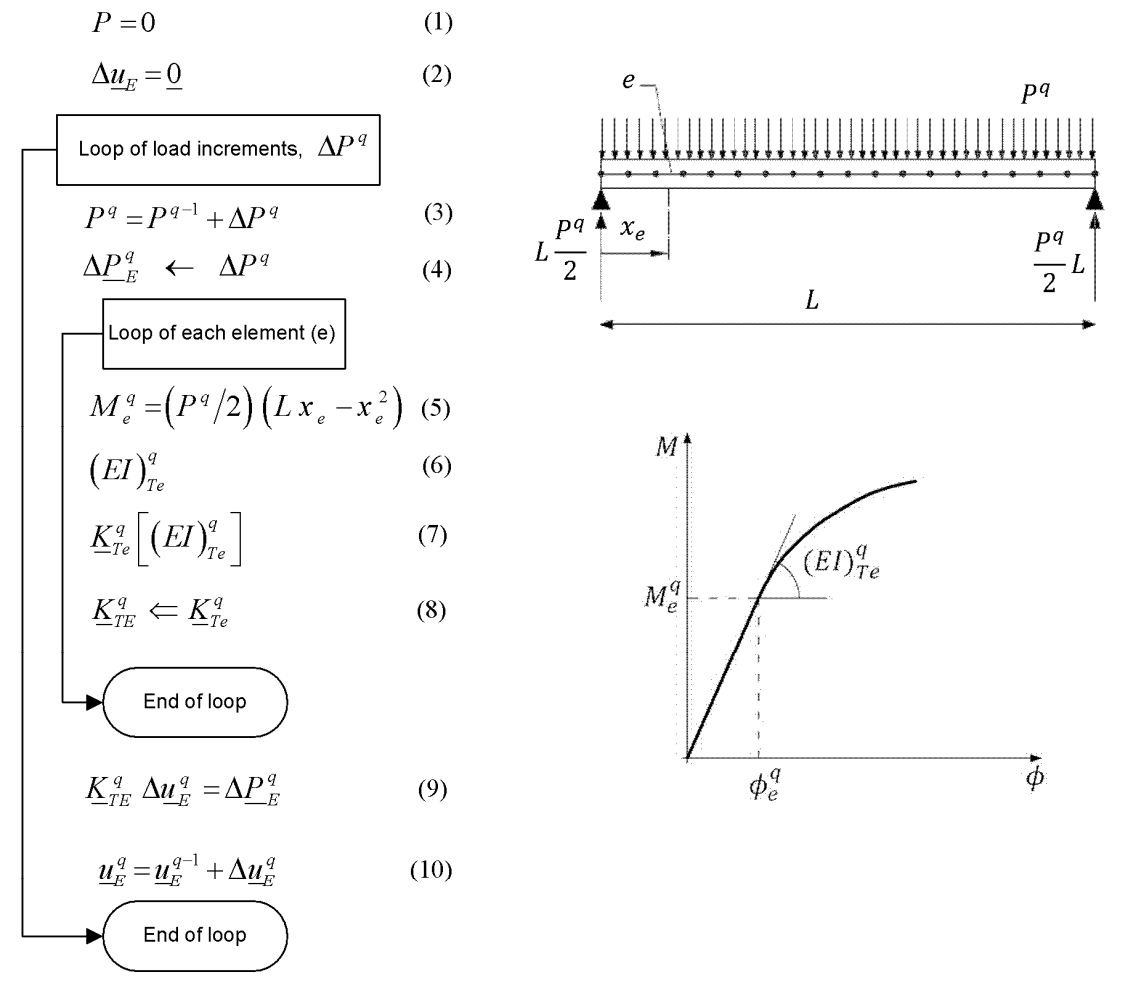

Figure 3 


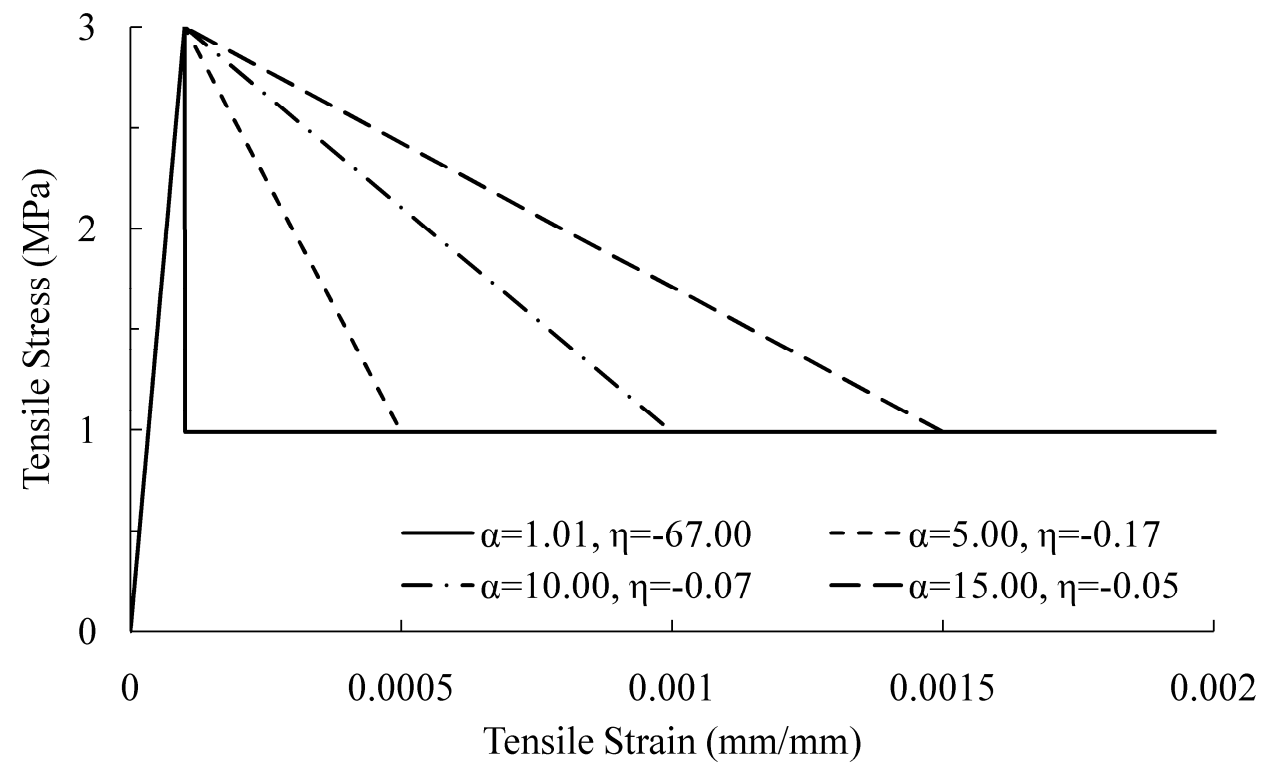

Figure 4a 


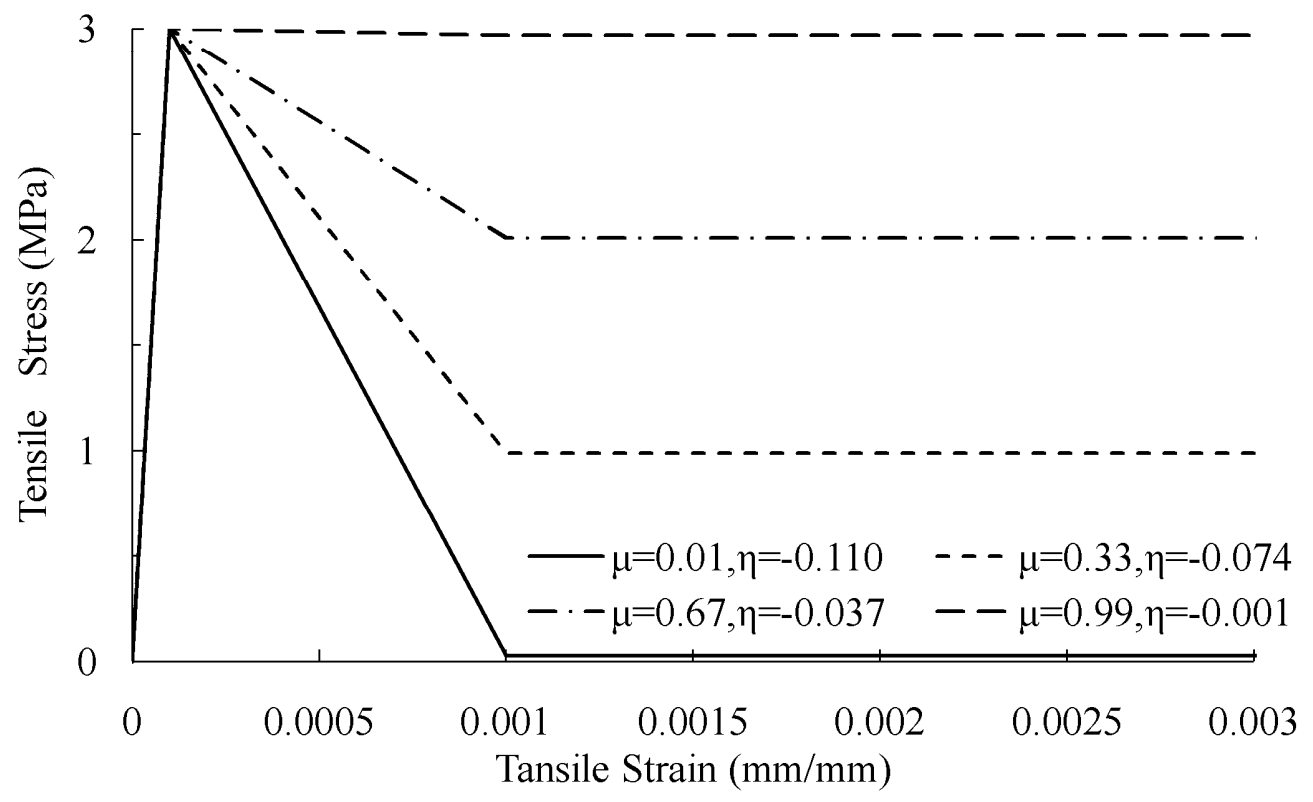

Figure $4 b$ 


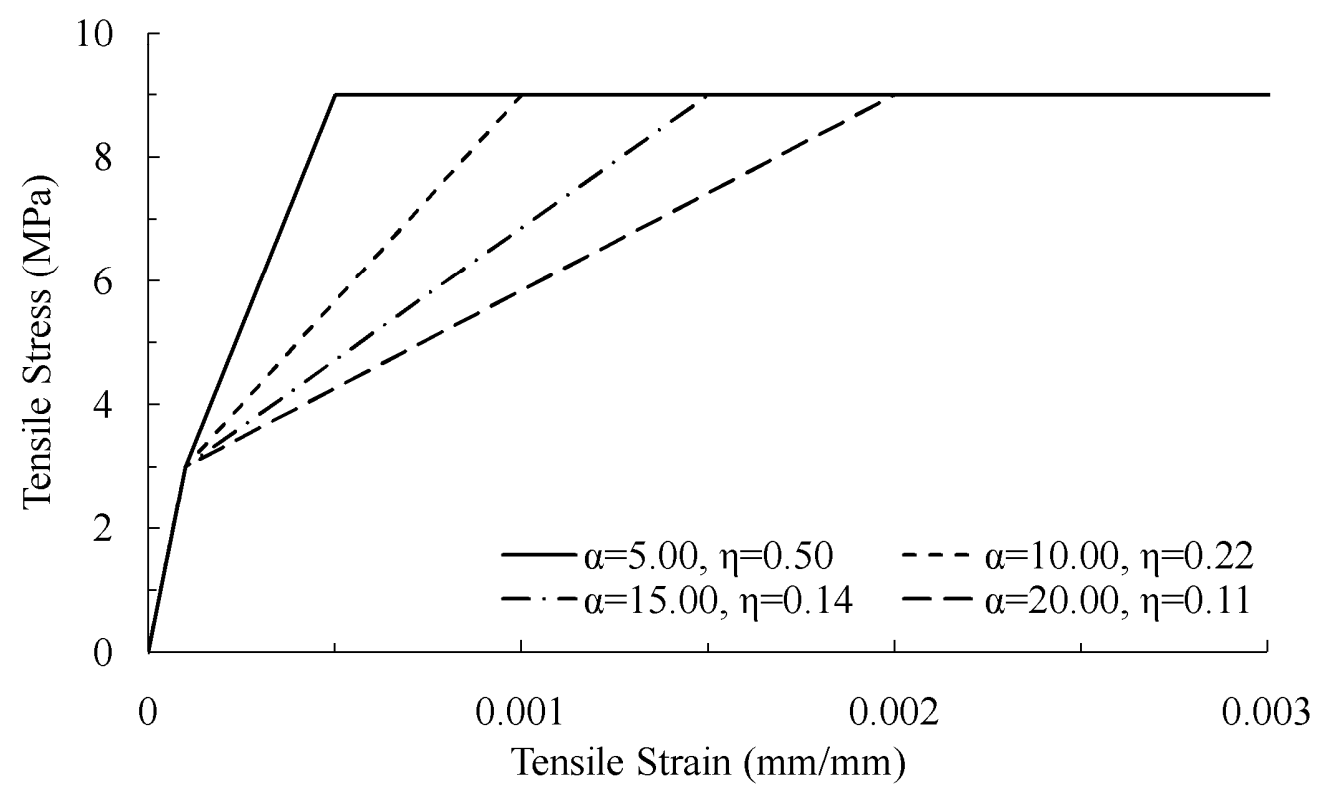

Figure 4c 


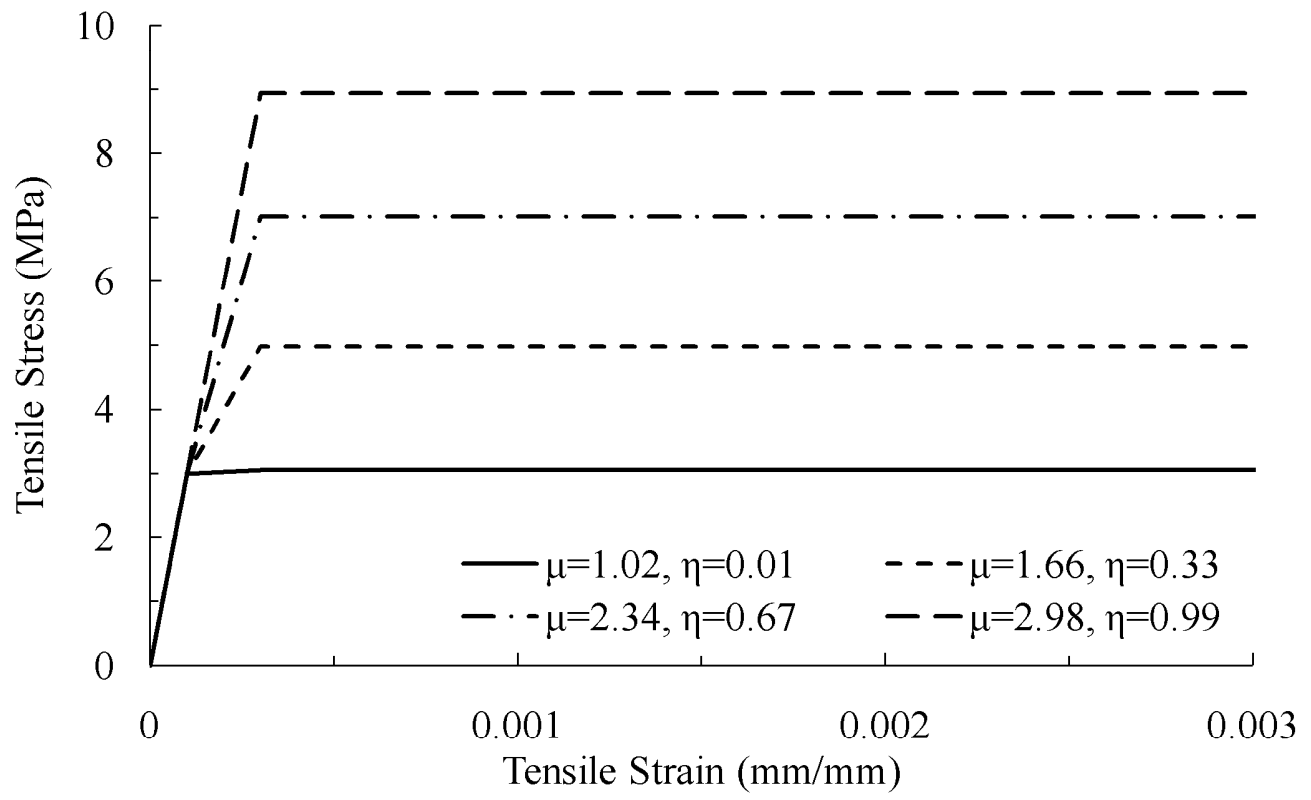

Figure 4d 


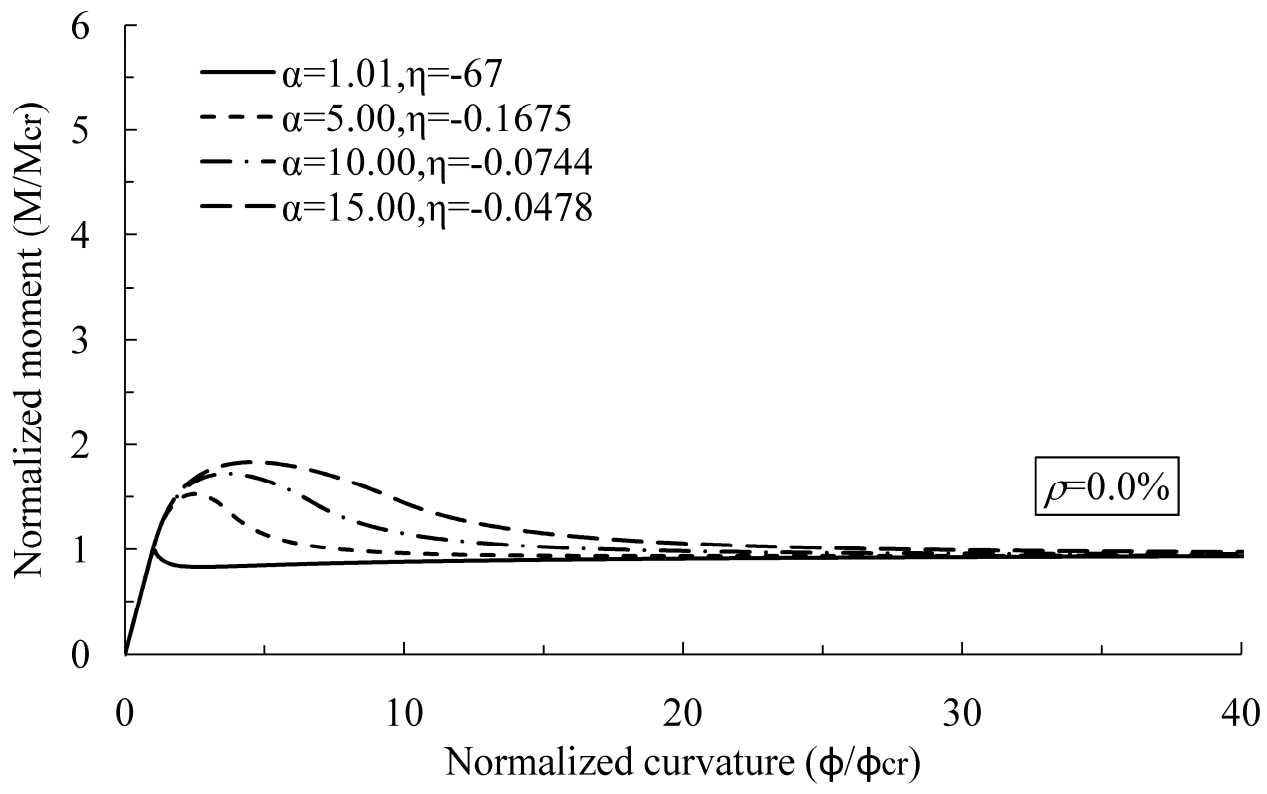

Figure 5a 


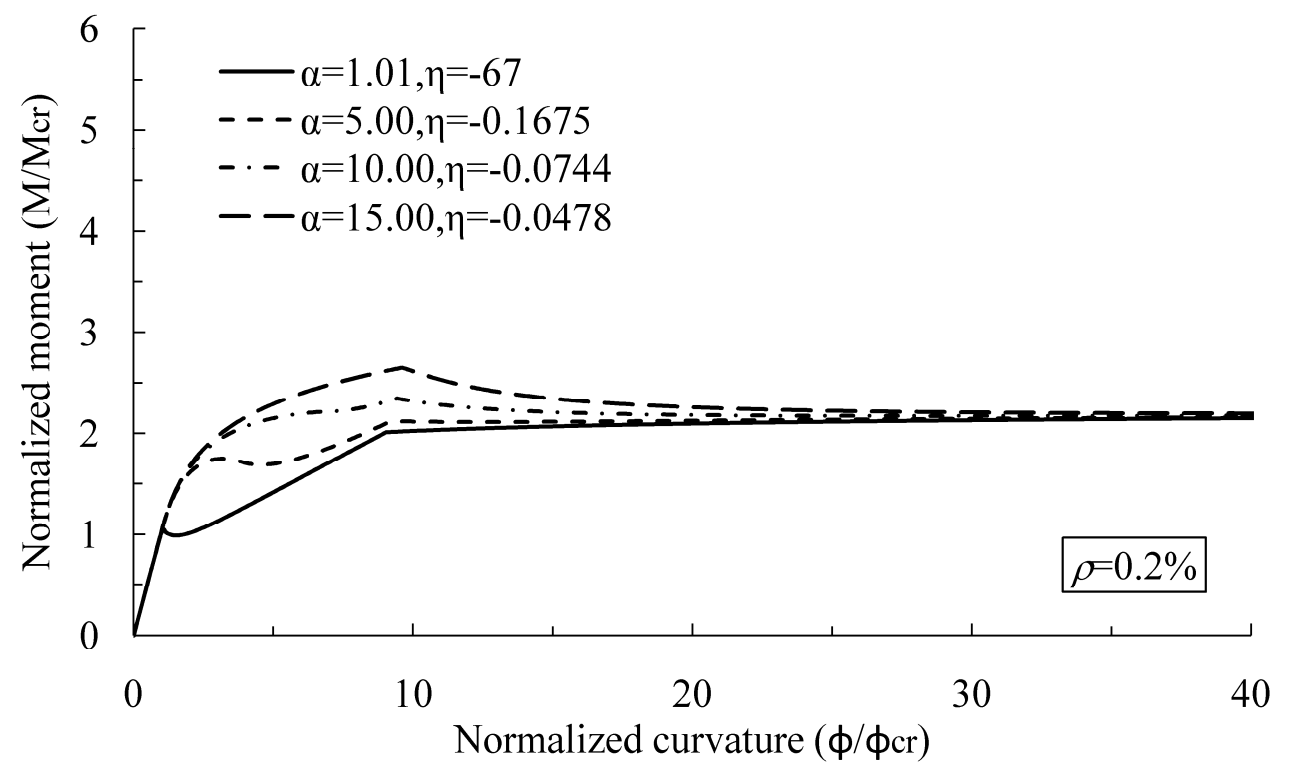

Figure 5b 


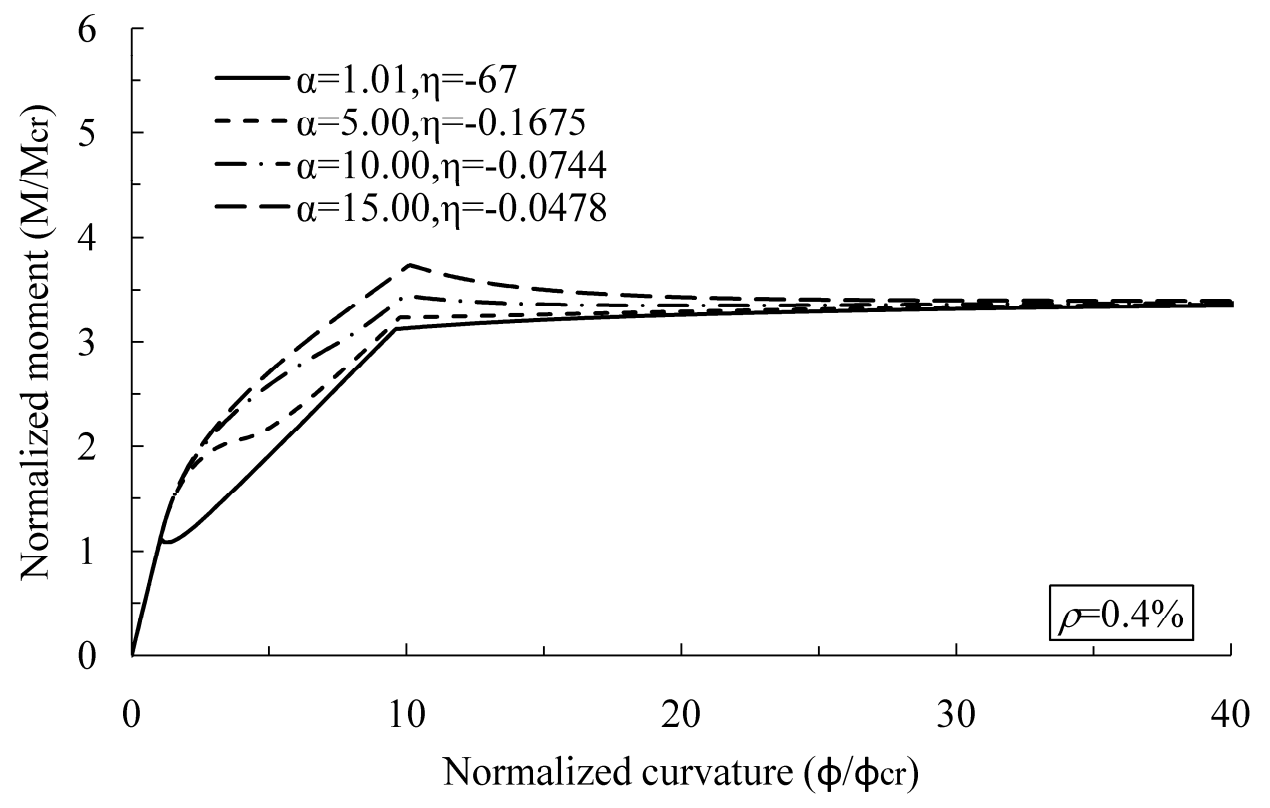

Figure 5c 


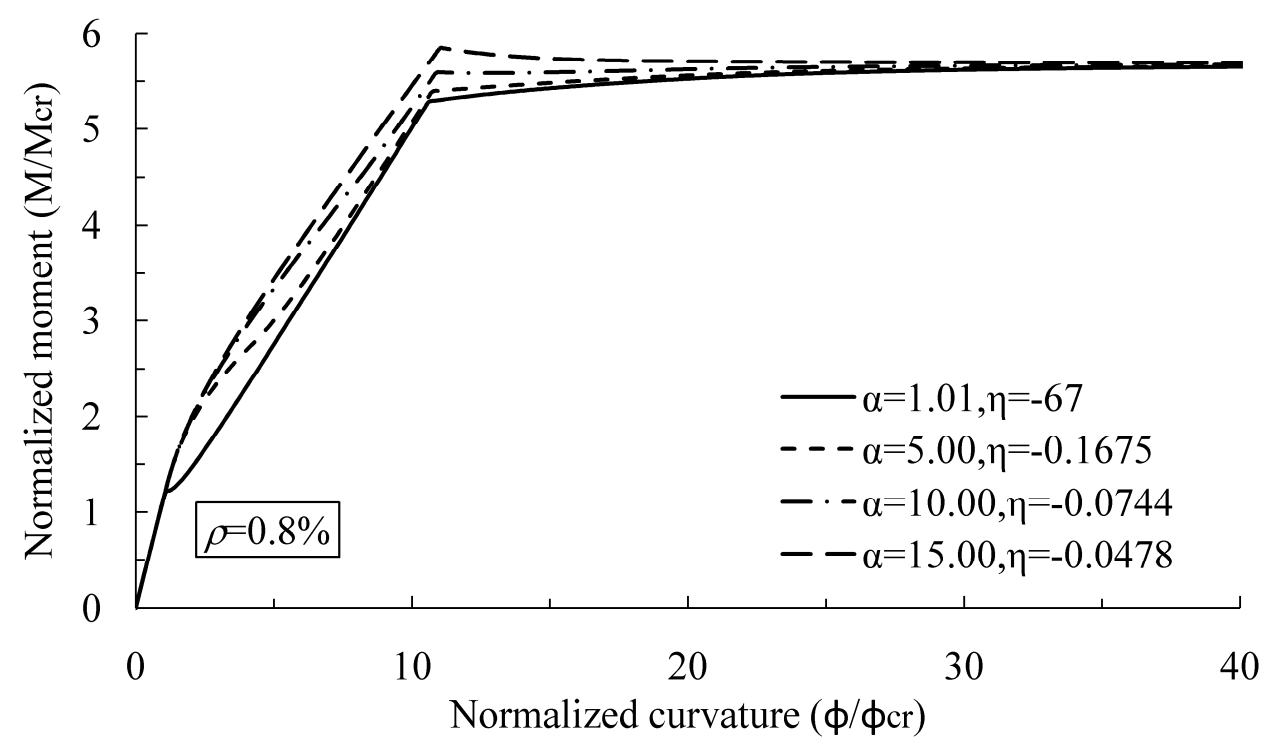

Figure 5d 


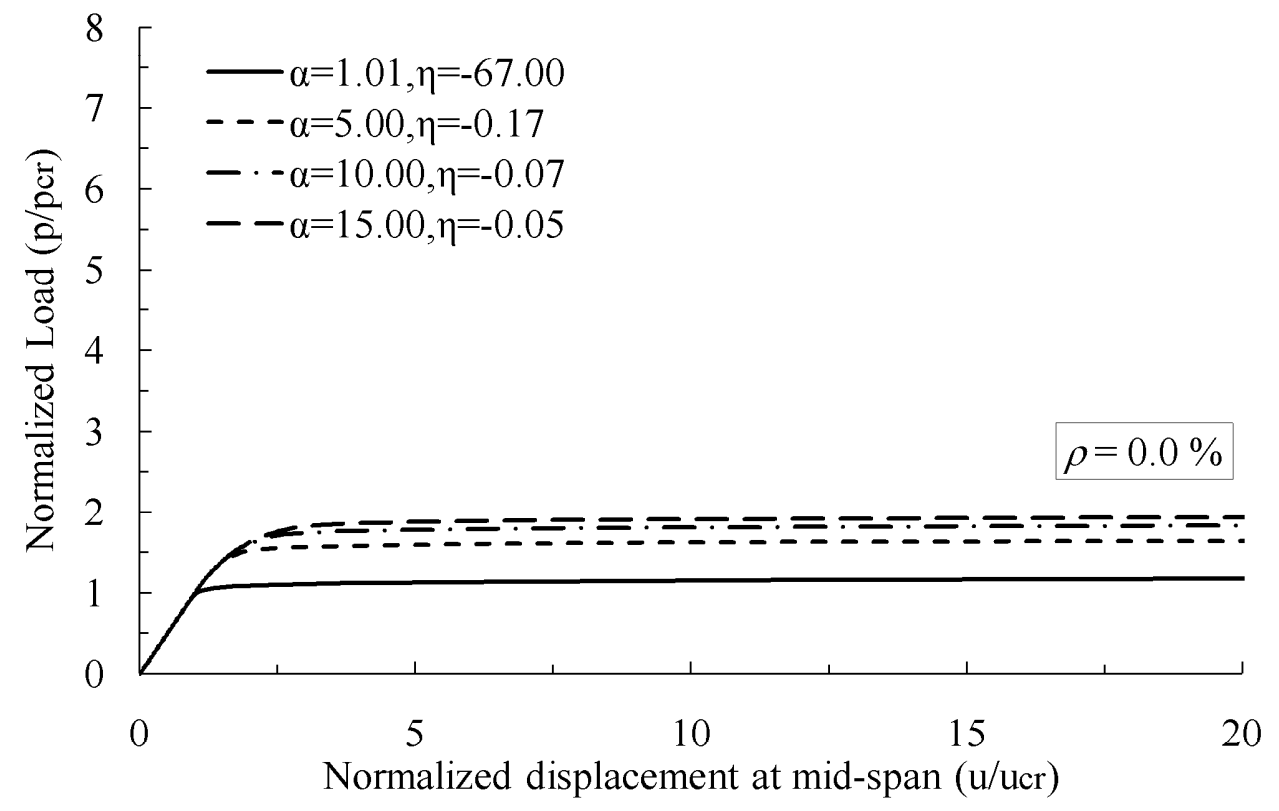

Figure 5e 


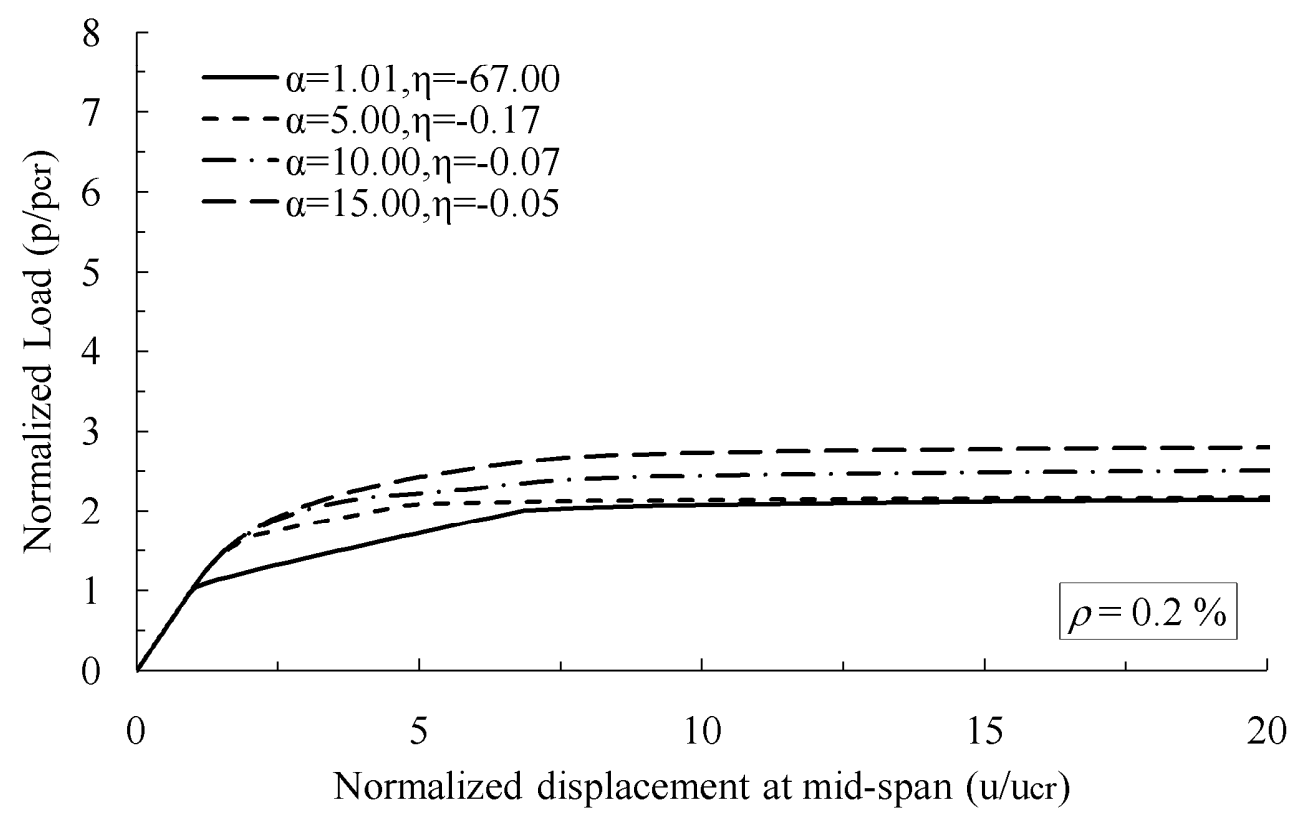

Figure $5 f$ 


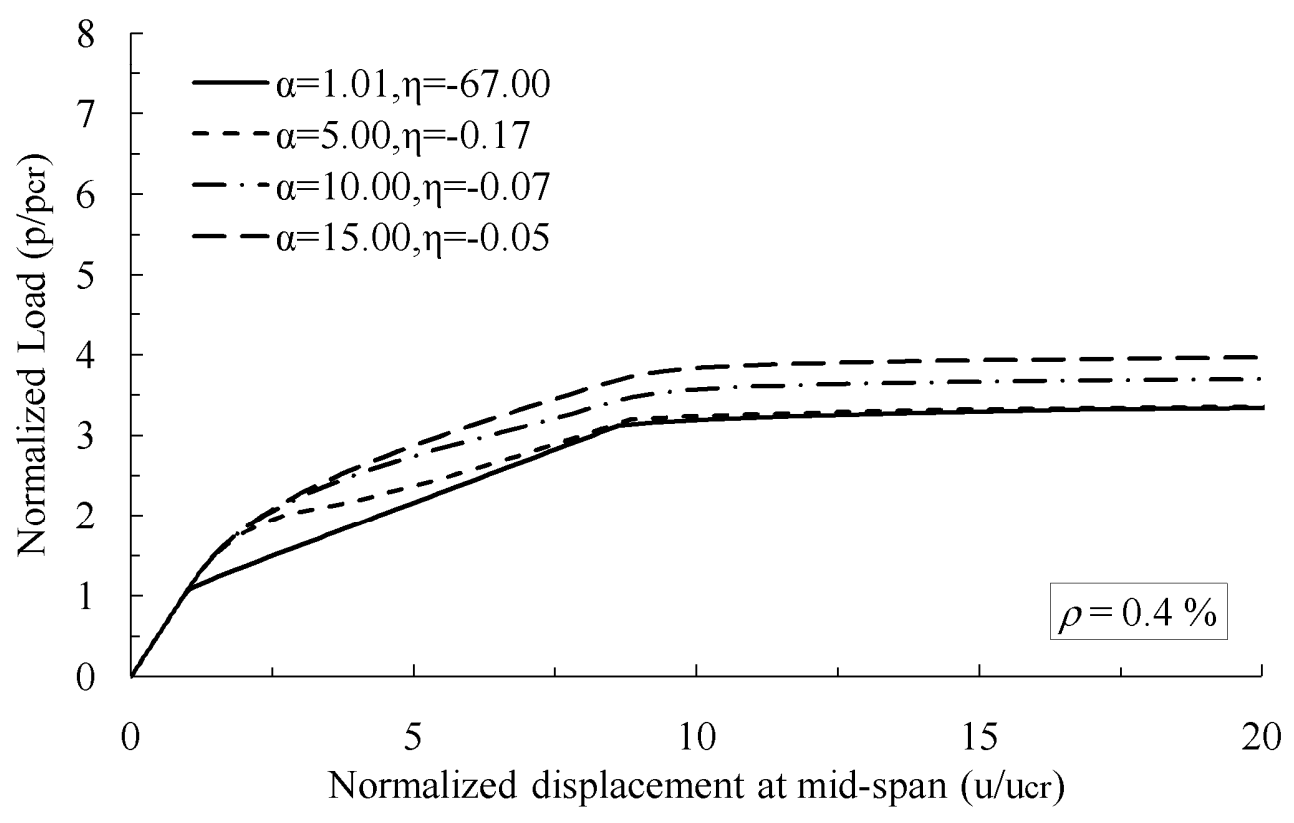

Figure 5g 


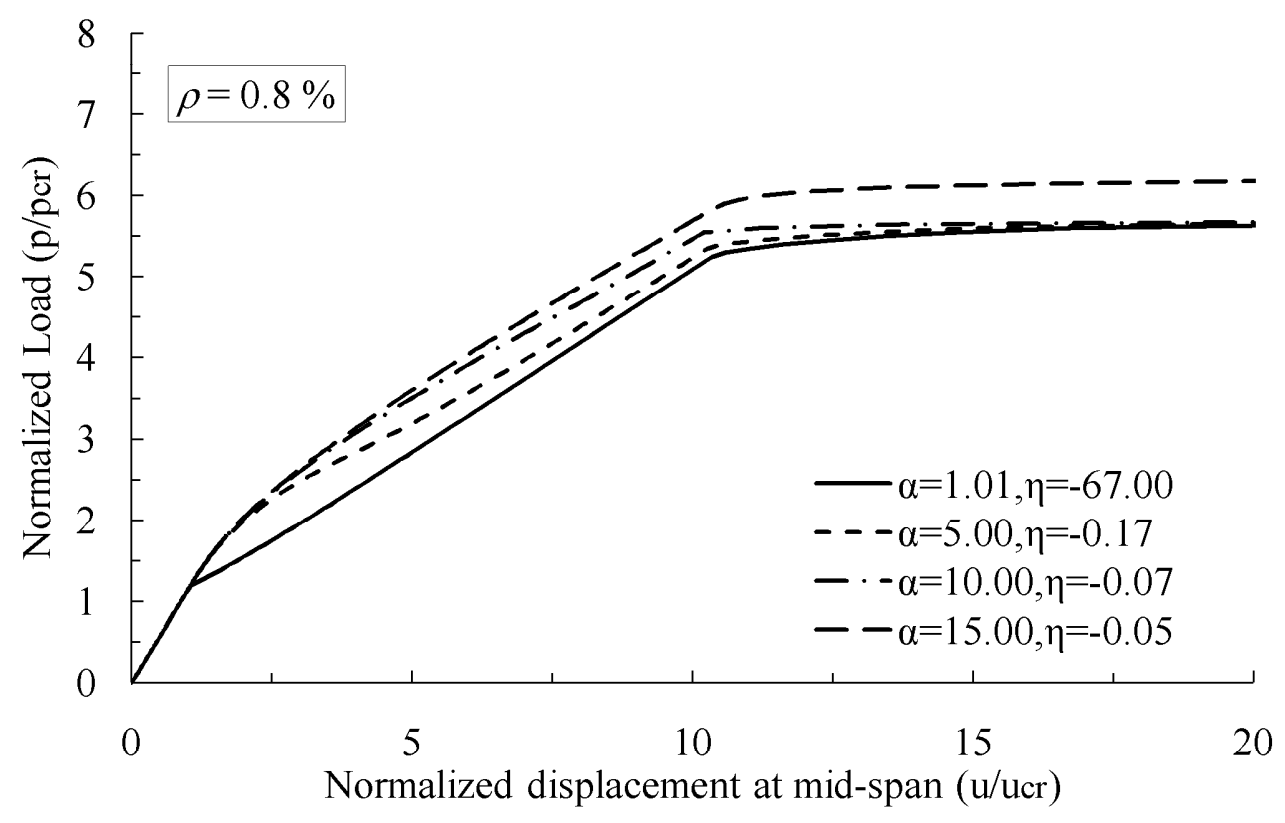

Figure $5 \mathrm{~h}$ 


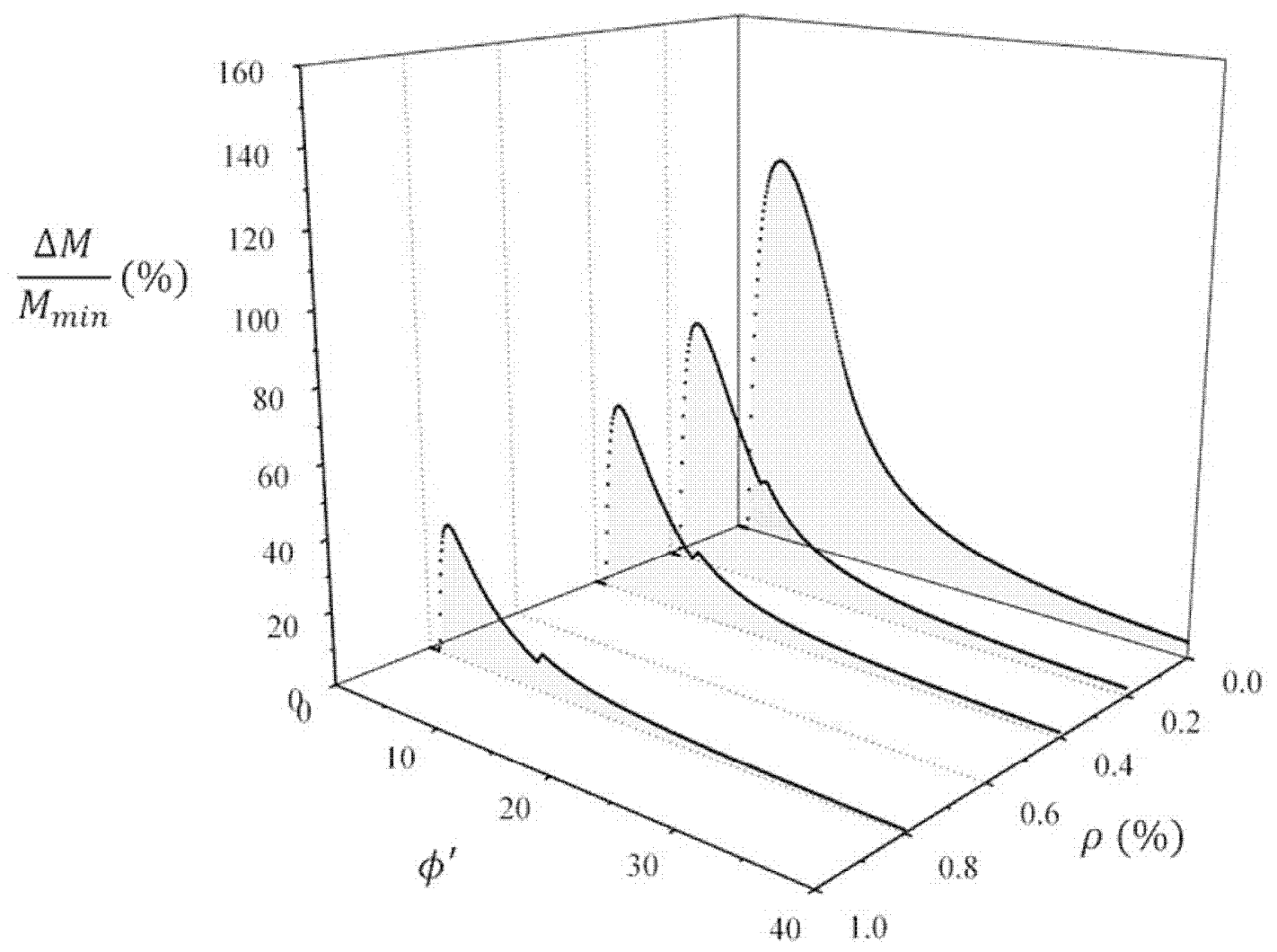

Figure 6a 


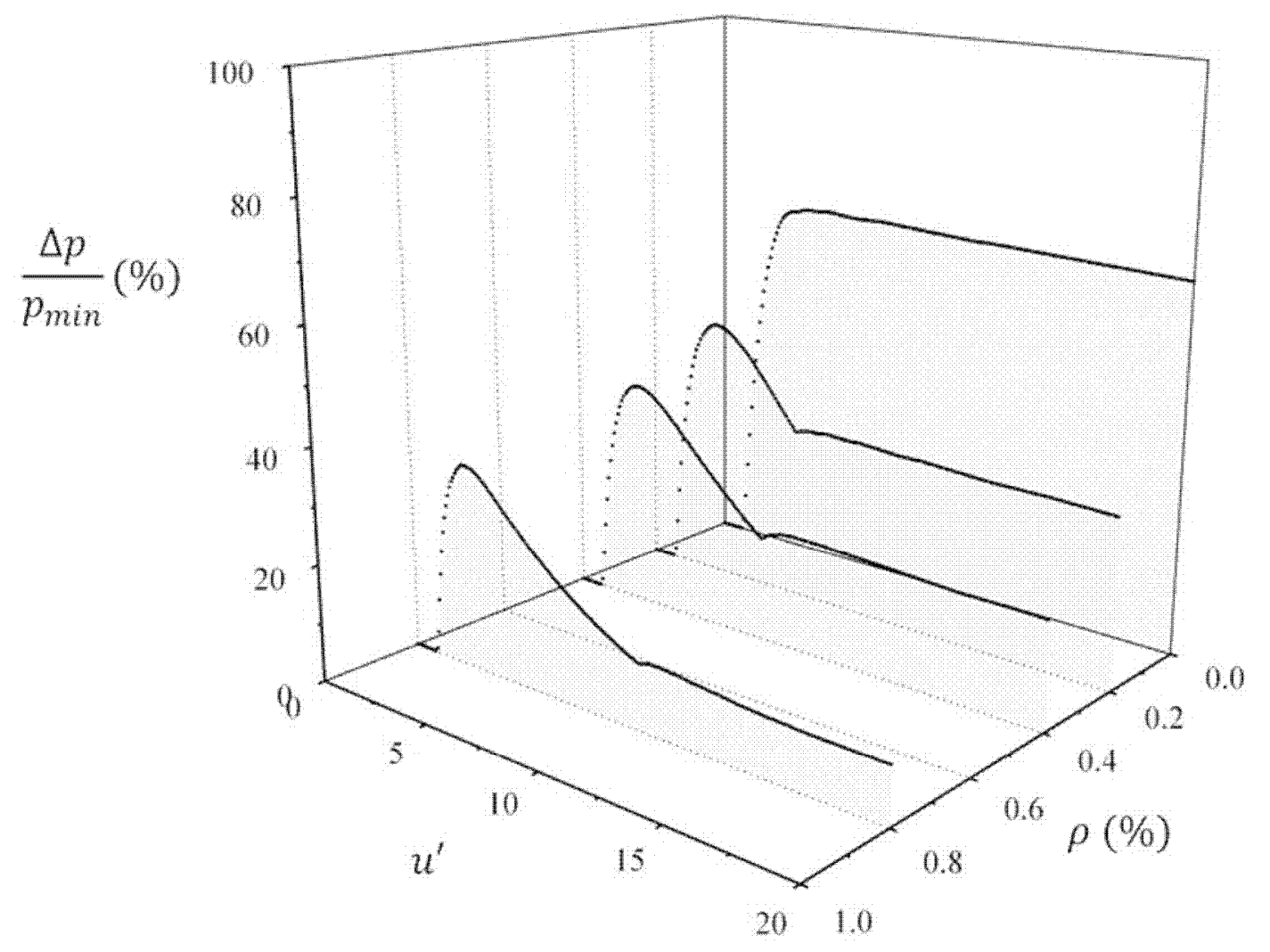

Figure $6 b$ 


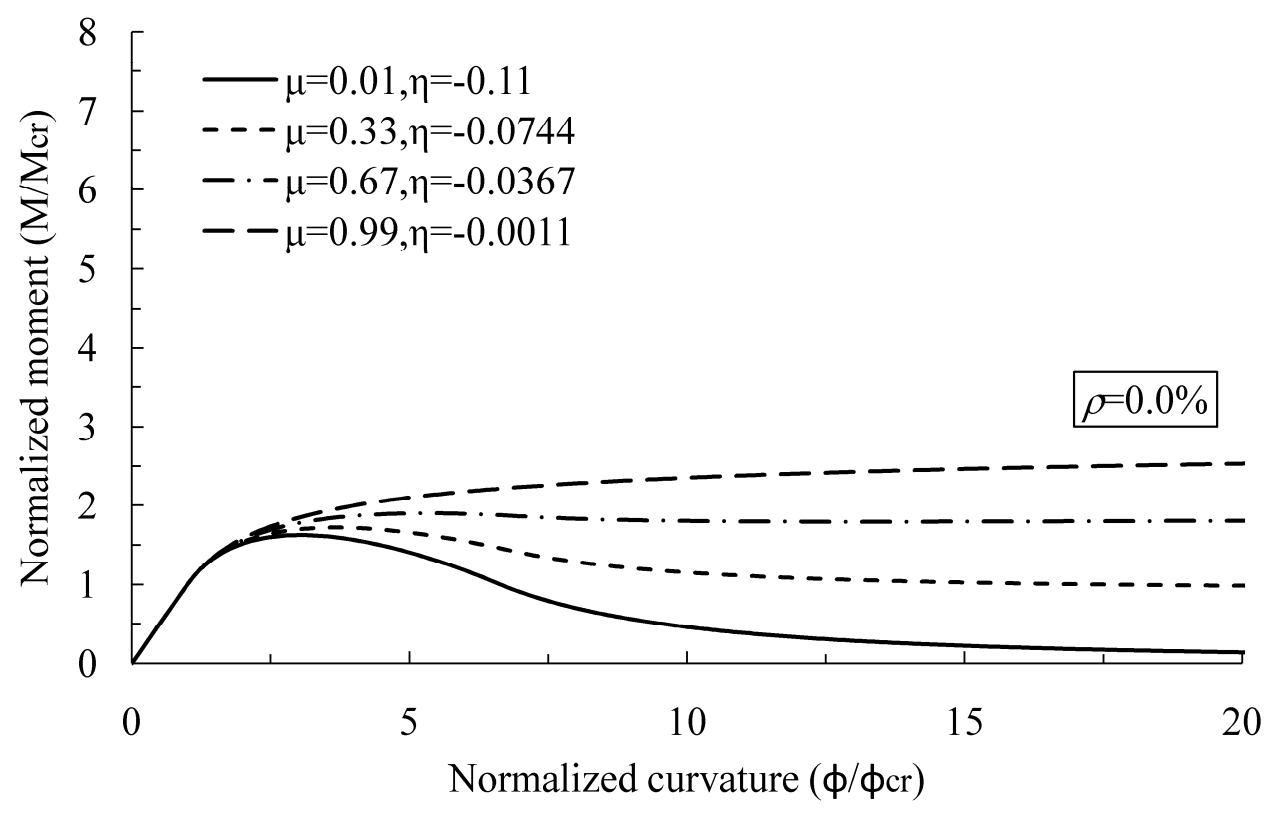

Figure 7a 


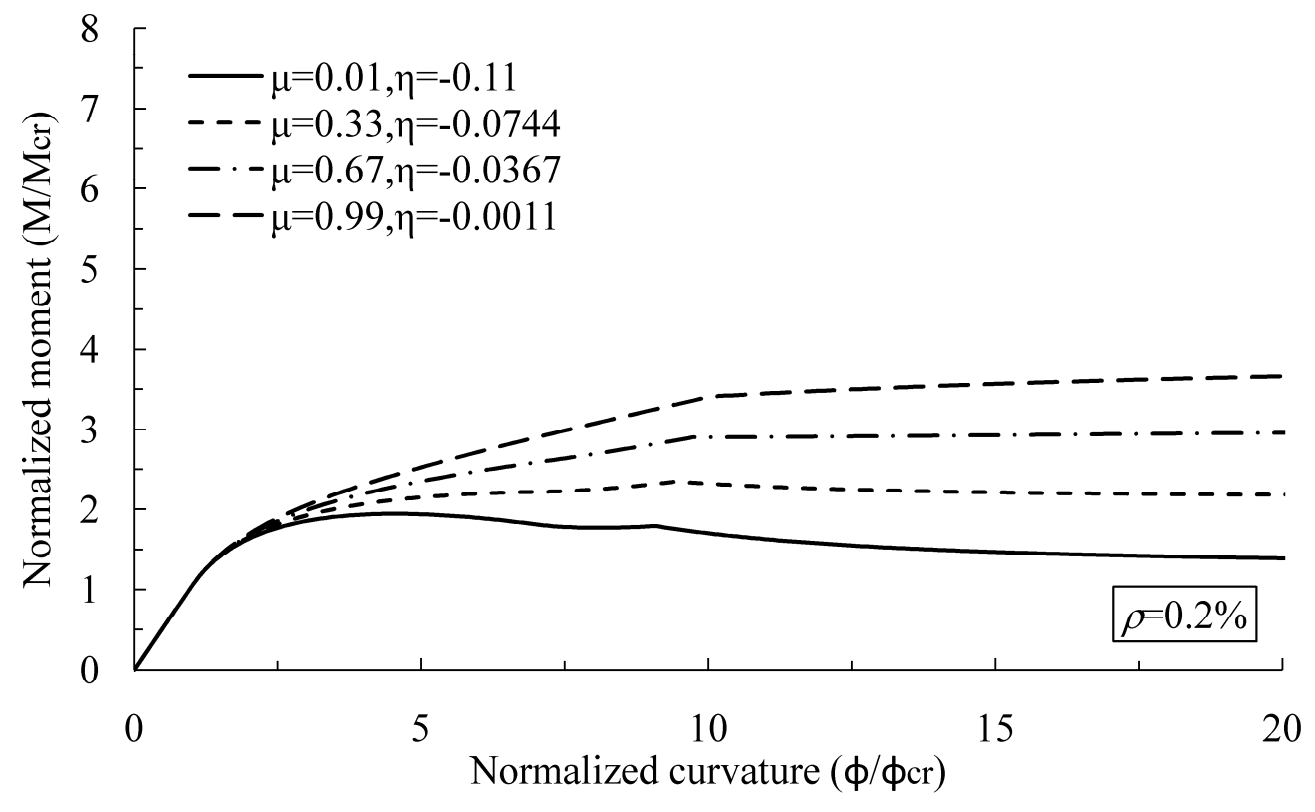

Figure $7 b$ 


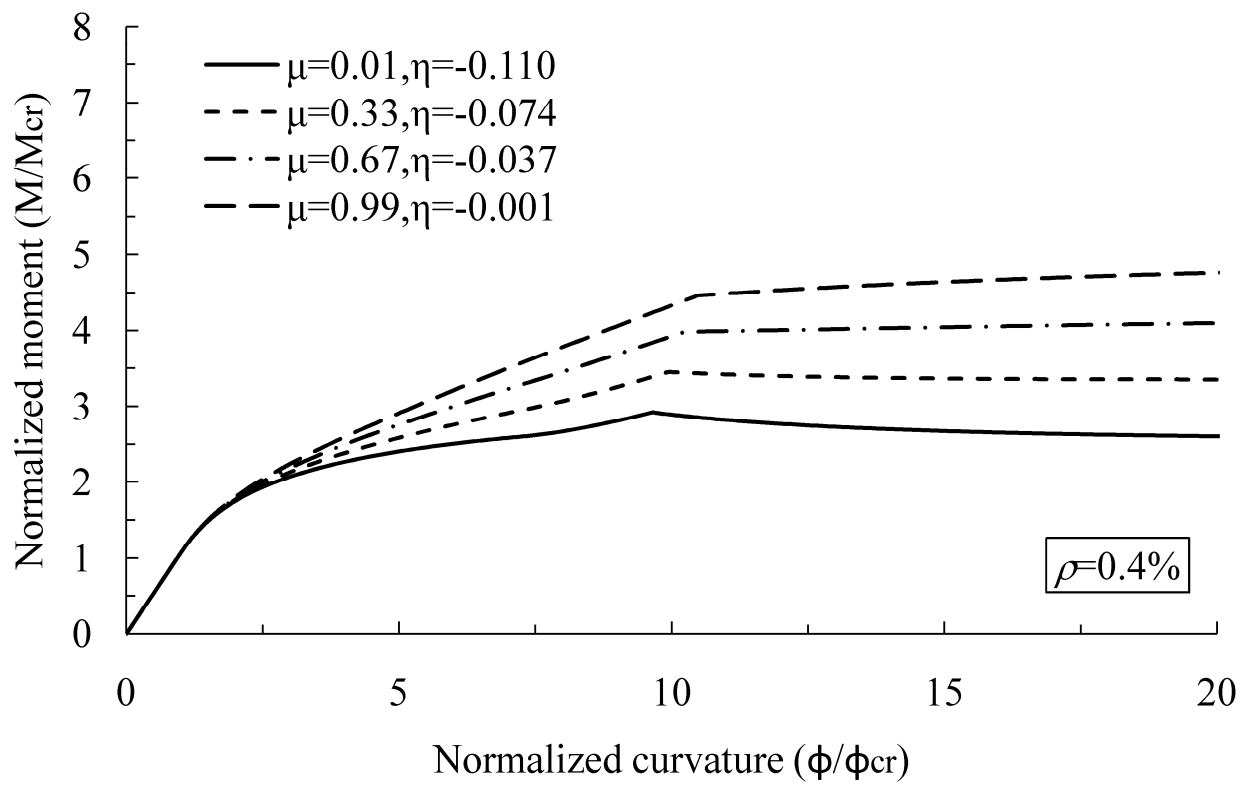

Figure 7c 


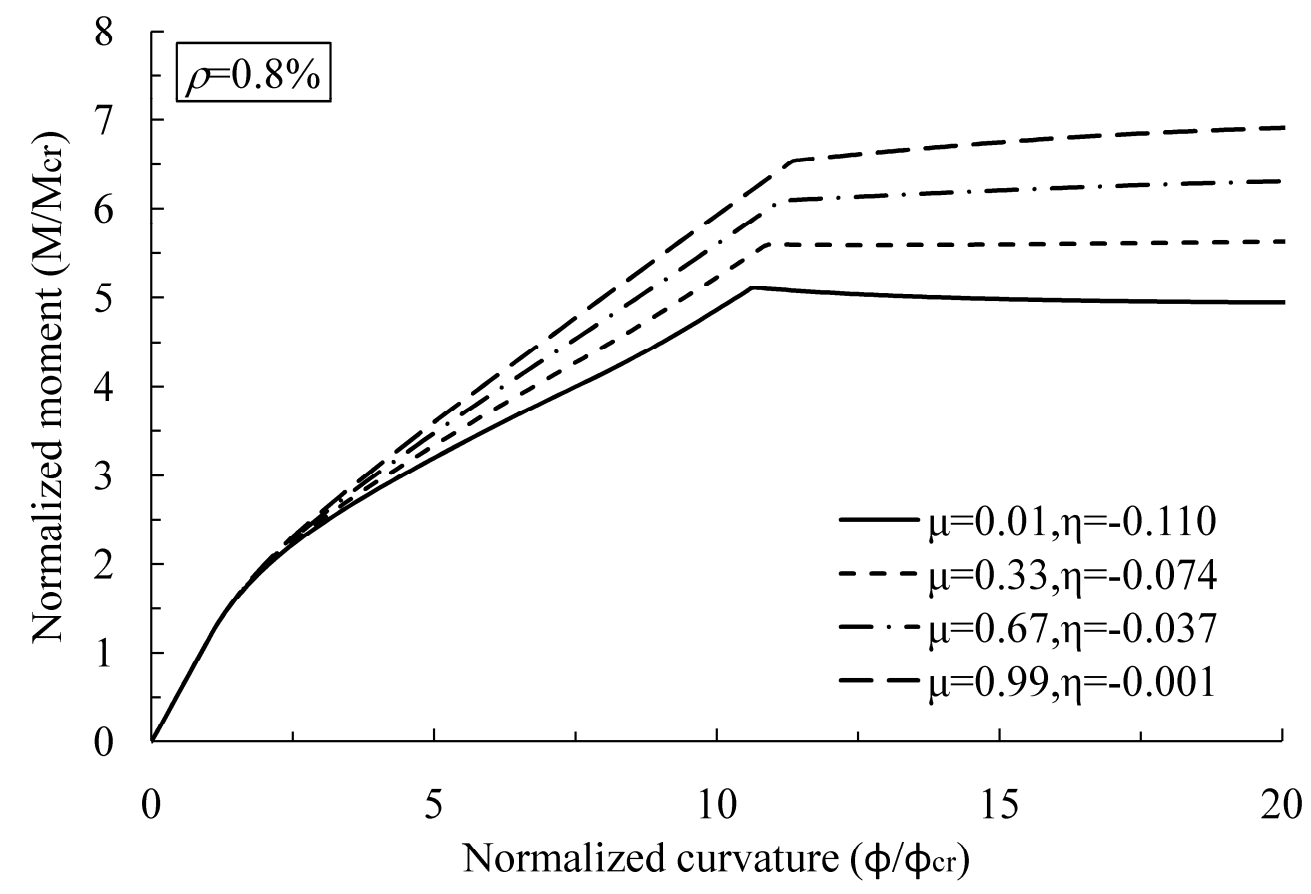

Figure 7d 


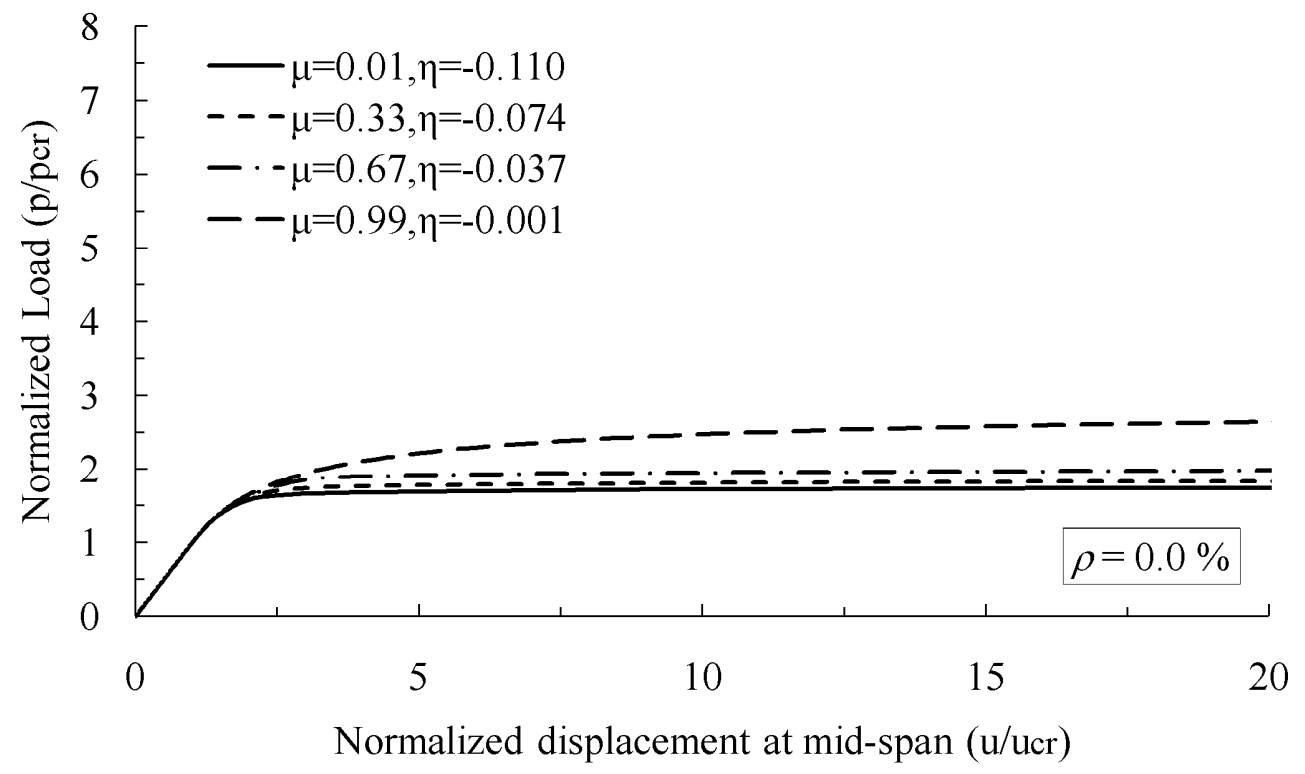

Figure 7e 


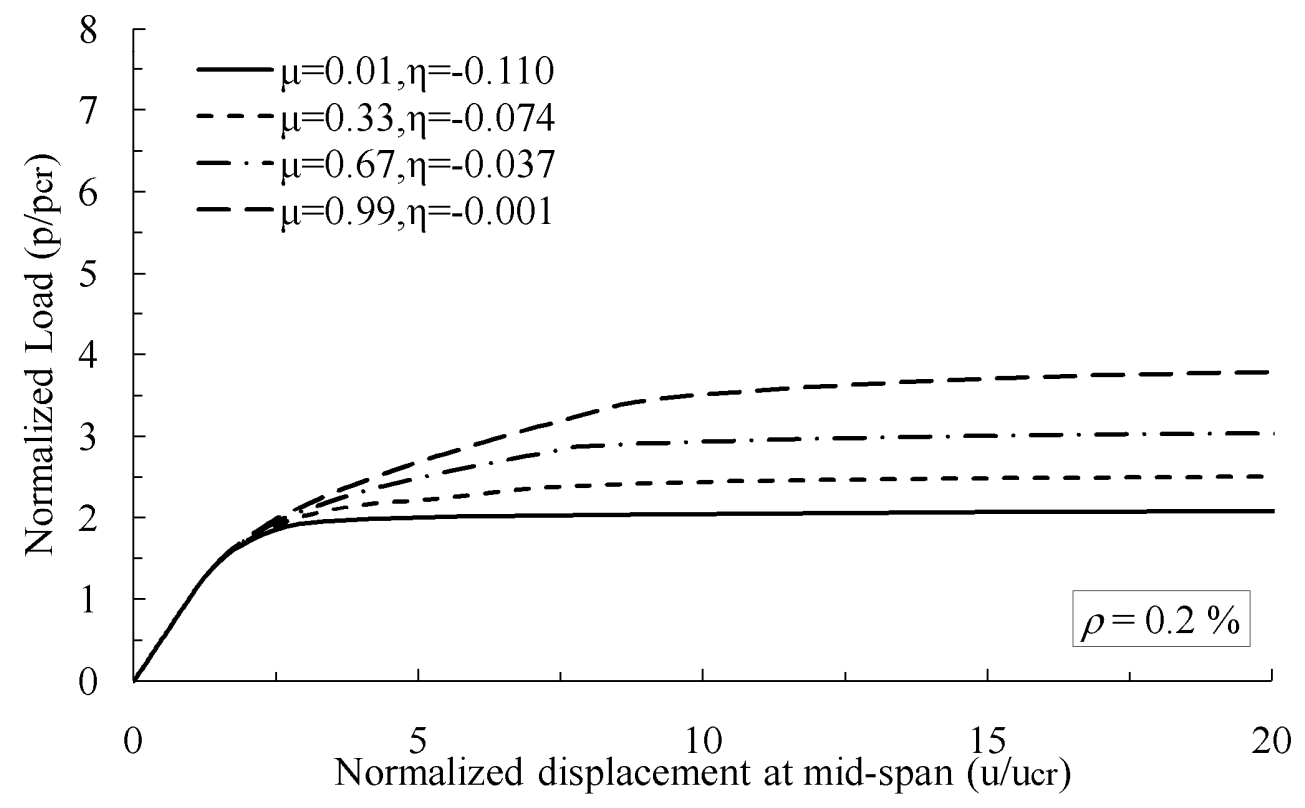

Figure $7 f$ 


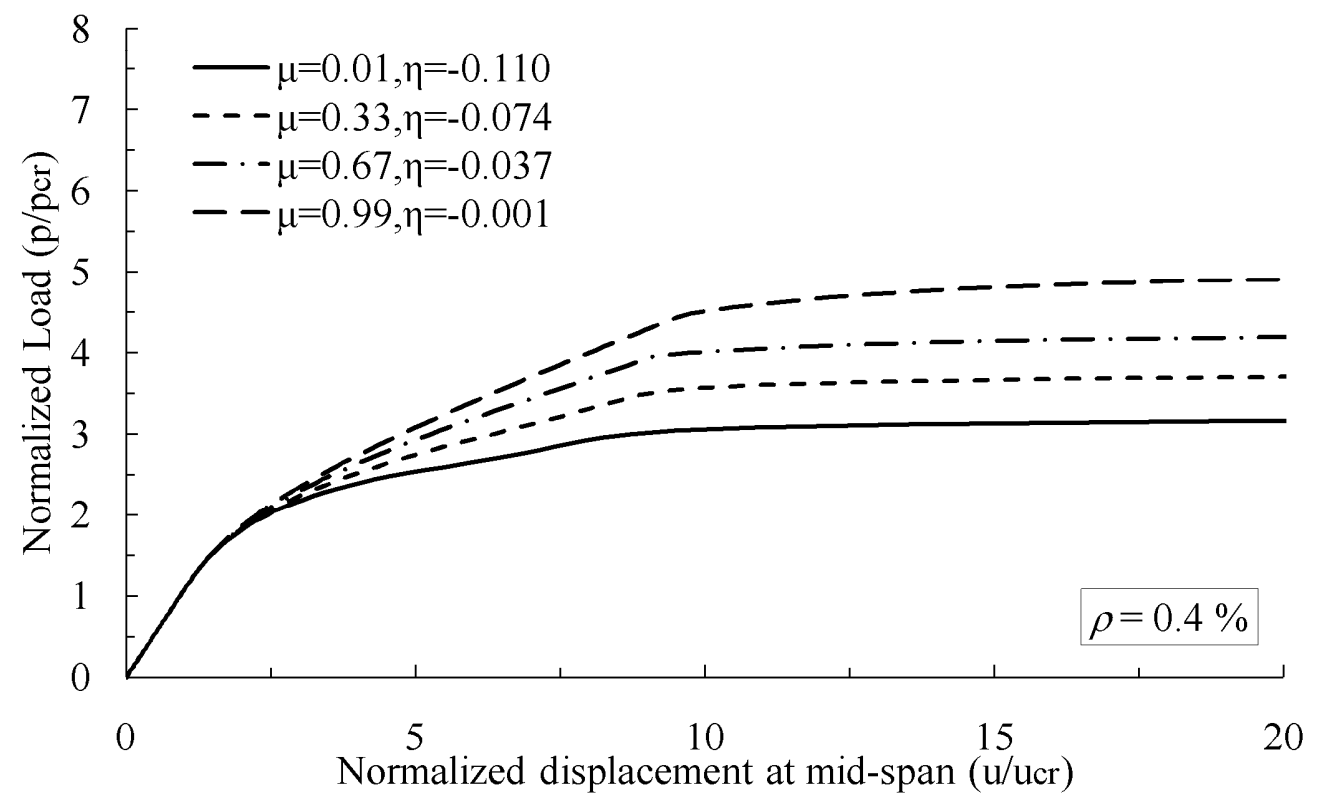

Figure $7 \mathrm{~g}$ 


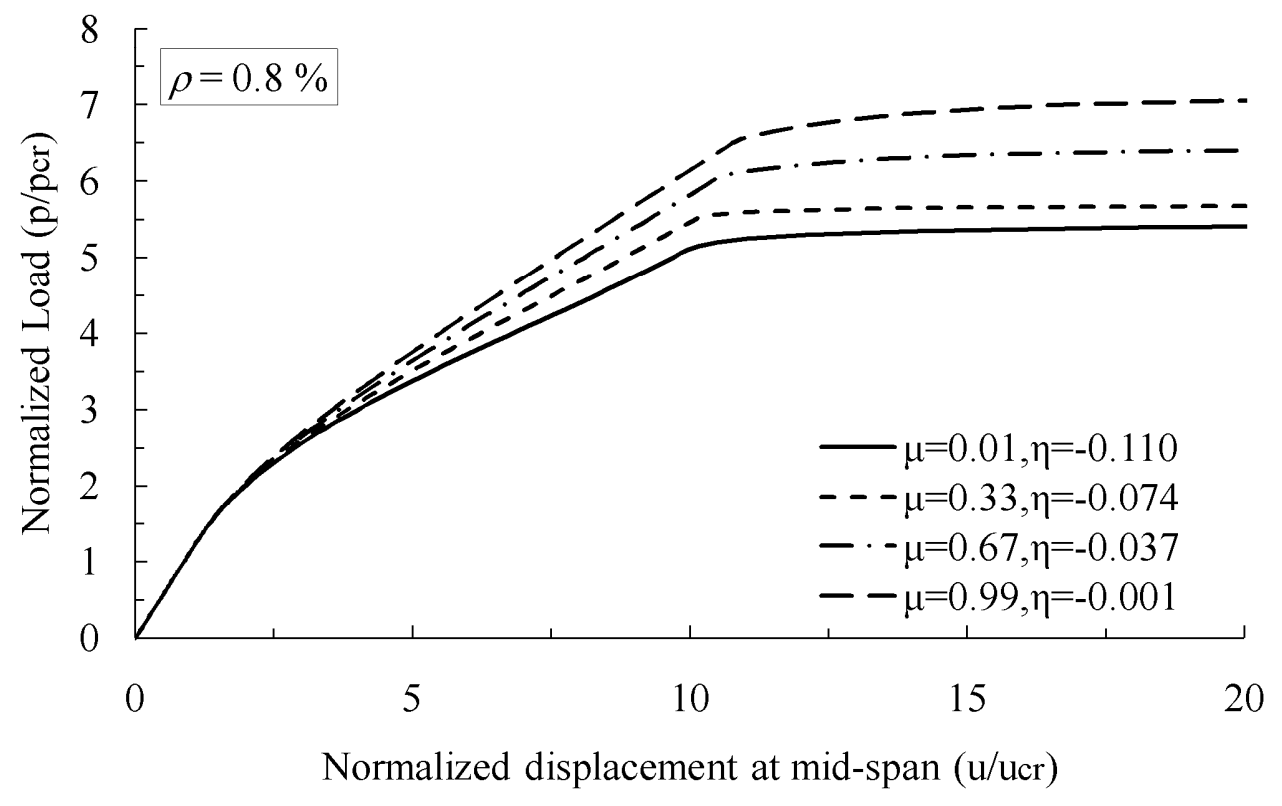

Figure $7 \mathrm{~h}$ 


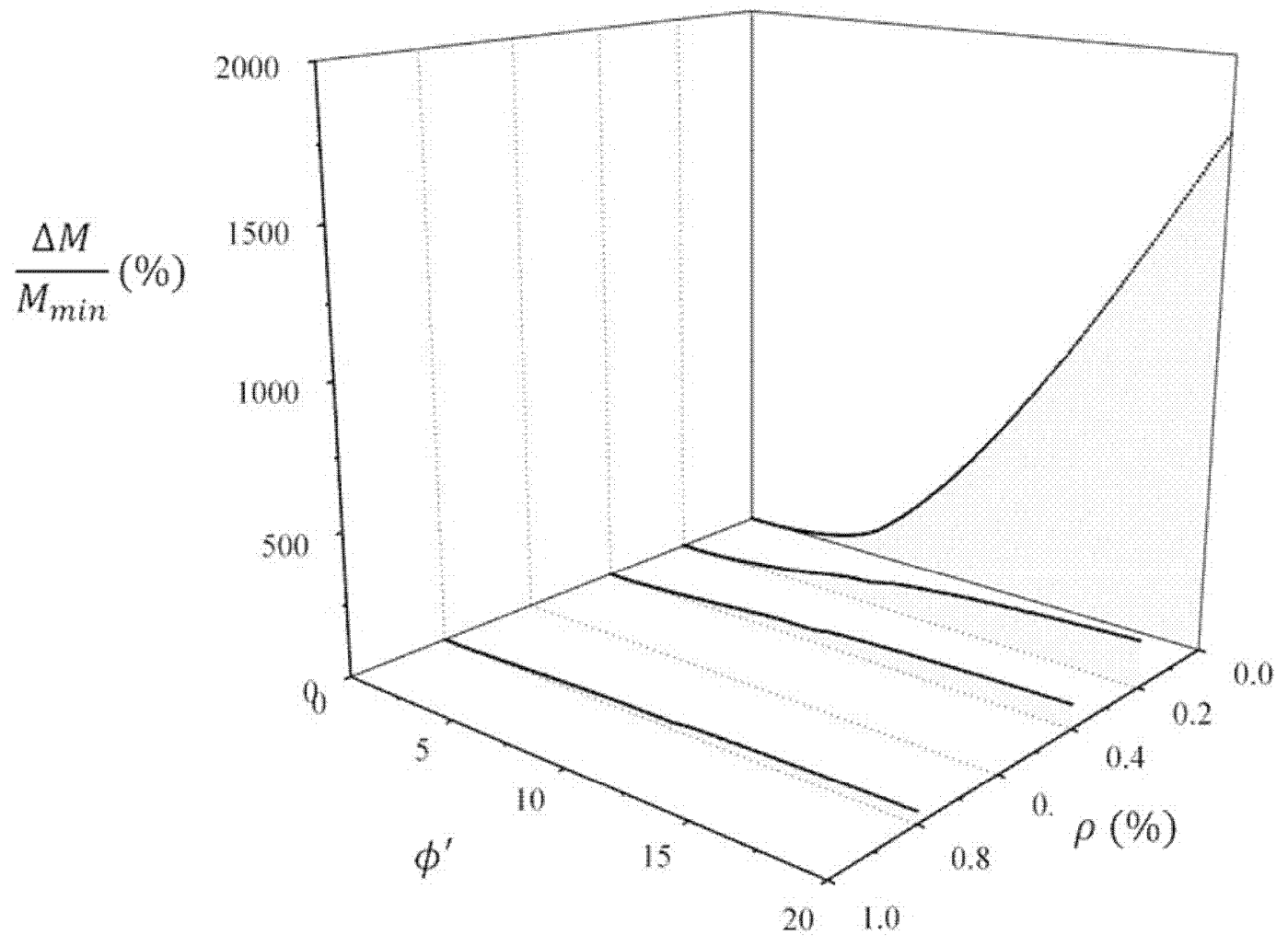

Figure $8 \mathrm{a}$ 


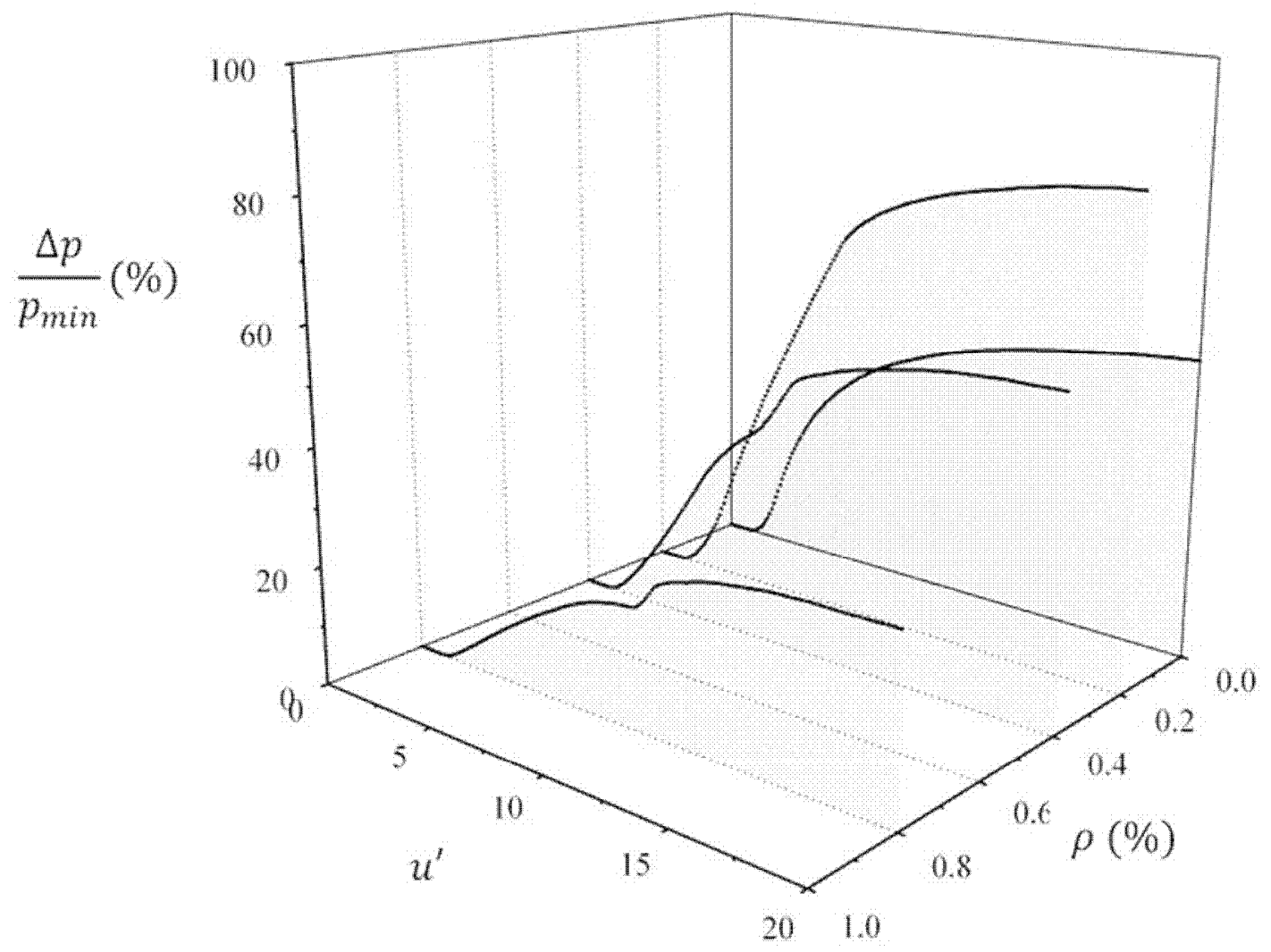

Figure $8 b$ 


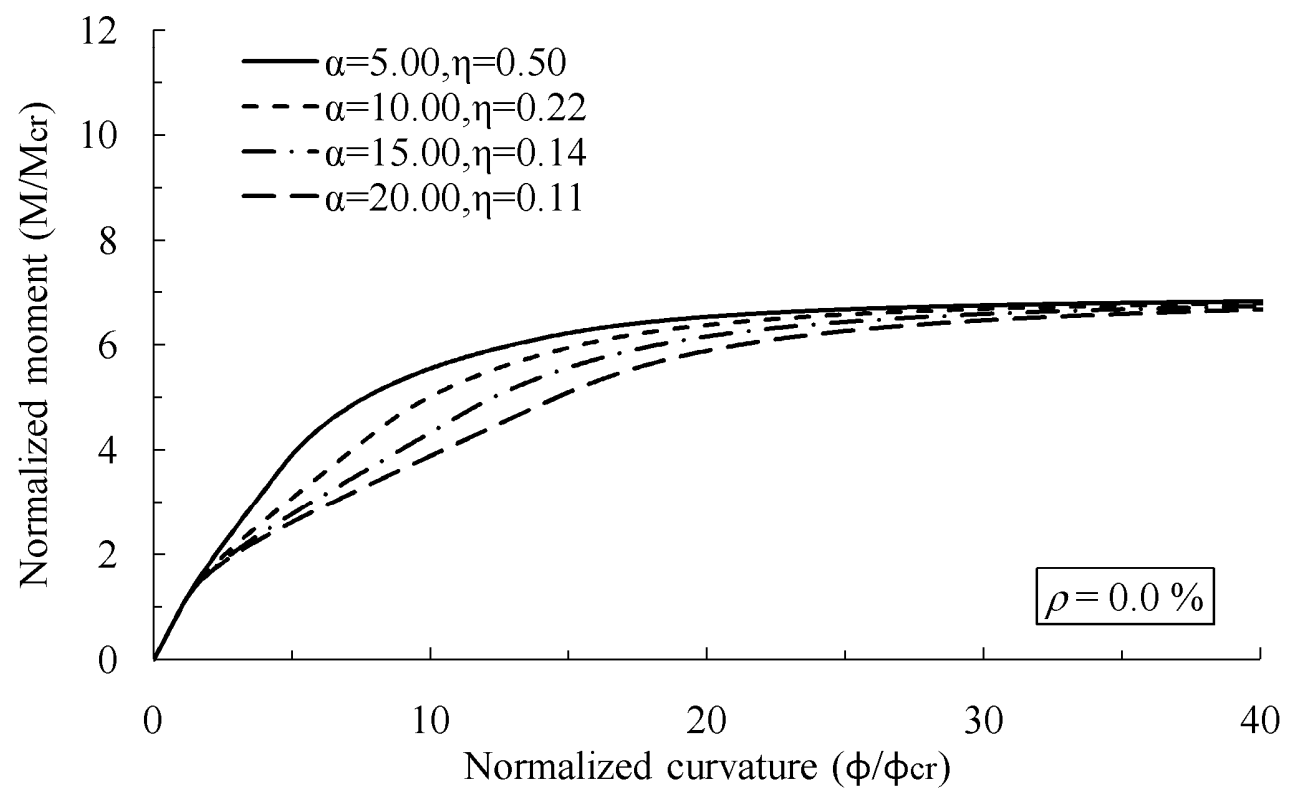

Figure 9a 


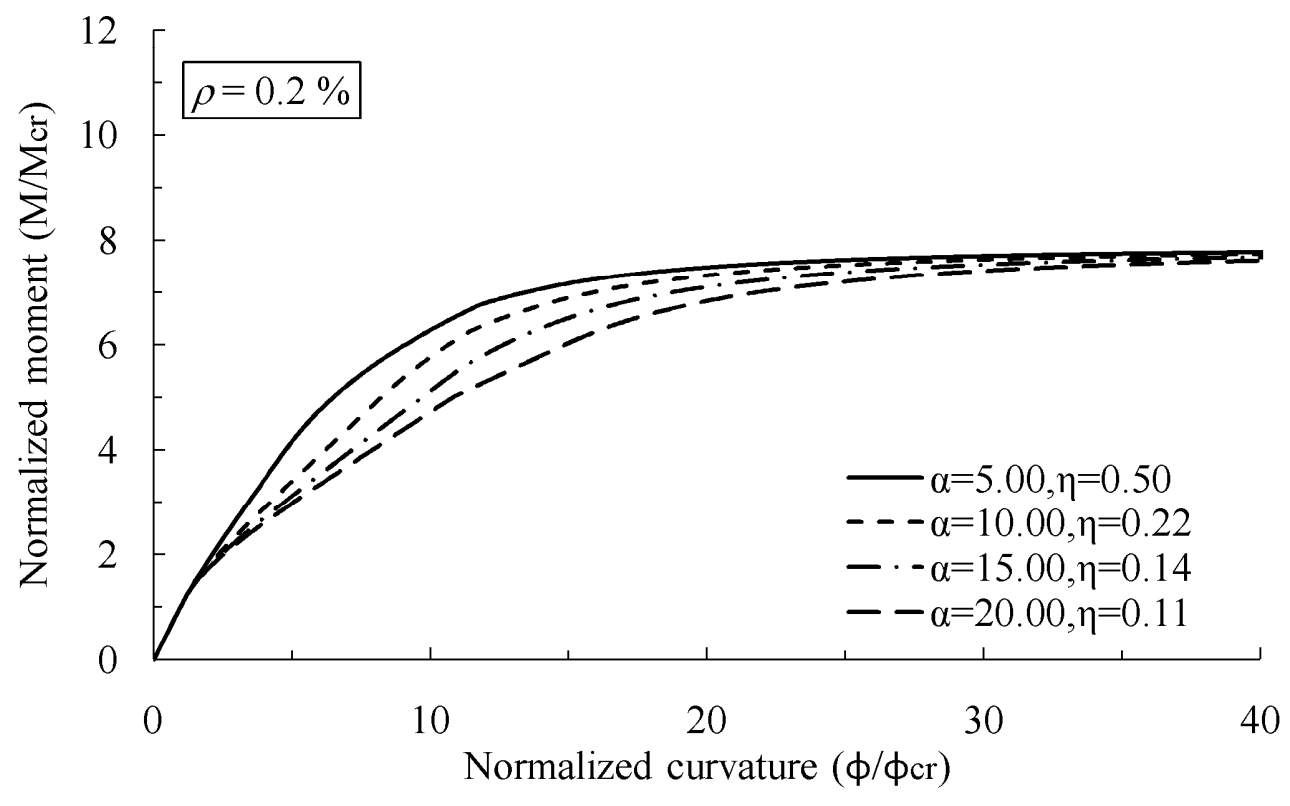

Figure 9b 


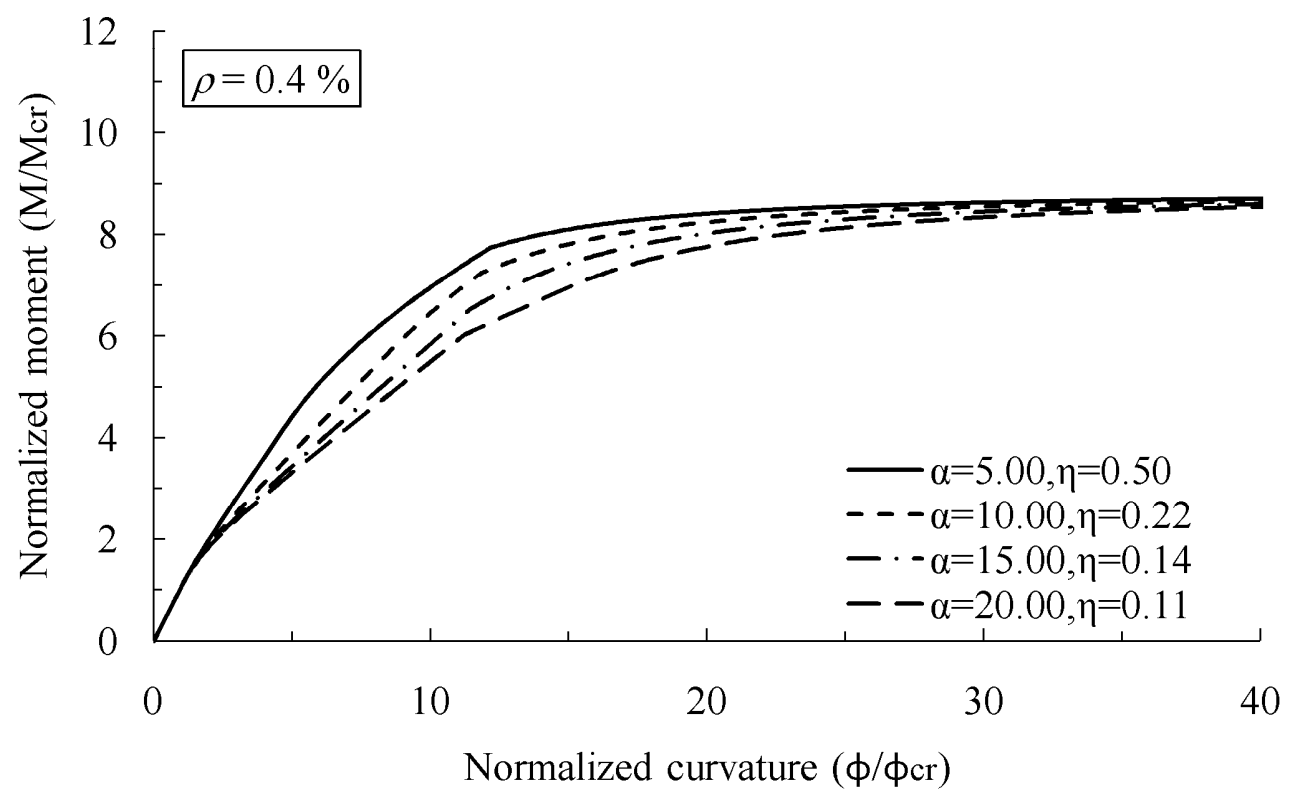

Figure 9c 


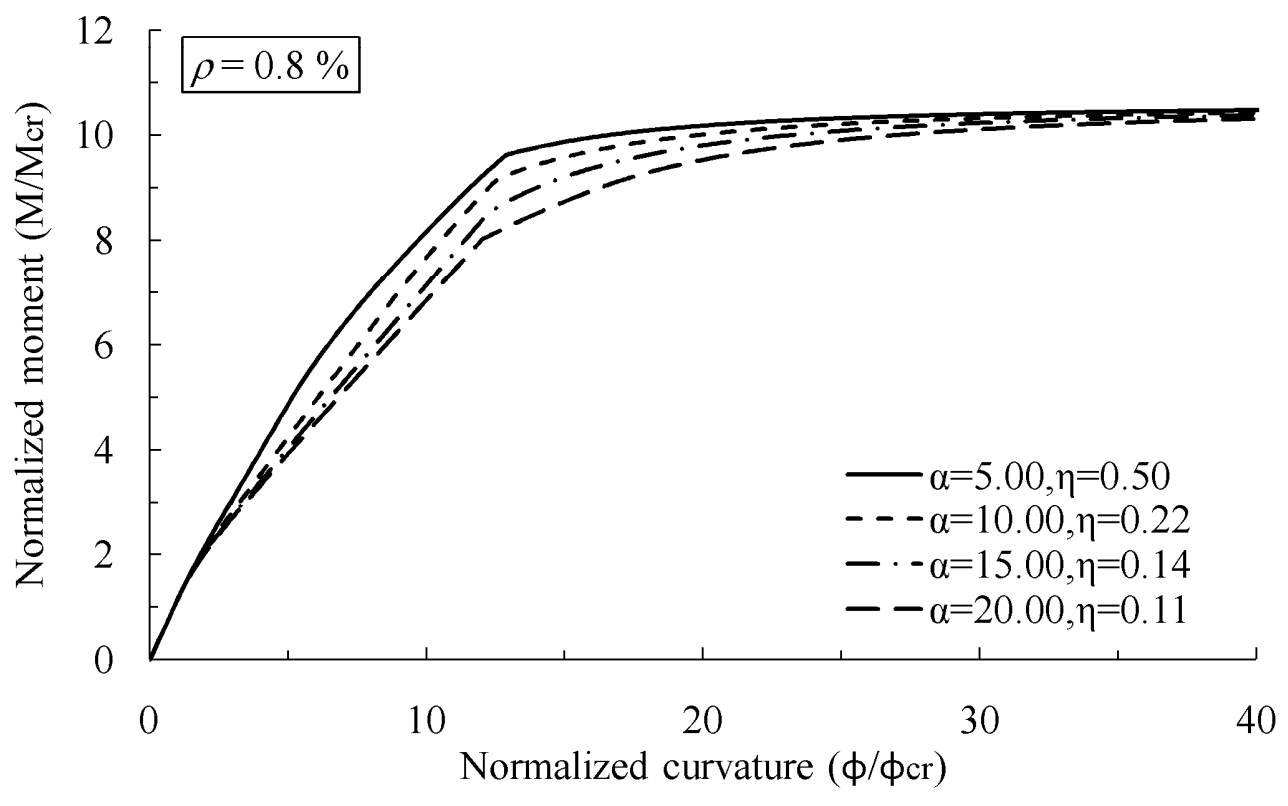

Figure 9d 


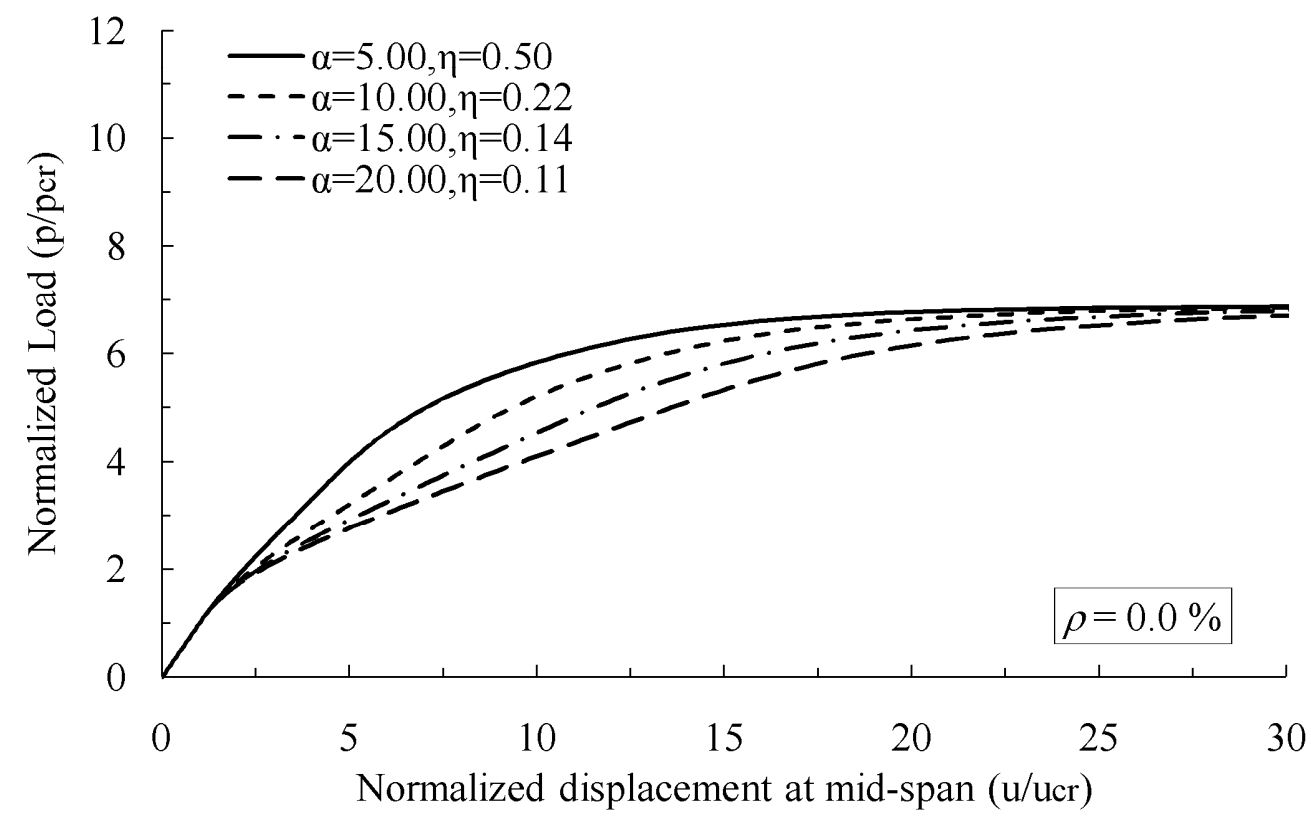

Figure 9e 


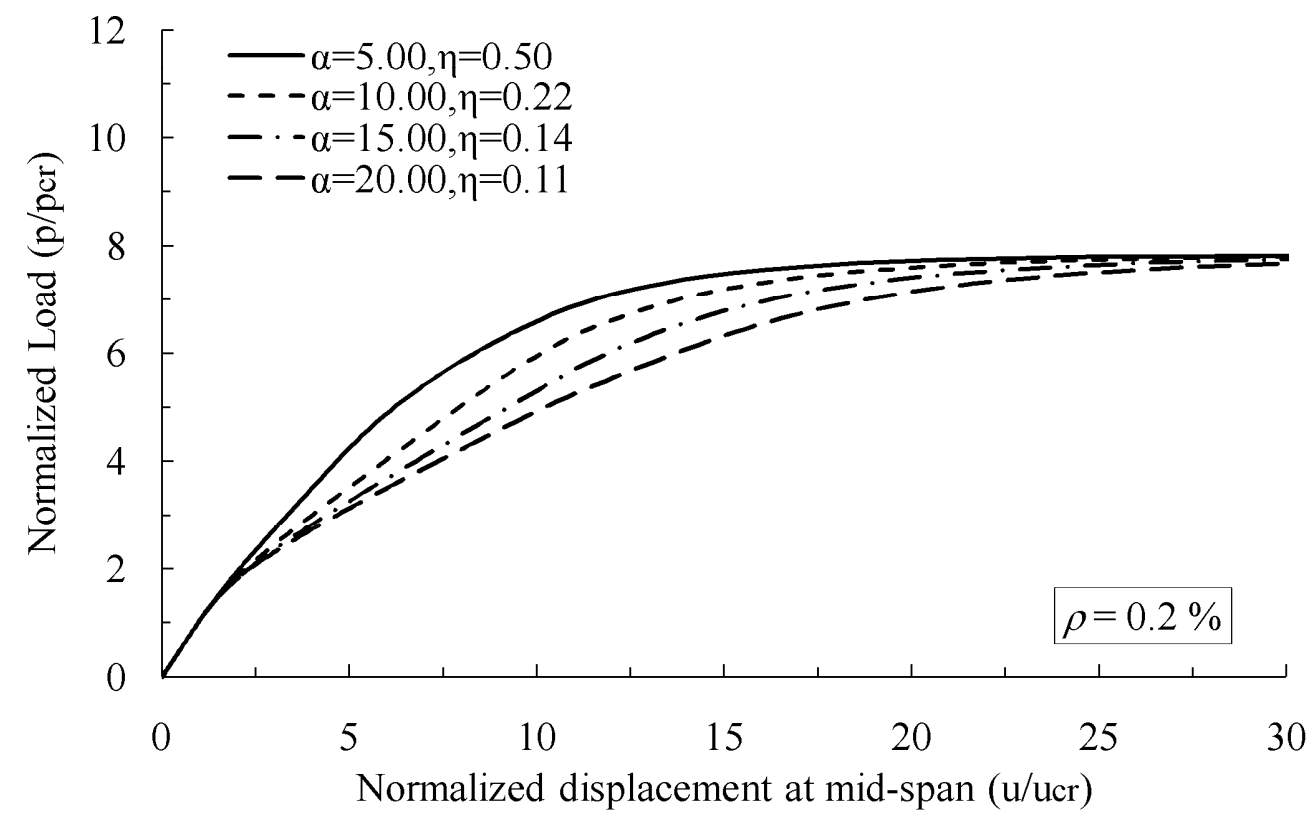

Figure 9f 


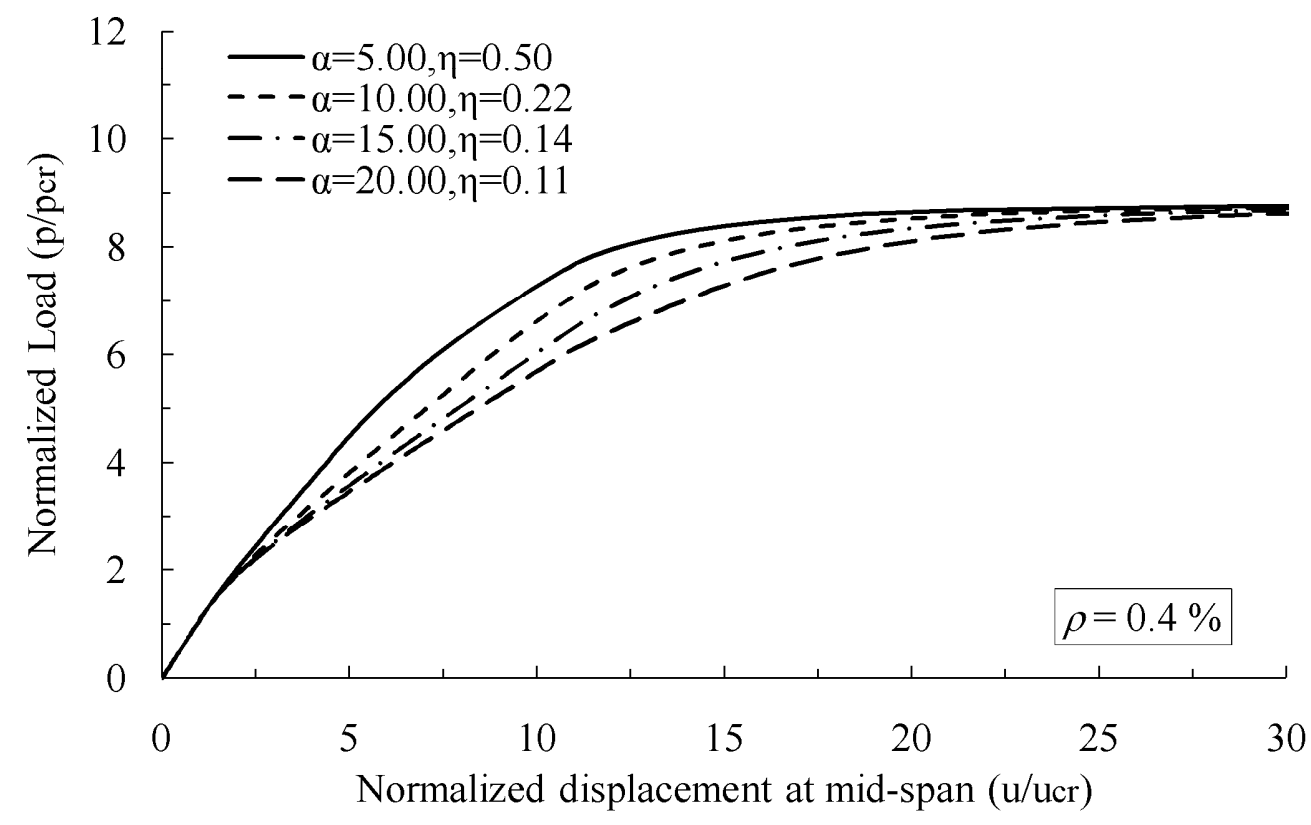

Figure 9g 


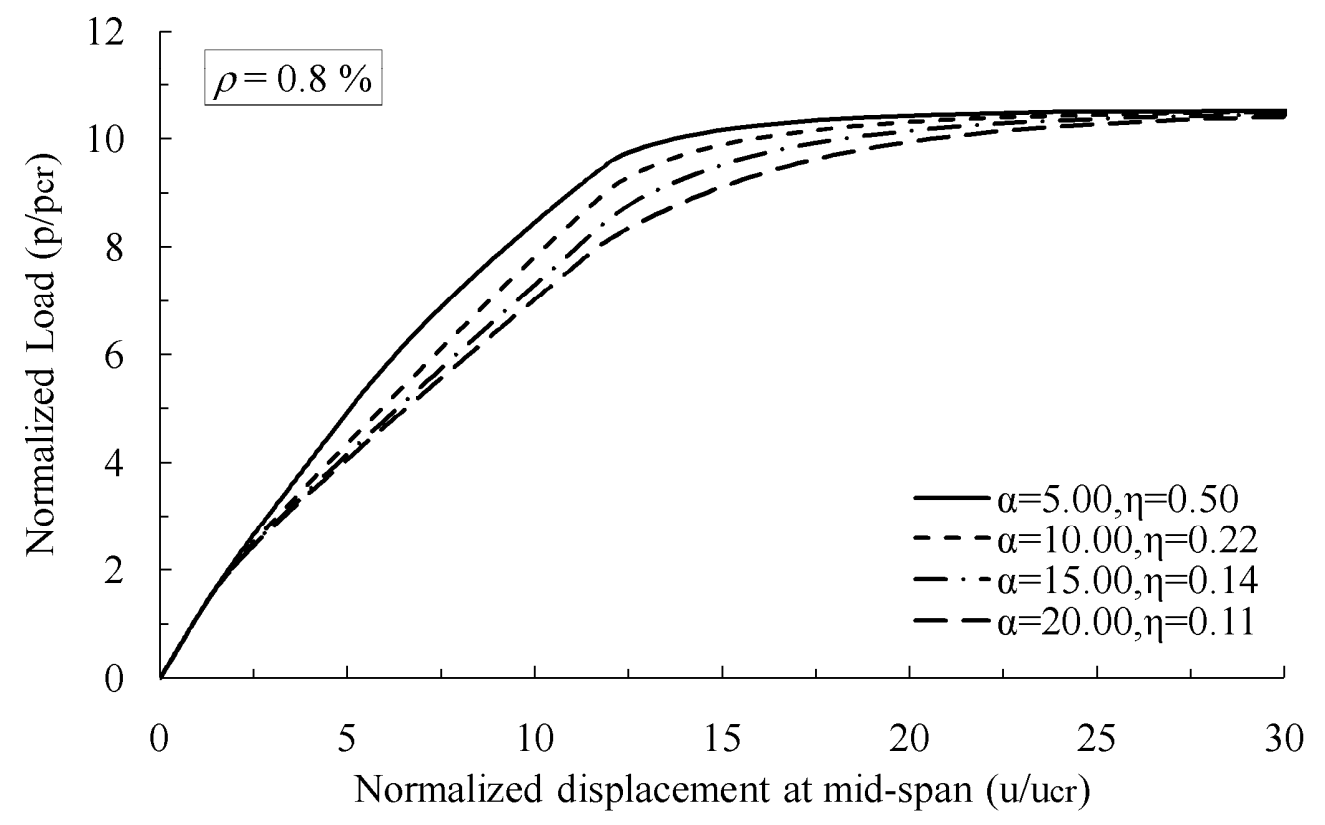

Figure 9h 


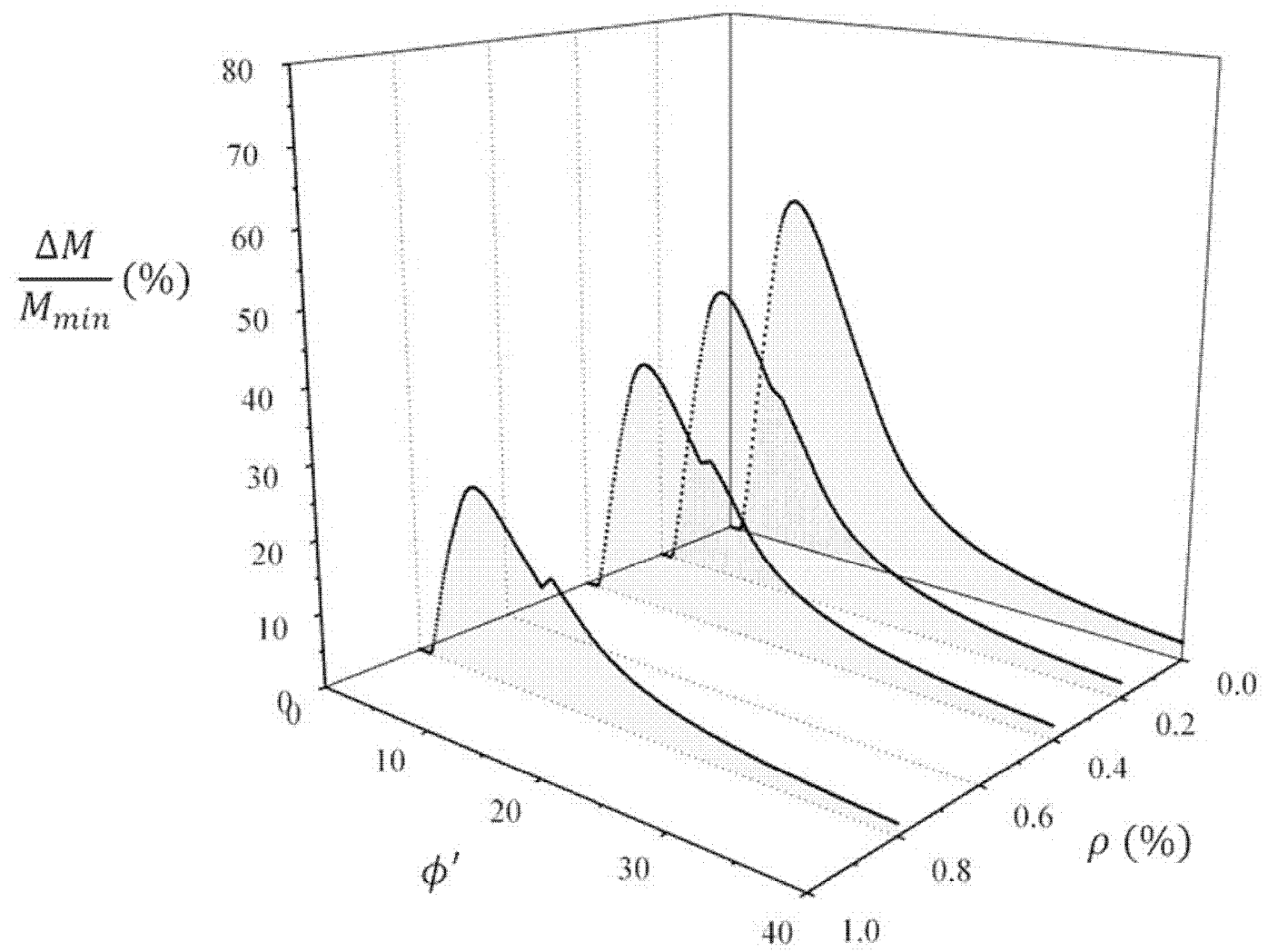

Figure 10a 


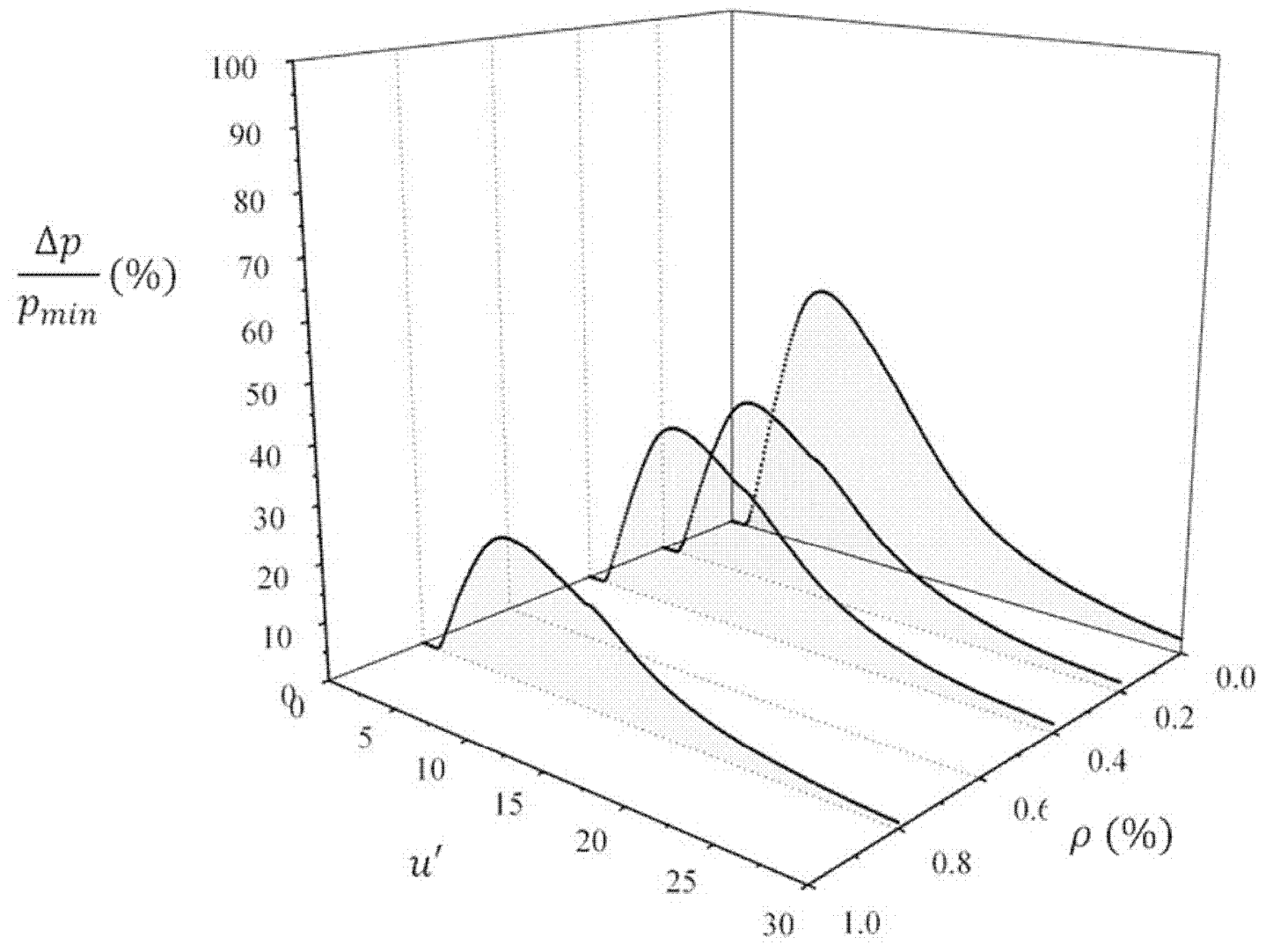

Figure 10b 


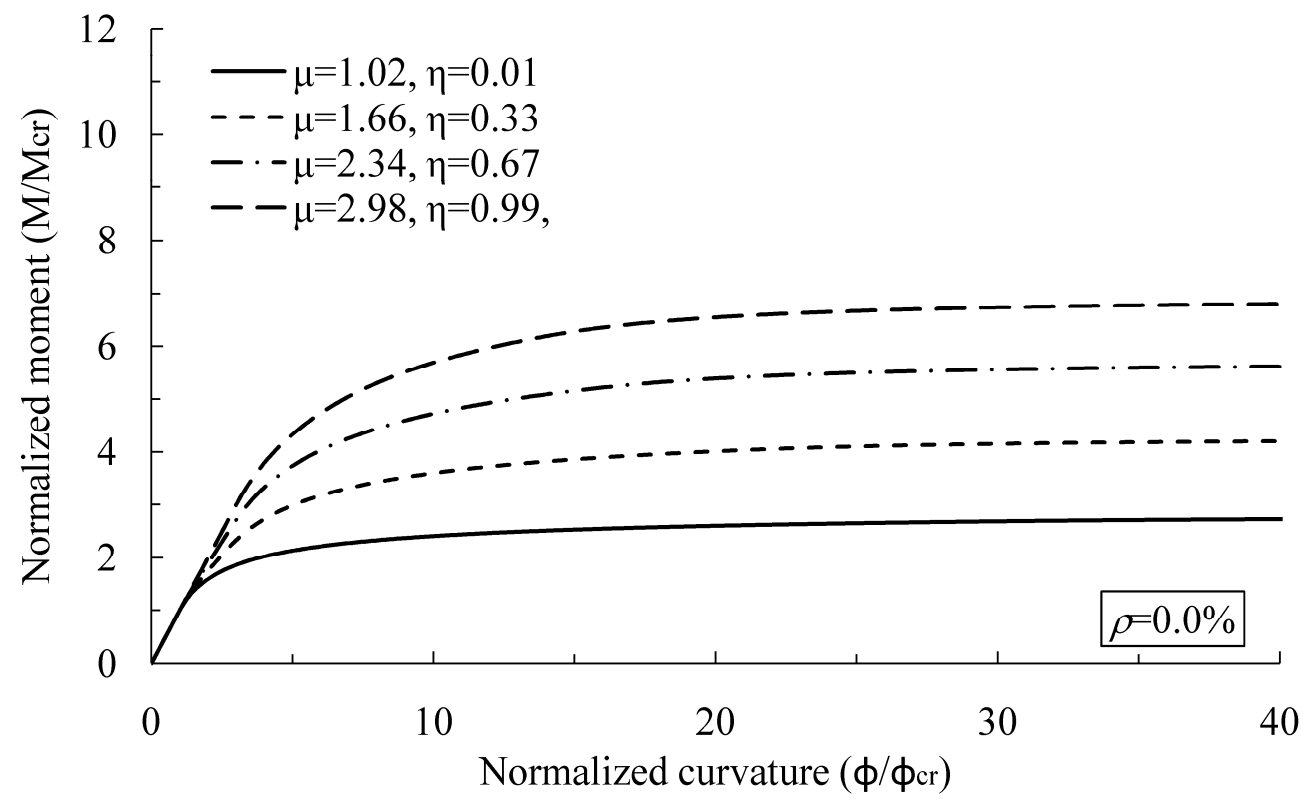

Figure 11a 


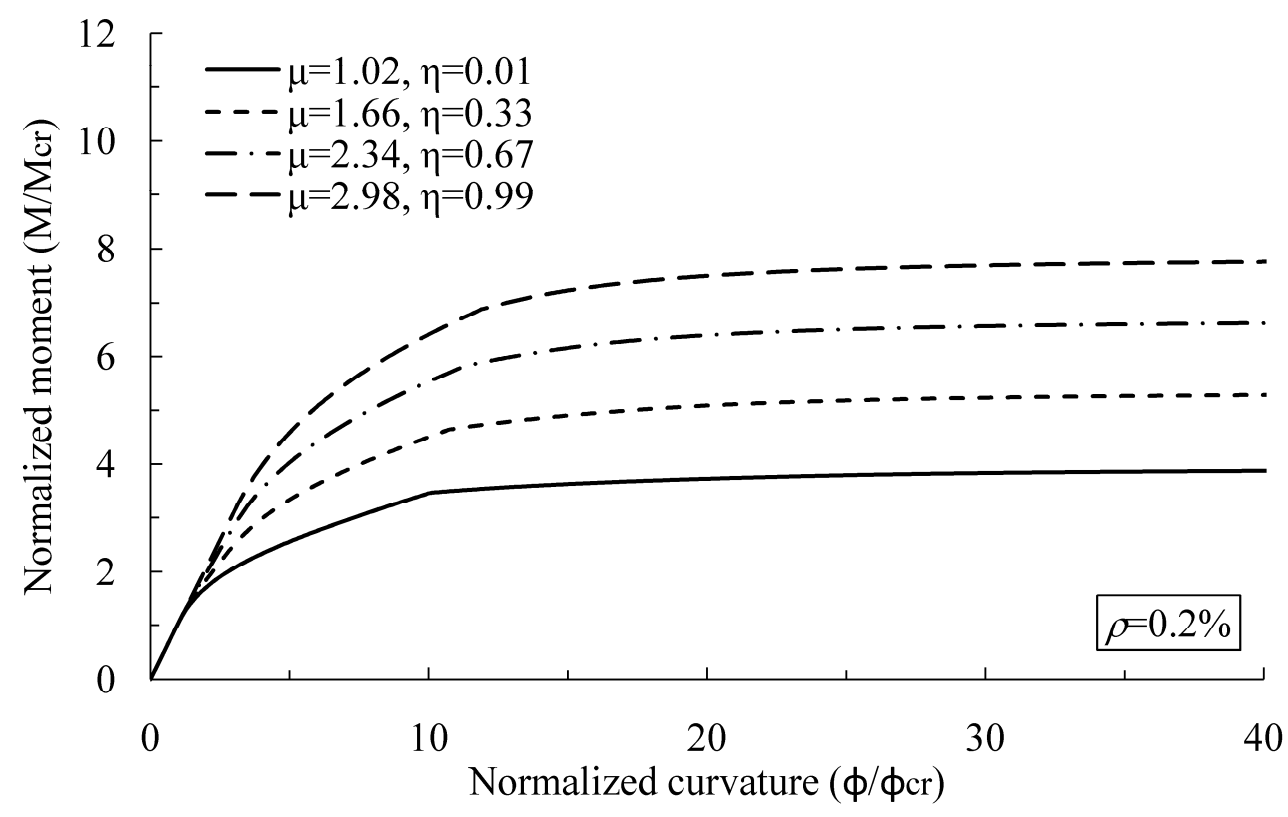

Figure 11b 


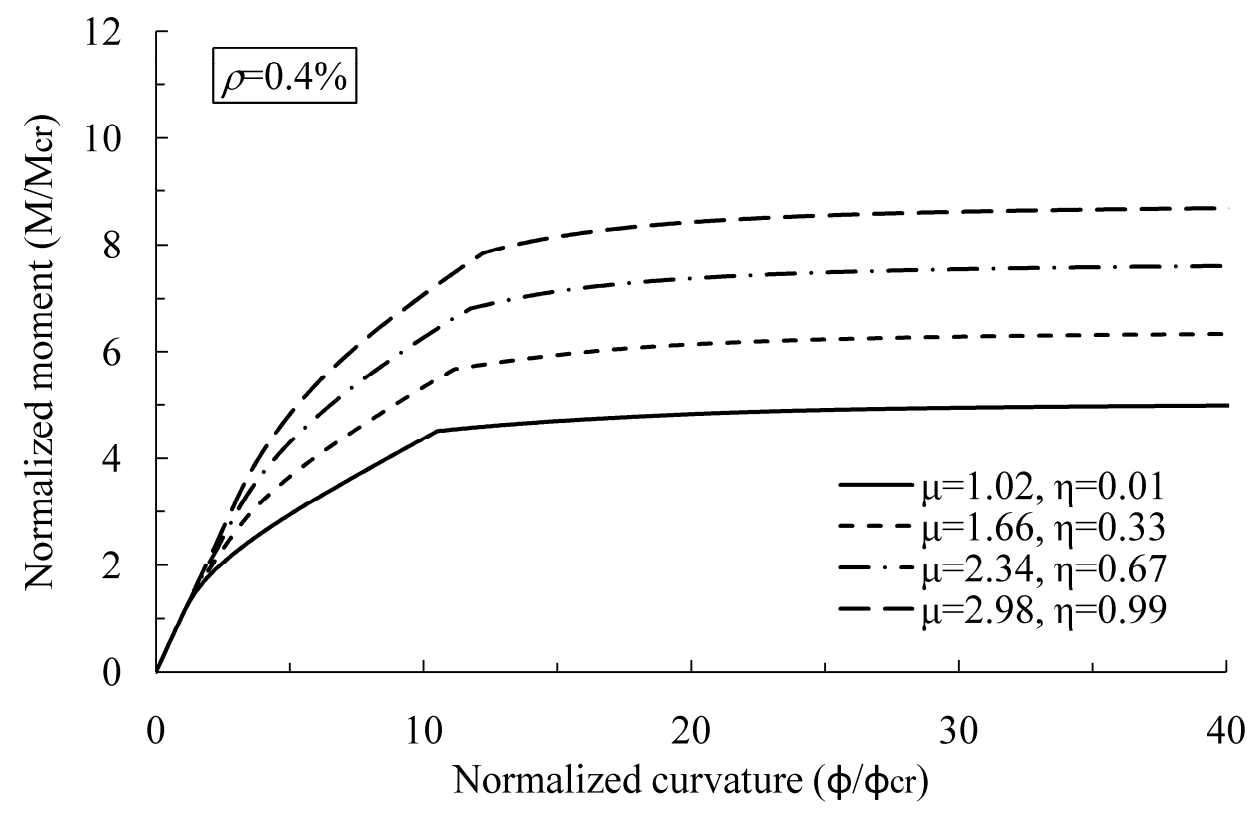

Figure 11c 


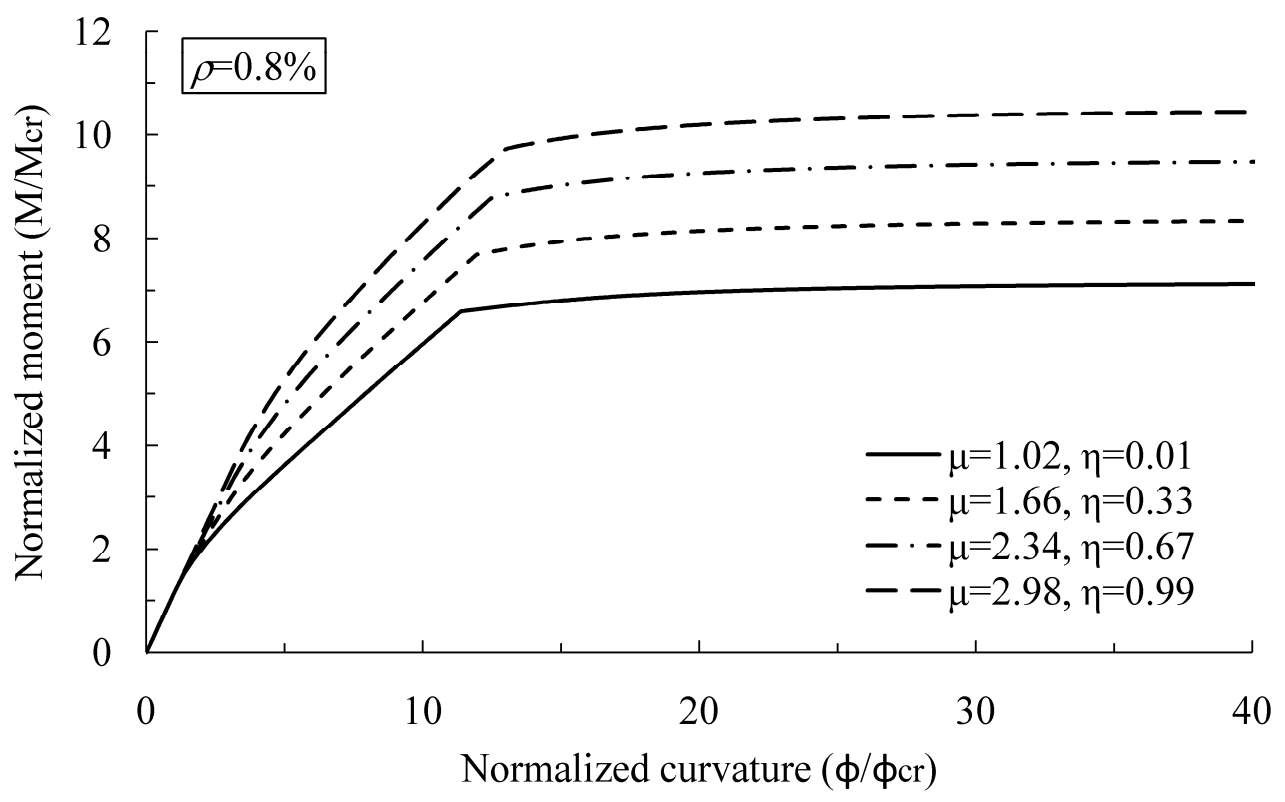

Figure 11d 


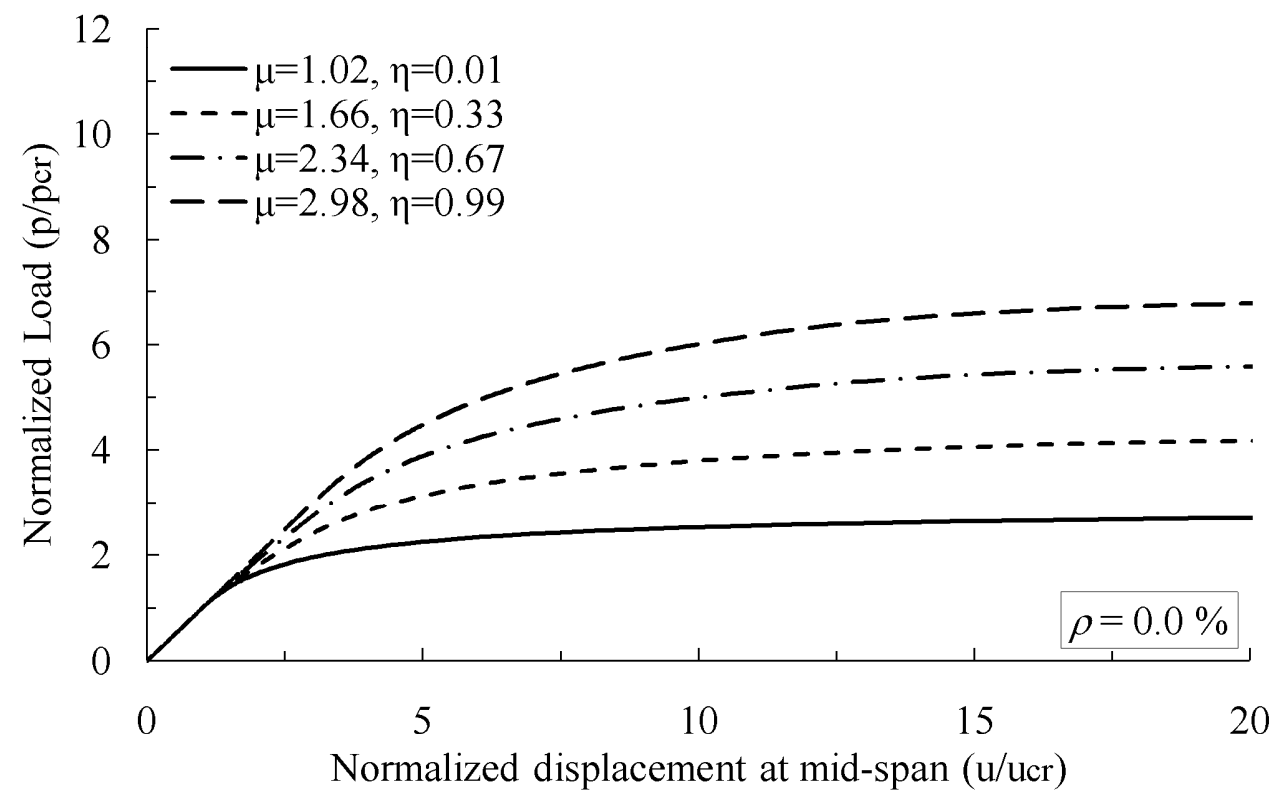

Figure 11e 


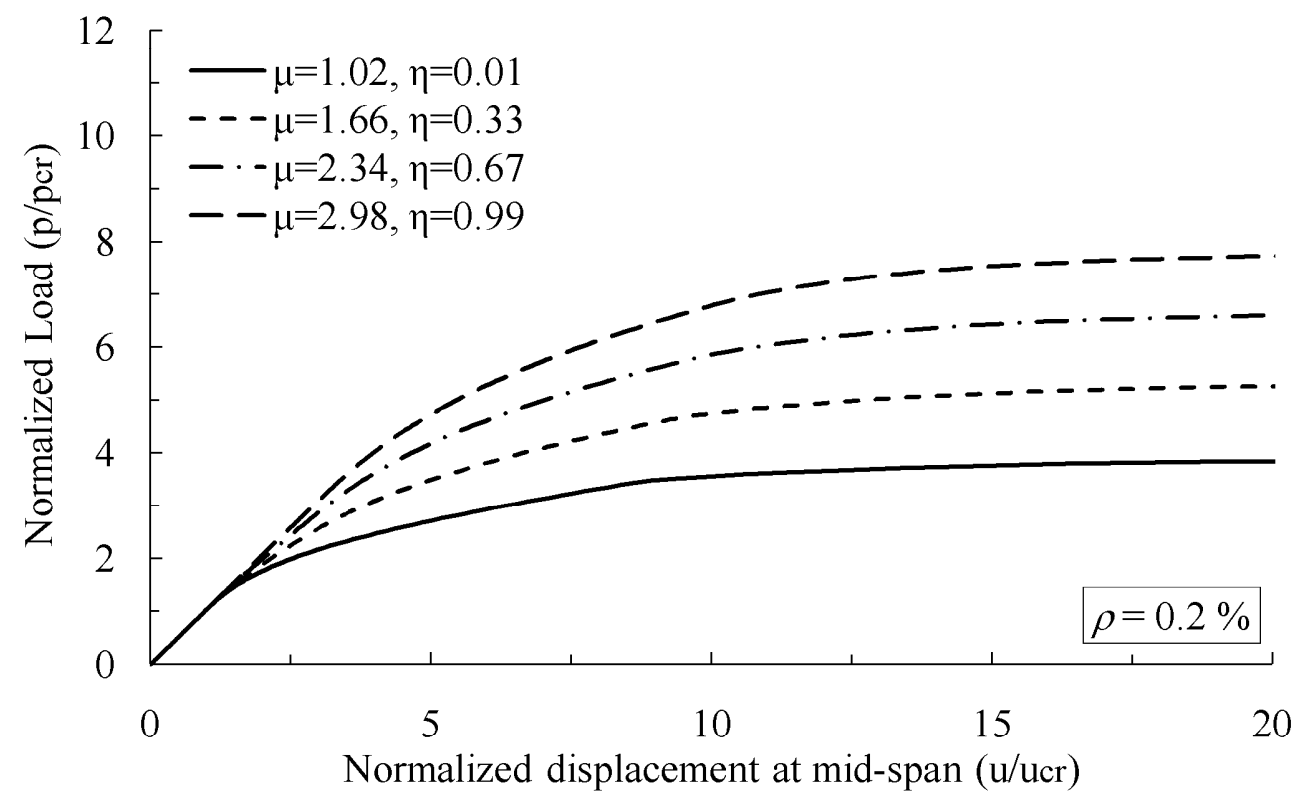

Figure 11f 


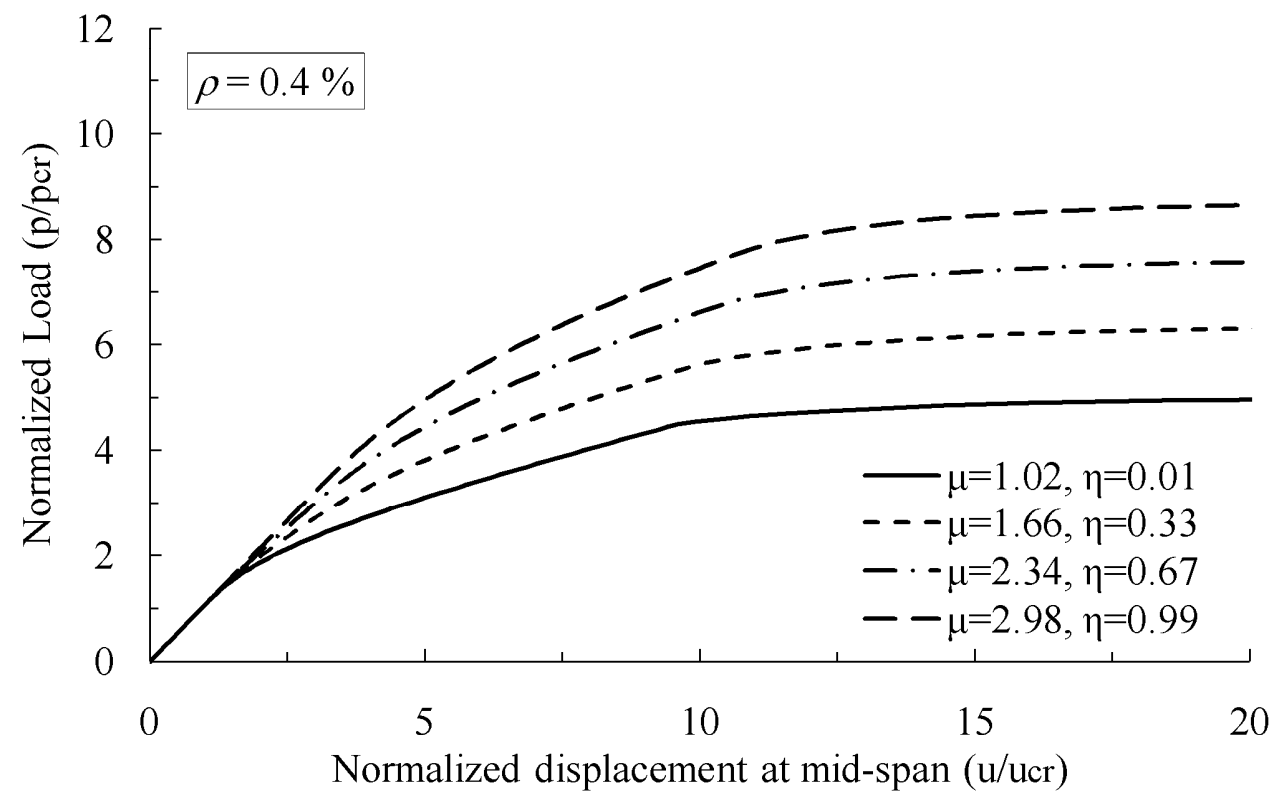

Figure 11g 


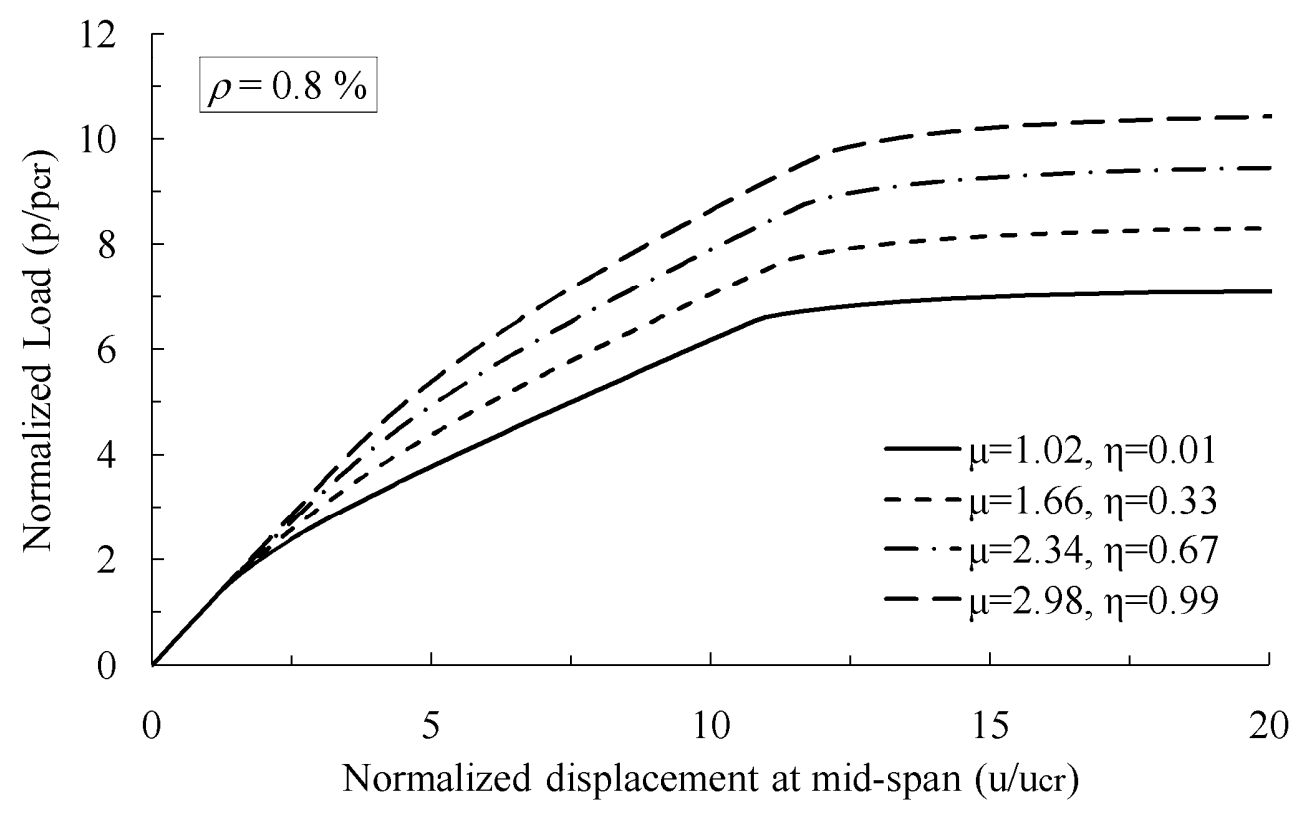

Figure 11h 


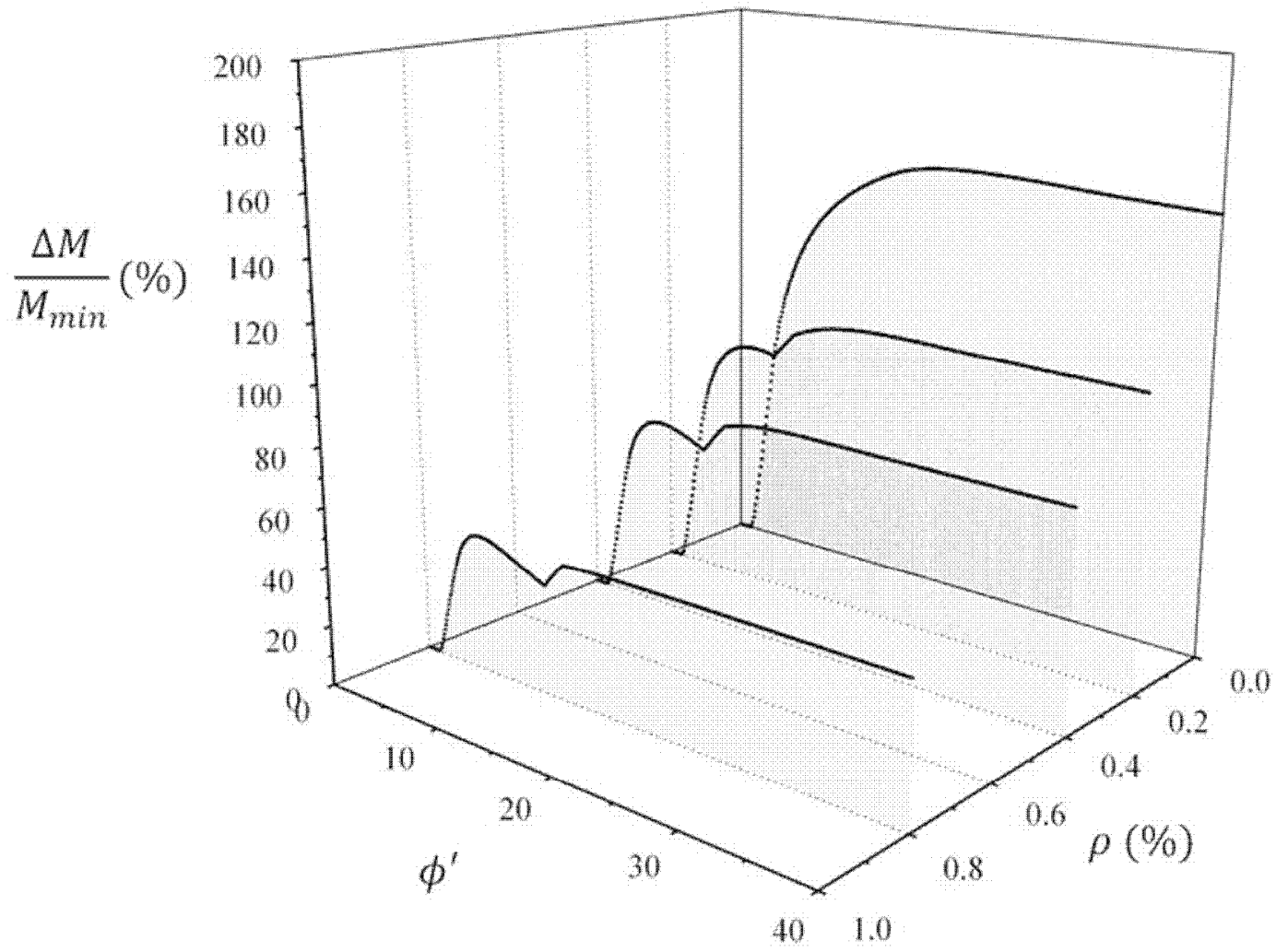

Figure 12a 


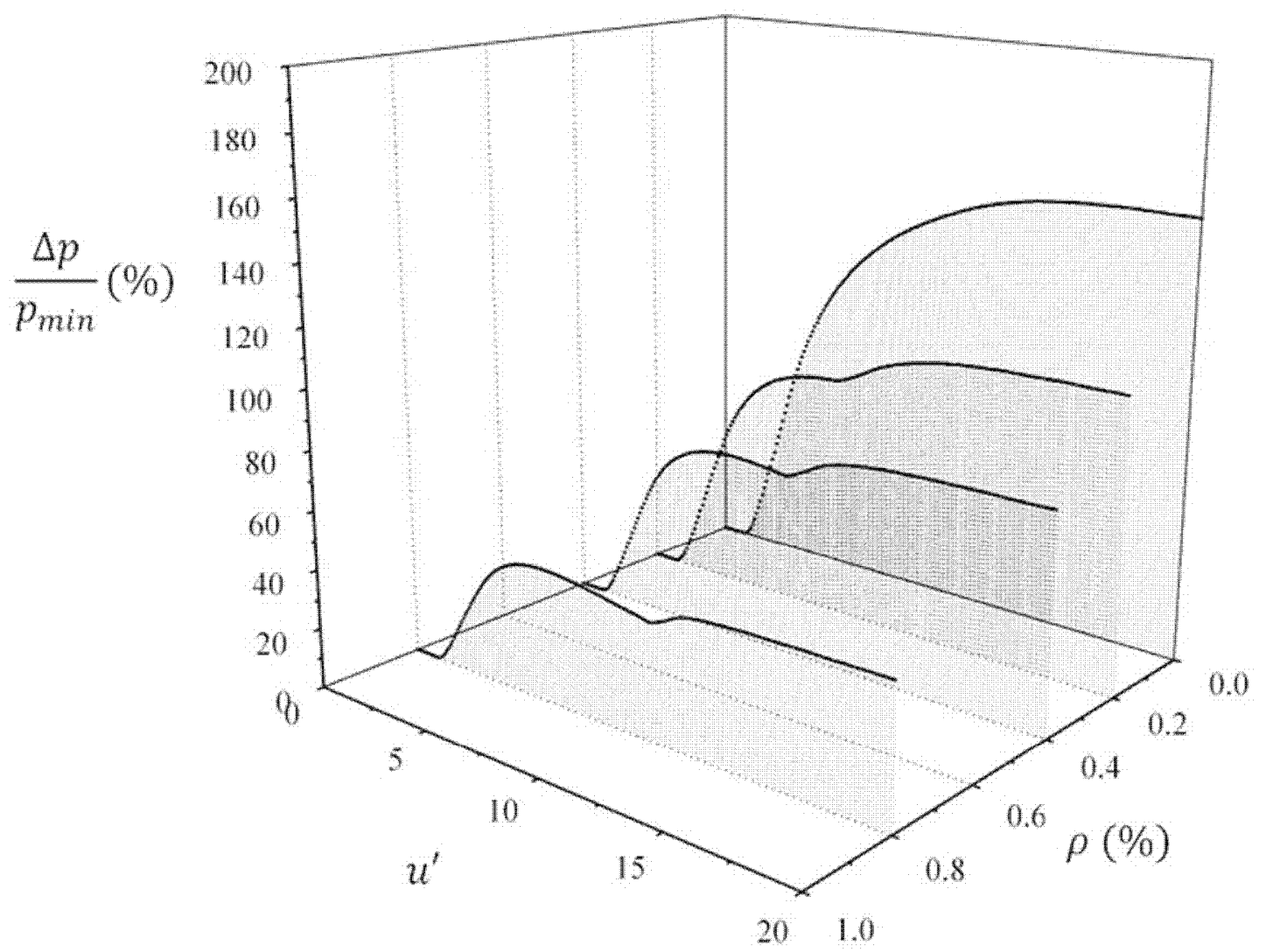

Figure 12b 

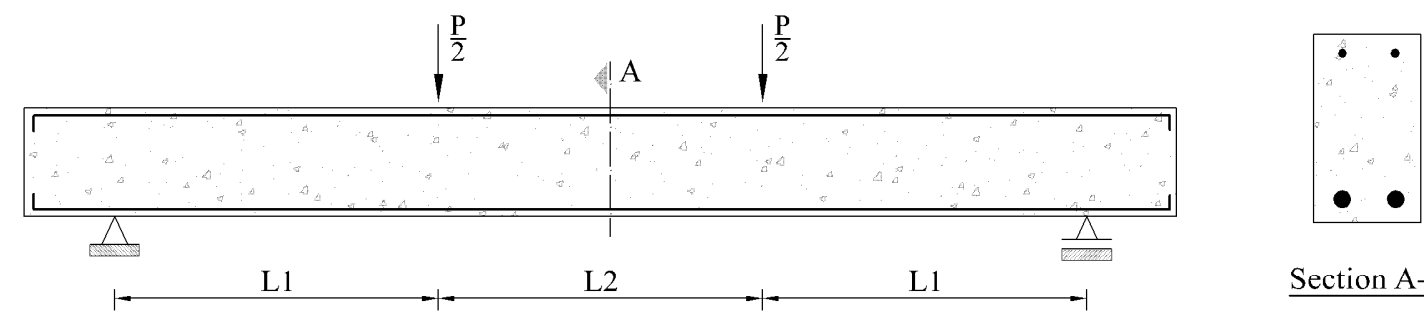

$\underline{\text { Section A-A }}$

Figure 13 


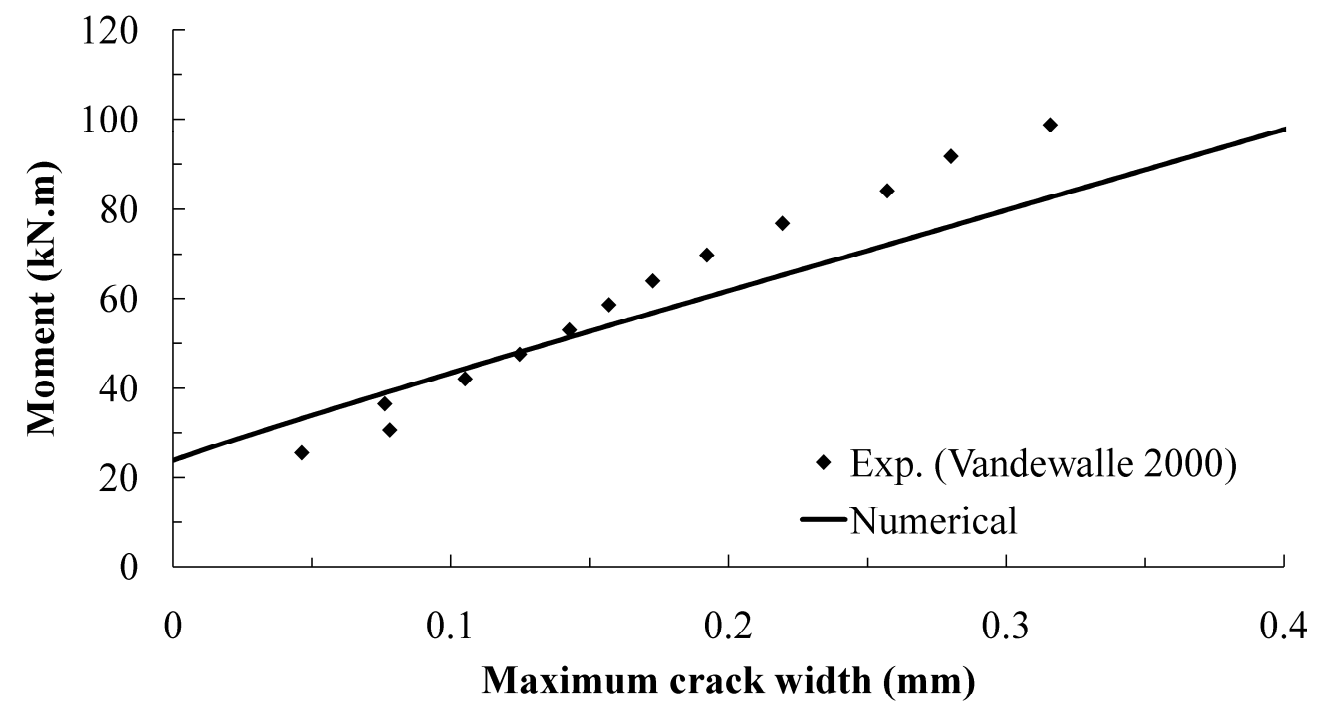

Figure 14a 


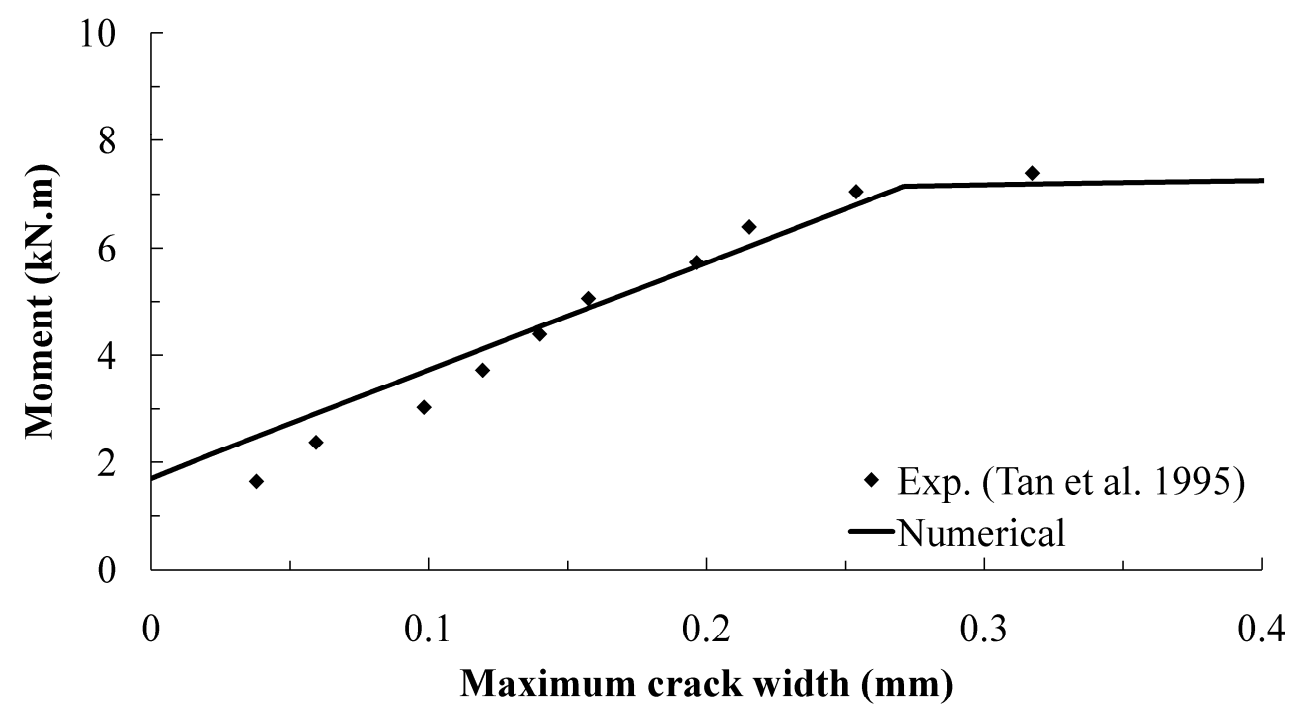

Figure 14b 


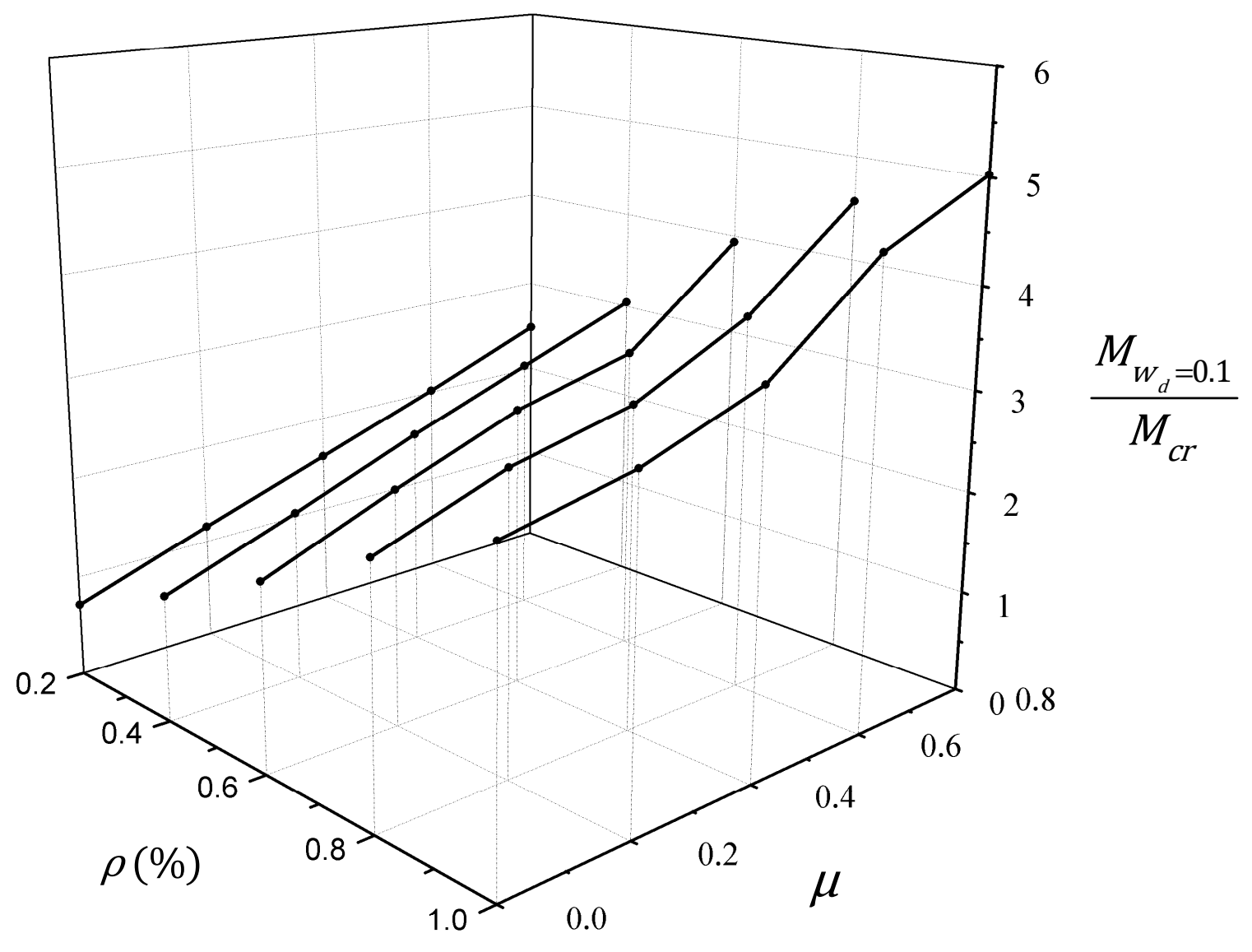

Figure 15a 


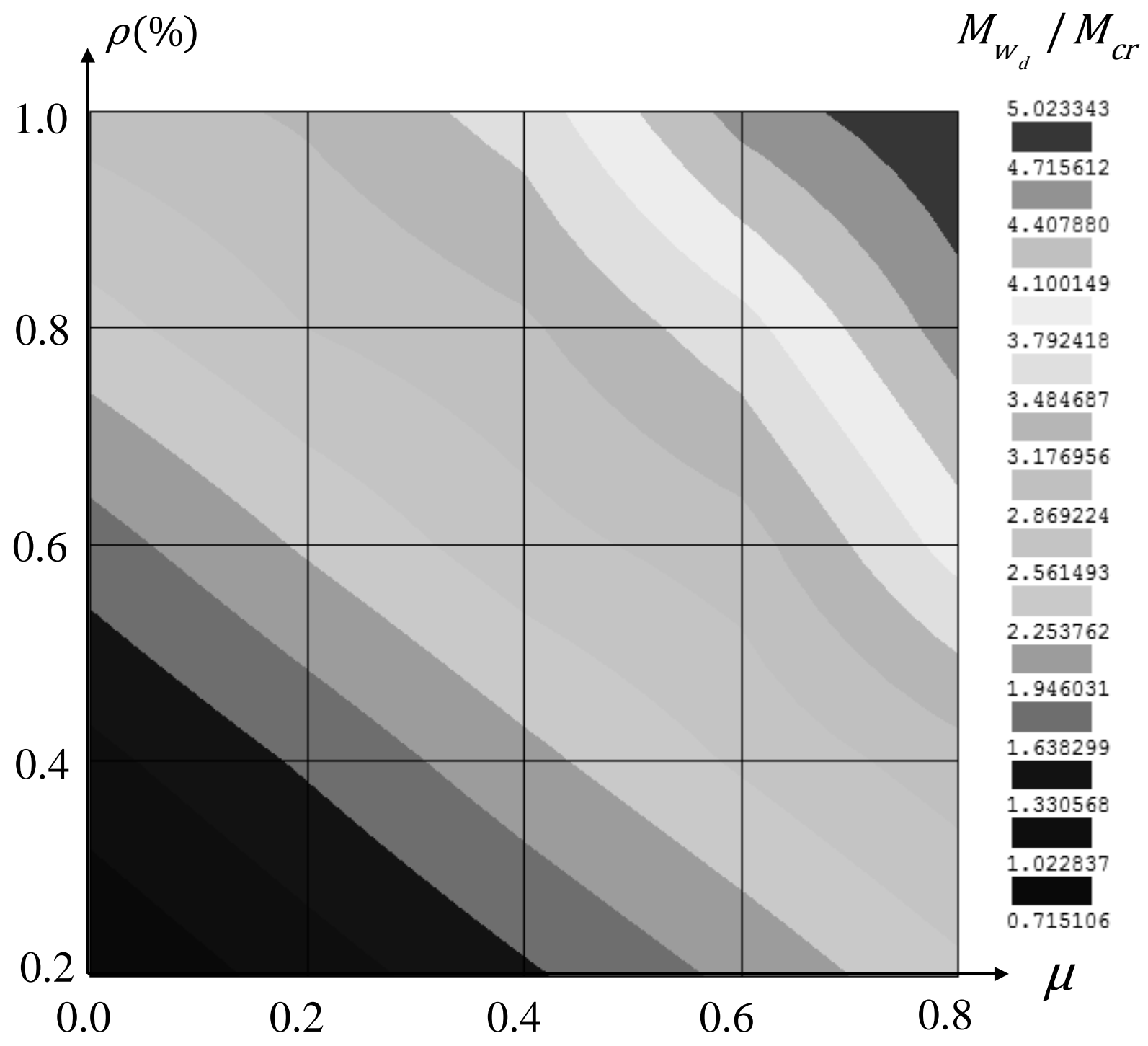

Figure 15b 